\title{
DR.2.52 ORNL/CSD-37
}

\section{MUICYCL and MUIFAP: \\ Models Tracking Minor Uranium Isotopes in the Nuclear Fuel Cycle}

S. R. Blum

R. A. McLaren

MASTER 


\title{
MASTER
}

ORNL/CSD-37

Dist. Category UC-16

\author{
Contract iv. H-7405-eng-2l: \\ COMPUTER SCIENCES DIVISION
}

MUICYCL and MUIFAP:

MODELS TRACKING MINOR URANIUM ISOTOPES

IN THE NUCLEAR FUEL CYCLE

S. R. Blum and R. A. McLaren

(Sponsor: G. H. Westley; Originator: S. R. Blum)

Date Published - October 1979

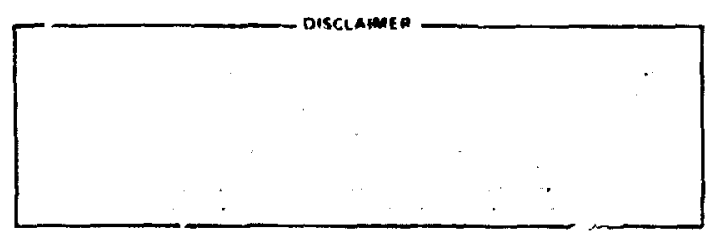

UNION CARBIDE CORPORATION, NUCLEAR DIVISION

operating the

Oak Ridge Gaseous Diffusion Plant - Oak Ridge National Laboratory

Oak Ridge $\mathrm{Y}-12$ Plant

for the

DEPARTMENT OF ENERGY 
CONTENTS

TABLE OF FIGURES ........................ . . v

ACKNDHLEDGMENTS .................... vi i

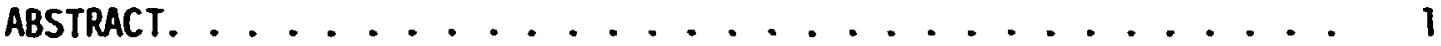

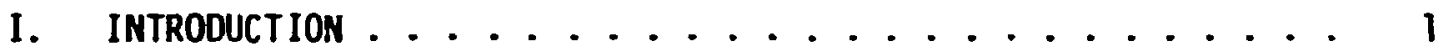

II. matched abundance RATIO CASCADE. . . . . . . . . . . 3

III. MINOR URANIUM ISOTOPE MODELS ............... 6

A. Reactor Operation ............... 6

B. Reprocessing. ................. 7

C. Enrichnent. .................. 8

IV. IMPUT DESCRIPTION. ................. 10

A. MUCYCL ................... 10

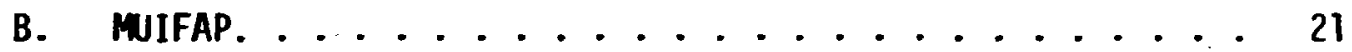

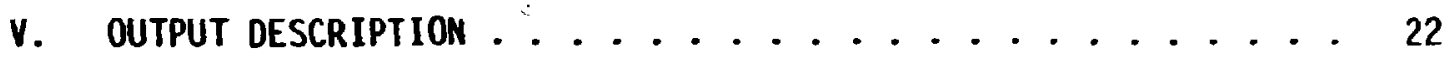

A. Standard output ................ 22

B. Debugging Output. ............... 24

C. Error Messages. . . . . . . . . . . . . 27

VI. DEMONSTRATION OF PROBLEM SOLUTION. . . . . . . . . . 29

A. MUICYCL ................. 29

B. MUIFAP. .................... 37

VII. INTERNAL PROGRAM ORGANIZATION. ............... 39

A. MUICYCL Program Structure ............. 3S

3. MUIFAP Program Structure. ............. 45

C. Enrichment Iteration Procedure. ............. 46

D. Common Blocks and Common Block Variables........ 50

VIII. LIMITATIONS OF THE MODELS ................ 61

REFERENCES. ...................... 63

APPENDIX A Formulation of PU236 $\rightarrow U^{232}$ Decay Equation. . . . . . 67

APPENDIX B Derivation uf Preproduction Estimate. . . . . . . . 73

APPENDIX C MUICYCL Program Listing . . . . . . . . . . . . 77

APPENDIX D MUIFAP Program Listing. ............. 105 


\section{IABLE GF FIGURES}

1. Sample En-ichment Cascade ................ 5

2. Sample Summary Report ................... 23

3. Sample Annual Report. . . . . . . . . . . . . . . 25

4. Setū̃ Deck for MUICíCL. . . . . . . . . . . . 30

5. Output From MUICYCL . . . . . . . . . . . . . 32

6. Setup Deck for MUIFAP . . . . . . . . . . . . . . 37

7. Output From MUIFAP. . . . . . . . . . . . . . 38

8. MUICYCL Program Chart ................. 40

9. MUICYCL Flowchart ..................42 


\section{ACKNOHLEDGMENTS}

The authors acknowledge with appreciation the helpful coments provided by St:ophen Prewett, DOE, and by J. Michael Friend, Dak Ridge Gaseous Diffusion Plant. The authors express their appreciation also to Collene Trammell and Carol Bullard for typing the manuscript.

Funds for the support of this work were provided by the Computing Applications Department, Computer Sciences Division. 
MICYCL and MIFAP:

MODELS TRACKING MINOR URANIUM ISOTOPES

IN THE NU,LEAR FUEL CYCLE

S. R. Blum

ABSTRACT

Two computer programs have been written to provide information on the buildup of minor uranium isoiopes in the nuclear fuel cycle. The Minor Uranium Isotope Cycle Program, $\mathrm{WICrCL}$, tracks fuel through a multiyear campaign cycle of E:richment, reactor burnup, reprocessing, enrichment, etc. MICrCL facilities include preproduction stockpiles, $U^{235}$ escalation, and calculation of losses. The Minor Uranium Isotope Flowsheet Analyzer Program, MUIFAP, analyzes one minor isotope is. one year of an enrichment operation.

The formulation of the enrichment cascade, reactors, and reprocessing facility is presented. Input and output descriptions and s.ample cases are presented. The programs themselves are documented by short descriptions of each routine, flowcharts, definitions of common blocks and variables, and internal documentation. The programs are written in FORTRAN for use in batch mode.

\section{INTRODUCTION}

The computer program MUICYCL was written to study the buildup of minor uranium isotopes in the nuclear fuel cycle over a campaign of up. to 40 years. From input cascade data on feeds, products, and capacities plus reactor and reprocessing data, MUICYCL will track material through several cycles of enrichment, reactor fuel, and reprocessing. The model produces output tables listing yearly values of flows, concentrations, and capacities. Up to three minor isotopes $-U^{232}, U^{34}$, and $U^{236}-$ may be studied in a case. The enrichment process is modeled by a single 
matched abuidance ratio cascade [1]; optional separative capacities may be specified at the user's option. For each type of reactor fuel le.g., BWR, PHR, initial core, reload core), burnup is simulated by a relationship giving minor isotope concentrations in spent fuel as a guadratic function of minor isotope concentrations of the fuel charged to the reactor. Stockpiles of spent fuel, segregated by fuel type, are impartially processed up to the rated capasity of the single reprocessing plant. Buildup of $\mathrm{PU}^{236}$ in the reactor and decay of $\mathrm{PU}^{236}$ to $\mathrm{U}^{232}$ in the reprocessing pliase are aiso tracked.

Other features of this model inclide the ability to define external returns to the reprocessing plant, a recovery factor for material losses, and user-supplied coefficients to define the escalation in $U^{235}$ assay of both loaded and spent reactor fuel necessary to of fset the presence of $U^{236}$. Initial stockpiles of unreprocessed spent fuel and preproduction inventury at the enrichment plant may be input.

The time step for both input and internal calculation is one year. Input each year are enrichment and reprocessing capacities, external returns for rep: xessing, and "stream cards" specifying feeds to and products from the enrichment facility. The program feeds to the enrichment plant any recycled streams from earlier years, then calculates concentrations of all minor isotopes in the product streams. Optionally determined in this phase are escalated $U^{23}$ concentiations of reactor bound streams plus preproduction stream rates which balance stated separative capacities. All enrichment output targeted for reactors is loaded and labeled by year. Next, any reactor fuel completing the burn period in the current year is caiculated and sent to reprocessing. Fuel is then 
reprocessed to be fed to the enrichment plant along with the following jear's input streams as the cycle is repeated.

The Minor Uranium Isotode Flowsheet Analyzer Progran (MUIFAD)

performs the same enrichment process for one year and one minor isotope per case. $U^{235}$ concentrations are not escalated and preproduction is not adjusted for separative capacity.

The programs execute independently in batch mode. MICrCL produces tabular data organized by isotcpe and stream type. Both programs were written in FORTRAN IV for the IBM/360-370 series of computers.

\section{MATChED ABUNDANCE RATIO CASCADE}

The matched abundance ratio cascade formulated in [1] and used in both computer models is the multicomponent analogue of the (binary) ideal casrade. Multicomponent formulations of "value function" and "separative work" are derived.

In the binary ideal cascade no separative work is lost: all streams which are mixed have idertical concentrations. A consequence of this is that the binary ideal cascade minimizes total flow and total separative work. While mixed streams in tre matched abundance ratio cascade cannot have identical concentrations they are made to have identical values of the abundance ratio $R$. In a three-component cascade,

$$
R=\frac{x}{1-x-y}
$$

where $x$ and $y$ are the concentrations of $\|^{235}$ and the "minor isotope," respectively. Nn separative work will be lost in this type of cascade but this cascade does not minimize total flow. The authors of [1] did show that "for uraniuri isotope separation the total flow in the 
matched $U^{2}: \sum / U^{2} \geq E$ abundance ratin cascade exceeds the minimum by an insignificant fraction for a wide range of $\mathrm{U}^{236}$ concentrations" [1,p.188]. Let

$$
H(x, y)=y R-(2 k-1),
$$

where

$$
k=\frac{\dot{v}_{2}}{t_{1}}
$$

$D_{1}$ is the stage separation factor for the two-component system of $\mathrm{U}^{235}$ and $\mathrm{U}^{238}$,

$\psi_{2}$ is the corresponding factor for separation of the minor isotope and $\mathrm{U}^{2.38}$.

$H$ is calied the "homogeneous function." It can be shown [1] from separative work considerations that, in the matched abundance ratio cascade, an "H balance" applied over the whole cascade and over any portion of the cascade. For the cascade of Figure 1 ,

$$
\begin{gathered}
P \cdot H\left(x_{p}, y_{p}\right)+Q \cdot H\left(x_{Q}, y_{Q}\right)+S \cdot H\left(x_{S}, y_{S}\right)+W \cdot H\left(x_{W}, y_{W W}\right) \\
\left.-E \cdot H\left(x_{E}, y_{E}\right)-F \cdot y_{1} \cdot x_{F}, y_{F}\right)=0 .
\end{gathered}
$$

An $H$ balance applied over portions of the cascade prisduces an equation for each side withdrawal stream. For the $Q$ stream

$$
P \cdot H\left(x_{p}, y_{P} ; x_{Q}, y_{Q}\right)=0,
$$

and for the $S$ stream

$$
P \cdot H\left(x_{D}, y_{D} ; x_{S}, y_{S}\right)+Q \cdot H\left(x_{Q}, y_{Q} ; x_{S}, y_{S}\right)-E \cdot H\left(x_{E}, y_{E} ; x_{S}, y_{S}\right)=0,
$$


where

$$
E(x, y ; \alpha, \beta)=H(x, y)-H(\alpha, \beta)-\left.(x-x) \frac{\partial H}{\partial x}\right|_{\alpha, \beta}-\left.(y-\beta) \frac{\partial H}{\partial y}\right|_{\alpha, \beta} .
$$

For a cascade with $M$ withdrawal streams, there are $M-2$ of thes sidestream $H$ balance equations, one cascade $H$ balance equation, and material balance equations for $U^{235}$, the minor isotope, and total material. A separative work equation, defined in the next section, completes the formulation of the matched abundance ratio (or "matched R") cascade.

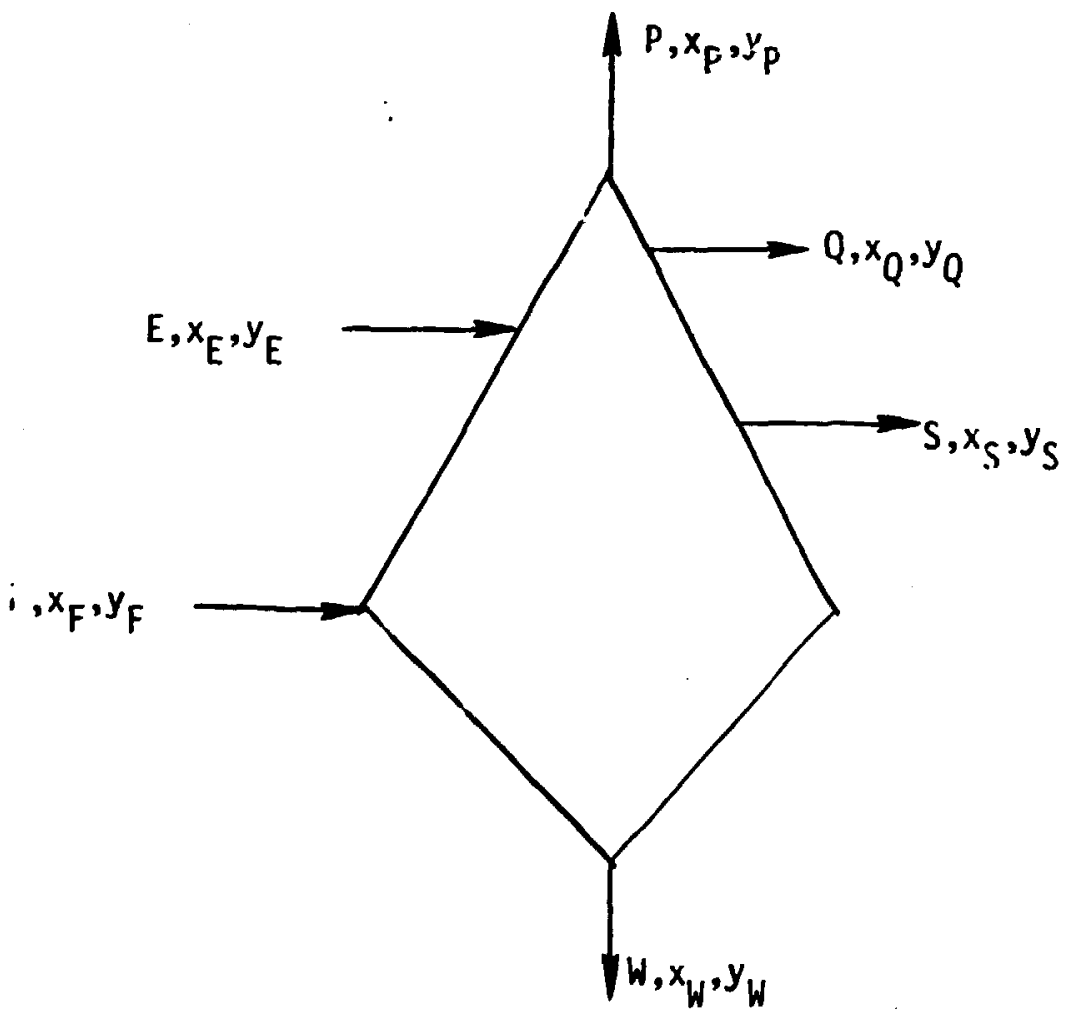

Fig. 1. Sample Enrichrient Cascade. 


\section{MINOR URANIUM ISOTOPE BODELS}

MUICYCL, the Minor Uranium Isotope Cycle Progran, may be analyzed in its three phasej - reactor operation, reprocessing, and enrichment. Each phase is executed once each year in the given order. MUIFAP involves enrichment only and is discussed in that section.

\section{A. Reactor Operation}

This phase calculates concentrations of minor uranium isotopes (MUI), PU23\%, and $\mathrm{U}^{235}$ in spent reactor fuel as functions of MUI concentrations of loaded fuel. All such functions are quadratic, or a sum of two quadratics of the form

$$
y=A+B x+C x^{2}
$$

where $C=0$ is acceptable. Recently used function coefficients were generated by least squares correlations [2]. For $U^{236}$, the discharge concentration $y$ is a function of the initial concentration $x$, and similarly for $U^{234}$. For $U^{232}$

$$
y=A_{1}+B_{1} x_{1}+C_{1} x_{1}^{2}+A_{2}+B_{2} x_{2}+C_{2} x_{2}^{2}
$$

where the discharge $U^{232}$ concentration is a function both of the initial $U^{232}$ concentration, $x_{1}$, and the initial $U^{236}$ concentration, $x_{;}$. Generally $A_{1}=C_{1}=0$. The discharge $P U^{236}$ concentration is a single quadratic function of the initial $U^{235}$ concentration.

Finally, initial $U:$ reactor concentrations were escalated above target values (in the enrichment phase) to compensate for the presence 
of $j^{i}: 3$. A quadratic equation then defines the discharge $U^{2}$ s concentration, $y$, as a function of the escalation, $x$, in initial $U^{235}$ concentration. The year in which reactor fuel is discharged is determined by the cycle time, an input parameter for each type of fuel.

\section{B. Reprocessing}

The reprocessing facility is modeled as a single plant whose capacity is input for each year. Stockpiles of spent fuel, segregated by fuel type, are accumulated and processed up to the rated capacity. If the total stockpile exceeds capacity, the same fraction of each stockpile is reprocessed, with one exception: when the stockpile of one fuel type is less than $: \%$ of capacity, all of this stockpile is reprocessed. Since $P U^{236}$ deiays to $U^{232}$ with a half-life of 2.95 years, concentrations of $\mathrm{U}^{23 \mathrm{z}}$ in reactor discharge awaiting reprocessinci may change significantly. A time-jependent $\mathrm{PU}^{236}-\mathrm{U}^{232}$ relationship developed in [2] is used in a modified form (Appendix $A$ ) which aliows yearly additions to each sinckpile.

As noted earlier, an input "recovery factor" defines material lojses; specifically, the reduction in weight from the time material leaves the enrichment facility to the same time one cycle later. The recovery factor is applied each year to material when it is unloaded from the reactor.

The user may add external returns to the reprocessing queue in any year. The recovery factor is applied to these returns when they are added to the requested stockpile. 


\section{Enrichment}

The enrichment phase is by far the most complex and time-consuming of the three phasf.s in MUICYCL. A single matched abundance ratio cascade [1] is modeled. Additional complexity is provided by the use of preproduction streams to match a rated separative work value, and escalation of specified $U^{235}$ values due to $U^{236}$.

This requires up to three levels of calculations:

1) Adjusting preproduction stream rates to attain the rated separative work value.

2) It $=$ ration on $\mathrm{U}^{235}$ concentrations of reactor bound products.

3) Determination of minor isotope concentrations in cascade product streams which will satisfy material balances and matched abundance ratic equations.

While the first two levels are optional, the third level is always executed each year. In MUIFAP, only the third level is availatle. Each level is now discussed in more detail, and in reverse order.

\section{Determination of Minor Isotope Concentrations}

The formulation of the matched abundance ratio cascade is implemented in this level. The model calculates concentration values of all minor isotopes in each withdrawal stream. Other than the flow rates of any two streams, all other rate and concentration data are given. The threecomponent formulation of the matched $R$ cascade is used, and each of the up to three minor isotopes is solved for the whole caripaign independently of the other minor isotopes. 
Each cascade with $M$ withdrawal streams, and thus $M$ unknown concentrations, satisfies $M-2$ sidestream $H$ balance equations of the form of Equations $(2-4)$ or $(2-5)$, one cascade $H$ balance (Equation (2-3)) and a minor isotope material balance equation. This system of equations is solved by a standard numerical technique, the Newton formulation of the Secant method [3]. The other two material balance equations, $U^{235}$ and total material, are satisfied by adjusting two stream rates selected iuy the user.

Adjusting U235 Concentrations of Reactor Bound Material

Since the presence of $U^{236}$ in reactor fuel reduces the fuel reactivity, the initial $U^{235}$ assay of the fuel may be escalated in the enrichment phase to compensate for this. A quadratic equacion of the forms of Equation (3-1) is again applied. However, the returned value $y$ is defined as the increment in the initial $U^{235}$ assay over the rated value. The independent variable $x$ is the $U^{236}$ assay of the stream as withdrawn from the cascade. Equation coefficients may be input for each type of fuel.

\section{Adjusting Preproduction to Match Rates Separative Capacity}

The separative capacity of the cascade may be forced to equal a specified value by feeding from, or adding product to, preproduction stockpiles. There are two preproduction stockpiles, each with a specified $U^{235}$ assay -- the initial inventory and the inventory of new preproduction. When inventory is being fed to the cascade the initial inventory is exhausted first. 
10

The three component "elementary value function" is

$$
V(x, y)=\left(2 x+\frac{2 x}{2 k-1} y-1\right) \ln R
$$

The three component separative work equation for Figure 1 is

$$
S W=p \cdot V\left(x_{p}, y_{p}\right)+Q \cdot V\left(x_{Q}, y_{Q}\right)+S \cdot V\left(x_{S}, y_{S}\right)-E \cdot V\left(x_{E}, y_{E}\right)-F \cdot V\left(x_{F}, y_{F}\right) \cdot(3-4)
$$

This is easily generalized to an $M$ stream cascade.

IV. INPUT DESCRIPTION

A. MUICYCL

Introduction

The input is set up so that any number of independent cases may be run in one job. Each case is an analysis of one to three minor isotopes in the nuclear fuel cycle for a campaign of several years.

Data for each case are entered as follows:

Case Card

Preproduction Inventory Card

Reactor Fuel Cards for first minor isotope

$U^{235} / U^{236}$ Cards (required only when first minor isotope is $U^{236}$ )

Yearly data for first year

Yearly data for second year

Yearly data for last year

End-of-Yearly-Data Card

Reactor Fuel Cards for second isotope if present

Reactor Fuel Cards for third isotope if present 
Yearly deta consist of the following cards, in order:

Year and Capacity Card

Returns Cards (Optional)

Stream Cards

The last data card of the job is the End-of-Job Card. A detailed description of the input data is provided in the next section.

\section{Detailed Description}

1. Case Card - First card of each case

\begin{tabular}{lll} 
Column & Format & \multicolumn{1}{c}{ Description } \\
$1-35$ & A35 & Name of case (optional). \\
$36-39$, & 314 & $\begin{array}{l}\text { Molecilar weight of the minor isotope(s) } \\
\text { in the same order in which minor isotope } \\
\text { data will be entered on succeding cards. } \\
44-47\end{array}$ \\
If there is more than one minor isotope in \\
this case, the first entry must be "236". \\
$48-50 \quad$ A3
\end{tabular}


1. Case Card (Cont'd)

Coiumn Ermat

Description

80

A1

Enter any character if an "Iteration Parameter Data Set" is to be inclujed with each isotope definition. See Special MUICYCL Input.

2. Preproduction Inventory Card - Second card of each case.

\begin{tabular}{|c|c|c|}
\hline Column & Format & Description \\
\hline $1-10$ & D10.2 & $\begin{array}{l}\text { Inventory of preproduction (by weight) } \\
\text { at beginning of case. }\end{array}$ \\
\hline $11-20$ & D10.2 & $U^{2}:$ fraction in inventory. \\
\hline $\begin{array}{l}21-30 \\
31-40 \\
41-50\end{array}$ & 3010.2 & $\begin{array}{l}\text { Minor icntope weight fraction(s) in } \\
\text { inventory, in the order as specified } \\
\text { on the case card. }\end{array}$ \\
\hline $51-60$ & 010.2 & $U^{2}:$ fraction in all new preproduction. \\
\hline
\end{tabular}

A. First Card - Required

\begin{tabular}{|c|c|c|}
\hline Column & Format & Description \\
\hline 1 & Al & $\begin{array}{l}\text { Enter an asterisk ( } * \text { ) if this is the } \\
\text { last type of reactor fuel defined. }\end{array}$ \\
\hline 2 & II & $\begin{array}{l}\text { Firel code number, KTYP. } 1 \leq K T Y P=\text { number } \\
\text { of fuel types input. No more than six fuel } \\
\text { types may be defined. }\end{array}$ \\
\hline $3-8$ & A6 & Fuel name (optional). \\
\hline $9-10$ & $\therefore 2$ & Cycle time in years. See note 5 . \\
\hline $11-20$ & E10.0 & $\begin{array}{l}\text { Weight of initial stockpile of this fuel } \\
\text { type awaiting reprocessing at beginning } \\
\text { of first year. }\end{array}$ \\
\hline $21-30$ & $E 10.0$ & $\begin{array}{l}\text { Weight fraction of } U^{23:} \text { in initial stock- } \\
\text { pile. }\end{array}$ \\
\hline $31-40$ & $E 10.0$ & $\begin{array}{l}\text { Weight fraction of minor isotope in initial } \\
\text { stockpile. }\end{array}$ \\
\hline
\end{tabular}


i. First Card (Cont'd)

\begin{tabular}{|c|c|c|}
\hline Column & Format & Description \\
\hline $\begin{array}{l}4 i . .0, \\
51-60, \\
61-70,\end{array}$ & 3E 10.0 & $\begin{array}{l}\text { Coefficients } A, C \text {, and } C \text {, respectively, in } \\
\text { the equation defining the concentration of } \\
\text { the minor isotope when the fuel is removed } \\
\text { from the reactor as a function of the minor } \\
\text { isotope concentration when the core is } \\
\text { loaded. The equation is the standard qua- } \\
\text { dratic equation, }\end{array}$ \\
\hline & & $\begin{array}{l}\qquad y=A+B x+C x^{2} \\
\text { where } y \text { and } x \text { are final and initial weight } \\
\text { fractions, respectively. }\end{array}$ \\
\hline $71-78$ & F8. 0 & $\begin{array}{l}\text { The recovery factor }(\leq 1 .) \text { applied to the } \\
\text { weight of the fuel loaded in a reactor to de- } \\
\text { rive the weight of the fuel after it is un- } \\
\text { loaded and reprocessed. The factor is applied } \\
\text { to reactor fuel when it is unloaded from the } \\
\text { reactor. The factor is also applied to } \\
\text { returns (Returns Card) prior to reprocessing. }\end{array}$ \\
\hline
\end{tabular}

B. Second Card - The second card is present only when the minor isotope is $U^{232}$.

\begin{tabular}{|c|c|c|}
\hline Coiumn & Format & Description \\
\hline $\begin{array}{l}11-20 \\
21-30 \\
31-40\end{array}$ & $3 E 10.0$ & $\begin{array}{l}\text { Coefficients } A, B \text {, and } C \text {, in the quadratic } \\
\text { equation (see above), to generate final } \\
U^{232} \text { concentration in the reactor as a } \\
\text { function of initial } U^{235} \text { concentration in } \\
\text { the reactor. }\end{array}$ \\
\hline $\begin{array}{l}41-50 \\
51-60 \\
61-70\end{array}$ & $3 E 10.0$ & $\begin{array}{l}\text { Coefficients } A, B, C \text {, respectively, in the } \\
\text { quadratic equation (see above) to calculate } \\
\text { final } P U^{2} 3 \varepsilon \text { colicentration as a function of } \\
\text { initial } U^{2} 3 F_{\text {. concentration in the reactor. }}\end{array}$ \\
\hline $71-80$ & E10.0 & Weight fraction of $P U^{3} 35$ in initial stockpile \\
\hline
\end{tabular}


4. $U^{<}: 5 / U^{2}:$ Card - Required only when minor isotope is $U^{2}: \because$.

\begin{tabular}{|c|c|c|}
\hline Column & Format & Description \\
\hline 1 & Al & $\begin{array}{l}\text { An asterisk }(*) \text { if this is the last data } \\
\text { card of this type; blank otherwise. }\end{array}$ \\
\hline $\begin{array}{c}2-3 \\
4-5 \\
6-7 \\
8-9 \\
10-11 \\
12-13\end{array}$ & 612 & $\begin{array}{l}\text { Enter the fuel code rismbers of all fuel tyl } \\
\text { to which the coefficients on the card apply }\end{array}$ \\
\hline $\begin{array}{l}21-30 \\
31-40 \\
41-50\end{array}$ & $3 F 10.5$ & $\begin{array}{l}\text { Coeificients } A, B \text {, and } C \text { in the quadratic } \\
\text { equation (see above) to generate the change } \\
\text { in } U^{2}: \text { assay of reactor requirements as a } \\
\text { function of } U^{\prime}: \text { assay. }\end{array}$ \\
\hline $\begin{array}{l}51-60 \\
61-70 \\
71-80\end{array}$ & $3 F 10.5$ & $\begin{array}{l}\text { Coefficients } A, B \text {, and } C \text { in the quadratic } \\
\text { equation (see above) to calculate the } U \\
\text { assay of spent reactor fuel due to the } \\
\text { increment in } U: \text { assay of loaded cores. }\end{array}$ \\
\hline
\end{tabular}

5. Year and Capacity Card - First card of data for each year in the case.

\begin{tabular}{|c|c|c|}
\hline Cnluinn & Format & Descriftion \\
\hline $2-5$ & $i 4$ & Current year. \\
\hline $6-15$ & F10.2 & $\begin{array}{l}\text { Capacity of reprocessing plant (in weight } \\
\text { units for the } y^{\prime} \text { ar) after the recovery } \\
\text { factor has bo in applied. }\end{array}$ \\
\hline $16-25$ & F10.2 & $\begin{array}{l}\text { Capacity of enrichment complex (in separative } \\
\text { work ur its for the year). If blank, inven- } \\
\text { tories will not be fed or produced. }\end{array}$ \\
\hline 30 & Al & $\begin{array}{l}\text { A non-blank character is entered if any } \\
\text { Returns Card.s are to follow. }\end{array}$ \\
\hline $31-35$ & I5 & $\begin{array}{l}\text { Flag, IYRPR, to affect printing of debug } \\
\text { output for this year. The value of IYRPR } \\
\text { may override (for this year only) the value } \\
\text { Of KASEPR un the case card. } \\
\text { IYRPR }=0 \text { : Suppress debug output } \\
\text { IYRPR=0: Defaul to value of KASEPR } \\
\text { IYRPR=1: Print limited debugging output } \\
\text { IYRPR=2: Print full debugging output. }\end{array}$ \\
\hline
\end{tabular}


6. Returns Card - One card for Each return tc the reprocessirg plant in a jear. The card(s) immediately follow the Yaar and Capacity Card. Each such return has an associated "fuel code number", i.e., a Reactor Fuel Card must have been input for each type of return.

\begin{tabular}{|c|c|c|}
\hline Co:umn & Format & Description \\
\hline 1 & Al & $\begin{array}{l}\text { If this is the last Returns Card for this } \\
\text { year, enter an asterisk (*) here. }\end{array}$ \\
\hline 2 & 11 & Fuel code number. \\
\hline $11-20$ & E10.0 & Stream rate. \\
\hline $2 !-30$ & E10.0 & $\begin{array}{l}\text { Height fraction of } U^{235} \text { Default is "base } \\
\text { value" on Reactor Fuel Card, Cols. } 21-30 .\end{array}$ \\
\hline $\begin{array}{l}31-40 \\
41-50 \\
51-60\end{array}$ & 3E10.C & $\begin{array}{l}\text { Minor isotope weight fraction(s), in the } \\
\text { order as specified on the Case Card. }\end{array}$ \\
\hline $61-70$ & $E: 0.0$ & $\begin{array}{l}\text { If } U^{2: 2} \text { is one of the mincr isotopes in this } \\
\text { case, enter here the weight fraction of } \\
\text { PU2: }\end{array}$ \\
\hline
\end{tabular}

7. Stream Cards - One card for each stream, in any order. See note 2.

\begin{tabular}{|c|c|c|}
\hline Column & Format & Description \\
\hline 1 & Al & $\begin{array}{l}\text { If this is the last stream card for this } \\
\text { year, enter an asterisk }(*) \text { here. }\end{array}$ \\
\hline 2 & Al & $\begin{array}{l}\text { "I" if stream is a feed ("Input" to cascade). } \\
\text { " } 0 \text { " if stream is a withdrawal ("Output" } \\
\text { from cascade). }\end{array}$ \\
\hline $3-9$ & A7 & Stream name (optional). \\
\hline 10 & 11 & $\begin{array}{l}\text { If this is a product stream to be used as } \\
\text { reactor fuel or, if this is a feed stream } \\
\text { which represents a reactor return, enter } \\
\text { the "fuel code number" here (seo Reactor } \\
\text { Fuel Cards). }\end{array}$ \\
\hline $11-20$ & E10.0 & $\begin{array}{l}\text { Stream flow rate. Leave this field blank } \\
\text { for one feed stream and one withdrawal } \\
\text { stream. The values will be determined by } \\
\text { material balance equations. }\end{array}$ \\
\hline
\end{tabular}


7. Stream Cards (Con:'d)

Column Format

$21-30 \quad E 10.0$

$31-40, \quad 3 E 10.0$ 41-50, $51-60$
Description

Weight fraction of $U^{235}$.

Weight fraction(s) of minor isotope(s). If this is a withdrawal stream, these fields are not processed.

8. End-ijt-Yearly-Data Card - Follows the last stream card of the last year in a case.

Column Format

Description

$1 \quad$ A1

$" \star "$

9. End-of-Jot Card - This is the last data card in the job.

Column Format

Description

$1-3 \quad A 3$

"END"

Notes on MUICYCL Input.

1. Any number of cases may be run in one job. The duration of each case plus the lungest cycle time may not exceed 40 years.

2. A maximum of 20 feed streams and 19 product stre.ms may be defined in each year, including recycle streams. No more than six types of reactor fuel streams may be defined.

3. The program expects at least one Reactor fuel Card. When running a case which doesn't contain aivy recycle, enter a "dummy" reactor card with "*" in column 1, "1" in column 2 . If this is a $U^{232}$ case, follow this card with i blank card.

4. The PPM (part per million) flag defines the mode of entry of the $U^{232}$ weight fraction on Preproduction Inventory Cards, Reactor Fuel Cards, Return Cards, and Stream Cards.

5. The definttion of cycle time is as follows: If a fuel type has a cycle time of $K$ years and leaves the enrichment facility in 1975, it will become ovailable to be reprocessed and fed to the cascade in year $1975+K$.

6. Reprocessing and enrichment both occur in the same year. 
7. The recovery factor entered on the Reactor Fuel Card defines the weight reduction from the time material leaves the enrichment facility to the time it is re-fed to the reactor after completing a cycle. It is applied immediately prior to the reprocessing step, both to "cycling material" and to "Returns Card Material."

8. No ass'umptions are made on the units of material flow although some output is labeled "MTU's".

9. Do not input any stream flows with magnitude less than 0.01 . Loss of accuracy will result. Increasing all stream rates by a constant fartor will solve this problem.

\section{Special MUICYCL Input}

orcasionally a run will fail because an iteration procedure could not converge. The user can get more information on the cause of failure by setting the flags KASEPR on the Case Card and IYPRP on the Year and Capacity Card. See "Dek'siging Output".

If "trouble shooting" has established that some parameter(s) in an iteration phase requires adjustment, the "Iteration Parameter Data Set" will perform this function during execution. The data set is entered once for each minor isotope and its use is signaled by the flag in column 80 of the Case Card. This data set immediately precedes the yearly data for the first year. For the second and third minor isotopes the data set follows the pertinent Reactor Fuel Cards. Data are read by the "Namelist" format; thus the data set will look like

$$
\text { SPARMS } a_{1} a_{2} \quad \ldots a_{n} \text { \&END }
$$

where data may be entered from column 2 to column 80 . At least one space must be left prior to $a_{1}$ and following $a_{n}$. Spacing between each $a_{i}$ is optional. Each $a_{i}$ takes the form

$$
\text { "llome = value," ; }
$$


"llome" is one of the variable names following, and

"Value" is the value assigned to the variable.

Spaces are permitted adjacent to the "=" sign, but not elsewhere in $a_{j}$.

To continue onto another card, break after an $a_{i}$. There may be from zero to seven $a_{i}$ entries. Each variable which is not entered takes its default value.

Variable Name

EXP

TOL235

\section{Description}

ExP is used in generating the initial estimate of minor isotope concentration (Method B) and in "unmerging" merged streams. The ratio of minor isotope concentrations in adjacent streams is estimated as the ratio of the corresponding $U^{235}$ concentrations raised to the EXP power. Default values are EXP=1.6 for $U^{232}, E X P=1.3$ for $U^{234}$, and EXP=.7 for $U^{236}$.

In the enrichment phase, the $U^{235}$ concentration of reactor brund product streams is escalated due to the presence of $\mathrm{U}^{236}$. When the largest calculated increment in the $\mathrm{U}^{235}$ weight fraction does not exceed TOL235, this iteration phase is considered complete. Tested in \$236. Default value is $50-8$. 
Variable Name

TOLSH

TOLGEN

TOLMRG
Description

In the enrichment phase, stream rates may be recalculated to attain the rated separative capacity. When the difference between calculated and capacity values divided by the capacity is less than TOLSW, this iteration process is completed. Tested in DELTA. Default $=10-4$. The relative difference between the calculated SH value and the targ:t value is compared with TOLGEN at the start of the lowest level cf iterations (level 3) in the enrichment phase. If it exceeds TOLGEN, a new initial estimate is more likely to be generated rather than using the previous final estimate, which may be inadequate. Tested in DOYEAR. Default is TOLGEN $=.3100$ In the enrichment phase calculation of product stream minor isotopes, streams whose $U^{235}$ weight fractions differ (in absolute value) by less than TOLMRG are temporarily merged into one stream. Larger TOLMRG values decrease the likelihood of non-convergence but increase the number of iteration steps. Executed in Subroutine-HERGE. Default is TOLMRG $=50-4$. 
Variabie Name

CP.1

CR2

The default values and changed values of these parameters are listed at the bottom of the Isotope Data Page of each minor isotope for which the data set has been entered.

Description

Convergence criterion of iterations to Jetermine minor isotope concentrations. For a cascade with $M$ withdrawal streams, there are $M$ simultaneous equations to be solved. Convergence is achieved when the sum of squares of the $M$ residuals is less than $M * C R 1$. Default is CRI $=2.50-17$.

Iteration stall criterion, tested in the same stage as CRI above. The program exits due to stall when the square of the distance between the previous and present estimate vectors is less than $M^{*} C R 2$. Since each estimate component was initially scaled to 1 , this is a relative change criterion. Default is $C R 2=10-16$. 


\section{B. MUIFAP}

Any number of independent cases may be loaded in a run. Each case, the anaivsis of oni minor uraniug isotope for one cascade time period, consists of a Case Card, Stream Cards, anu a Final Card.

1. Header Card - First input card in a run

$\begin{array}{ll}\text { Column } & \text { Format } \\ 1-6 & \text { A6 }\end{array}$

7-12 A6
Description

Classification flag - leave blank if unclassified; punch "SECRET" if secret output; punch any other characters if confidential.

Debug flag - punch any characters to generate iteration data.

2. Case Card - First card of each case

Column Format

1-35 A35

$37-39 \quad 13$

40-41 A2

Description
Name of case (optional).
Molecular weight of the minor isotope; e.g.,
"232". Any uranium isotope other than
$U^{235}$ and $U^{238}$ is acceptable.

PPM flag - if the "weight fraction of minor isotope" is to be input as parts per million of $\mathrm{U}^{235}$, punch any character here.

3. - stream Eard- - Gue cef for each stroam, in any order. A maximum of 20 feed streams and 20 withorawa if sireans aly be defined per case.

Column Format

Description

$1 \quad$ Al

3-10 A8

$11-20 \quad$ E10.0*
"I" if stream is feed (input to cascade); " 0 " if stream is withdrawal (output from cascade).

Stream name (optional).

Stream flow rate. Leave this field blank for one feed stream and one withdrawal stream; these rates are calculated internally to satisfy material balance equations. 


\begin{tabular}{|c|c|c|}
\hline Column & Format & Description \\
\hline $21-30$ & E10. $0^{\star}$ & Weight fraction of $U^{2}{ }^{2} \Xi$. \\
\hline $31-40$ & E10.0* & $\begin{array}{l}\text { Weight fraction of minor isotope. If PPM } \\
\text { flag is on, parts per millian of } U^{2} 35 \text {. } \\
\text { This field is not processed if the stream } \\
\text { is a withdrawal. }\end{array}$ \\
\hline
\end{tabular}

4. Final Card - Last card of each case.

Column $\frac{\text { Format }}{1}$ Al $\quad \frac{\text { Description }}{" \star "}$

\section{v. OUTPUT DESCRIPTION}

A. Standard Output

Standard MUICYCL output from a case consists of a title page, case data page, isotepe aata pages, a set of summary reports and, optionally, an annual report for each year and each minor isotope. Each summary report presents a tabulation of assays, material flows, and capacities, listed year-by-year. Figure 2 portrays a sample summary report. The set of summary reports consists of the following:

Material Flows and $U^{235}$ Concentrations - Feed Streams

Material Flows - Other Feed Streams

Material Flows and $U^{235}$ Concentrations - Product Streams

Material Flows - Other Product Streams

Minor Isotope Concentrations in Products

Minor Isotope Concentrations in Feeds

FIf the data are entered in exponential form, it must be right adjusted. If exponential form is not used, the data may be located anywhere in the field with a decimal point, or right adjusted without a decimal point. 
VーMM

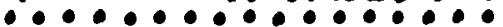

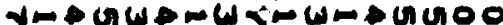
Jing cogogogogogogo mogudougr mmmmm mmm mmmm

000000000000000 NWWWGGWNNNNNNNN

00000000000000000

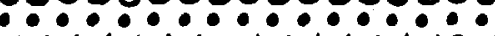

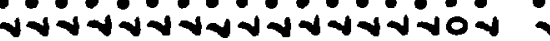
unuguesust

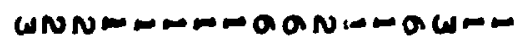

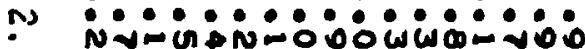
NUM Unt

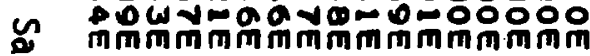

음

mminmminmmmmm

OOOOOOOOOOOOOOOOO

0000\%000\%00\%00\%?: 00000000000000000 WNNM-DNE-O00000000 OVO- NGNAODOOOOO

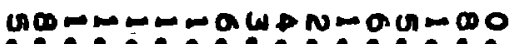
OW-NNOOOOOOO :NWDO OWWNNOOOOOOA NWO no $\rightarrow$ wor

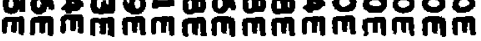

0000000000000000 NNWWWGWNNNNNNNNNO

00000000000000000

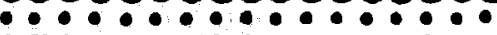
0000000000000000 vyviagavanagooga

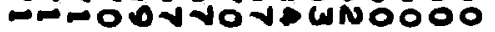

$-\infty-\infty$ VGGGWN $\bullet \bullet \bullet \bullet \bullet \bullet \bullet \bullet \bullet \bullet \bullet \bullet \bullet$

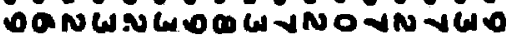

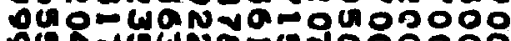

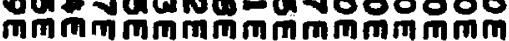

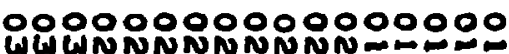
00000000000000000

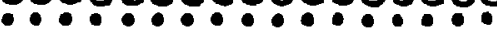

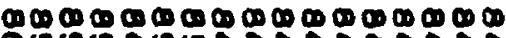

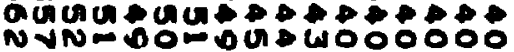


Preproduction Inventories and Sumary

Unprocessed Returns Inventory (by core type!

Miscellaneous Annual Data

Móre detailed mUICYCL information and standard MUIFAP output are provided by annual reports for each isotope, as displayed in Fig. 3. The data INPUT-H and OUTPUT-H are the unsigned contributions of feed streams and product streams respectively to the $H$ balance equation (2-3) of the cascade. The three component separative work values are calculated by Equation (3.4) while the two component SH value uses $V(x, 0)$ in the same equation. Annual miCrCL output may be suppressed by a flag on the Case Card and is always printed if a serinus error occurs.

\section{B. Debugging Output}

Debugging output in MUICYCL is generated by setting to a positive value one of the input flags KASEPR or IYRPR.

To utilize this output, the enrichment iteration procedure must be understood (see Chapter VIII, Section C). One "cascade solution" step consists of solving a cascade with $M$ withdrawal streams for the $M$ minor isotope concentrations. Pairs of adjacent withdrawal streams with nearly identical concentrations may have been merged (IMERGE>0) prior to this step as an aid to convergence. They will be "unmerged" for a later cascade solution step (IMERGE $=-1$ ). One level higher than the cascade solution, an iteration procedure to adjust $U^{235}$ concentrations due to the presence of $U^{236}$ is performed (U236ITERS $=\ldots$ ). At the highest leve1, preproduction stream rates are adjusted to attain the 


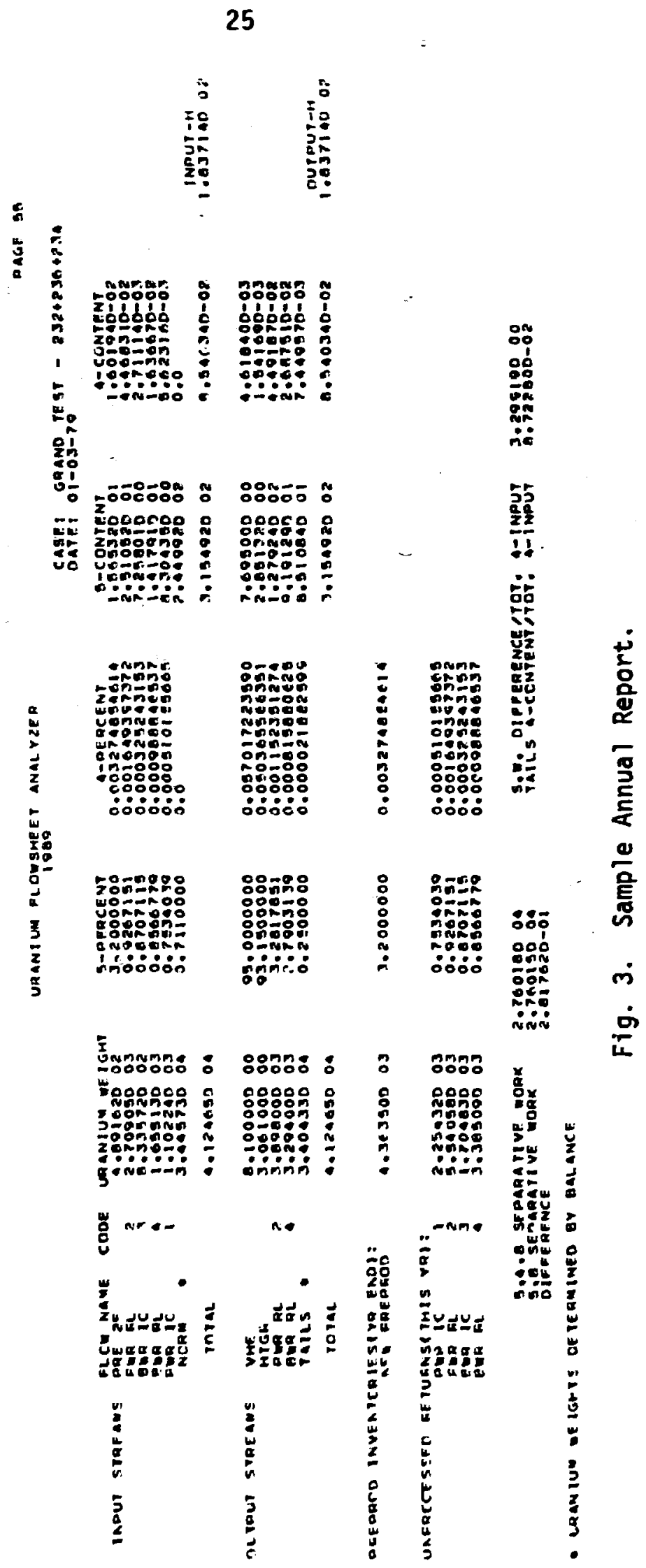


rated separaitive work values (SWITERS $=\ldots$ ). These two spper level iterations are performed only when the minor isotope is $U^{z}:$ and their execution is not sufpressed by input flag.

IPR is the internal print flag set each year to the value of KASEPR or IYRPR. When IPR = I initial and final data for each cascade solution step are printed. This includes values of iteration counters at the start of the solution step, a measure of convergence of the SW iteration phase (see the definition of TOLSW in the Iteration Parameter Data Set), a list of the initial and final minor concentration estimates, and the maximum possible minor isotope values (YPMAX) when used in the initial estimates. No extra reactor or reprocessing output is printed. The annual report comprises the final $I P R=1$ output.

When IPR $=2$, the IRP $=1$ output is printed. A.dditionally, data for each iteration within a cascade solution step is printed - the scaled and unscaled concentration vector $(x)$, the calculated fincticn vector ( $G$ and $F$ ), and the estimate to be dropped from the basis. The estimate vector has been scaled so that each component of the initial estimate is 1. At the beginning of each cascade solution step a stream table is printed, the rates of the feed and product stream calculated to close the total material balance and $U^{2} 35$ balance are displayed, and the estimates and function vectors entering the basis are evaluated and listed. At the end of the cascade solution step the mode of termination is explained. The operation of the iteration routine used, SECANT, is detailed in [4].

A running account of reactor and reprocessing operations is printed :hen IPR=2. Future reactor output, $U \geqslant 3:$ 'fraction in reprocessing pots, 
direct returns to reprocessing plants, present reactor output to reprocessing, and quantity reprocessed and remaining in each pot are all enumerated. Use of care in the request for IPR=2 output is advised. The use: may expect up to 15 pages of debug output per year for $U^{2} \equiv E$ with no iterations suppressed, and less than 5 pages per year for $U^{232}$ or $U^{2 \vdots 4}$. IPR $=1$ generates less than a page per year per minor isotope. Gebugging output from MUIFAP, set by the debug flag, is virtually identical to the extra MUICYCL output generated when IF?=2, as defined previously.

\section{Error Messages}

Warning messages and terminating messages are listed below in alphabetical order, followed by a short explanation where necessary. The subroutine from which the message was printed is displayed in parentheses. The messages refer to the MUICYCL frogram only unless otherwise noted.

BLEW IN YEAR $\mathrm{i} i \mathrm{i}$ AFTER COMPLETING $\mathrm{j} \mathrm{j}$ kk U236 LOOPS AND SW LODPS RESPECTIIVELY.

This is a warning message only (IER=-2). It indicates some convergence difficulties. If the problem is not resolved by the end of the year, however, it results in the message "SERIOUS ERROR (IER=1)..." and termination of the case.

COLUMN 2 OF STREAM CARD FOR STREAM " $i \mathbf{i} i \mathrm{i} i$ " IS INCORRECT: " $k$ "

The value of " $k$ " must be either "I" or " 0 ".

(DOYEAR)

ERROR: ONE OF THE FOLLOWING MINOR ISOTOPE VALUES IS

INVALID. EXIT. i i j jjj kkk.

(NEWCAS)

On the Case Card, at least one nonzero minor isotope value, $m$, was outside the range $230-m=240$. 
??FEED STREAH! TYPE $i$, TO REPROCESSIPG?? NOT DEFIHEO. EXIT A Returns Card has an undefined fuel code number.

(REPROC)

(SECANT)

ITERATION IS STALLED. RETURH BEST ESTIMTE. EXIT. Before icerations had converged, the relative charige in the estimate vector fell below a "trigger value". This is not usually of ccicern. Check firial function values. This has the same implication in BUIFAP. In soth jrograms this message is printed only when the full debug fla's is on.

SERIOUS ERROR (IER $=i$ ) IN YERR $j \mathrm{jjj}$ j PREVENTED CONTINUATION OF CASE. PRINT REPRIPT AND EXIT FROM CASE. The case is terminated with this year. Check input date for tiils year ard previous years. Generate debug output for this year (IYRPR=2) and consult with programer contact.

STOP: MAXIMUM ITERS. RETURN BEST ESTIMATE

The SECANT routine couldn't converge in the maximum number of iterations, presently 30. This is a warning message oniy. With MUIFAP this is a serious error of ten implying an input data eiror.

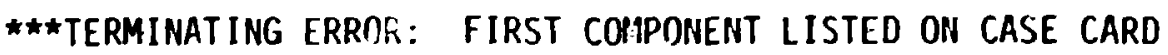
MUST BE 236.

TOO MANY COEFFICIENTS

More $U^{2} 3^{3} / U^{3} 3$ cards were present than the maximum al lowable number of core types (MAYKOR=6).

***WARNING: EXCEEDED MAXIMUM NI'ABER OF ITERATIONS FOR ATTAINING SW CAPACITY, ij. EXIT FROM THIS LDOP. " $i$ " iterations were not sufficient to converge on the input separative capacity value by changing preproduction rates. Check input data.

(SECANT)

(MAiN)

(NEWCAS)

(ISOPAG)

(MAIN!;

WARNII!G: IN $j \mathrm{j} j \mathrm{j}$ WITH SA ITERS, U236 ITERS, IMERGE $=\mathbf{i} j \mathrm{j} j \mathrm{k}$, CONVERGED TO A NEGATIVL CCNCENTRATION.

This warning message (IER=-1) indicates convergence difficulties. It may be ignored if no higher level error messages follow.

WARNING. . .LAST ITERATIONS, IN i $i$ i DIDN'T COMPLETELY CONVERGE DUE TO VECTOR SI $\because$ iLL. FINAL RESIDUAL WAS $x . \times x D-x x$; TARGET 
The "final residual", which is the sum of the squares of the $M$ balance equation values, is greater than the "target" value for convergence. If the rinal value exceeds the target value by two orders of magnitude or more, the results are suspect. Consultation with the programmer contact is suggested.

WARIVIH: MAXIMUM NUMBER OF ITERS ON U235 ESCALATION, ii.

EXIT FROM THIS LOOP.

Check input data.

*** WARNING THERE IS A DEFICIENCY OF $x \times x \times x . x x$ SWU OF

SEPARATIVE HORK CAFACITY THIS YEAR. TERMINATE THIS

(DELTA)

YEAR jjjj, BUT CONTINUE CASE.

In year " $\mathrm{jjjj}$ " the cascade could not produce the required products from given feeds plus all available stockpiled production except by using "xxxxx.xx" SWU's above capacity.

YARHIIHG... YOU HAVE DEFIMED THE MAXIMUM RUMEER OF FUEL TYPES

ALLOH:ED AND YOUR LAST REACTOR FUEL CARD HAS NO "*" IN COLUMN

(ISOPAG)

1. PROGRAM ASSUMES THIS WAS YOUR LAST SUCH CARD AND CONTINUES.

WHEN RECYCLE STREAMS ARE ADDED, THE NUMBER OF STREAMS

EXCEEDS THE MAXIMUM.

Ir the present year being executed, the total number of streams exceeds the maximum of 40 . Recall also that there are always two, and sometimes three, preproduction streams involved in a solution when iterating upon $U^{2} 36$ anu matching SW capacity.

VI. DEMONSTRATION OF PROBLEM SOLUTION

A. MUICYCL

Use of MUICYCL to solve a samiple problem is demonstrated here. A list of the setup deck, consising of Job Control Language (JCL) and input data, is displayed in Fig. 4. The full output of the case is presented in Fig. 5 .

The program is set up to run on the IBM $360 / 70$ class of machines and was written in IBM FORTRAN IV. The user executes an object module, which resides on a 1600 bpi tape. The resource requests of "CPu95" and 


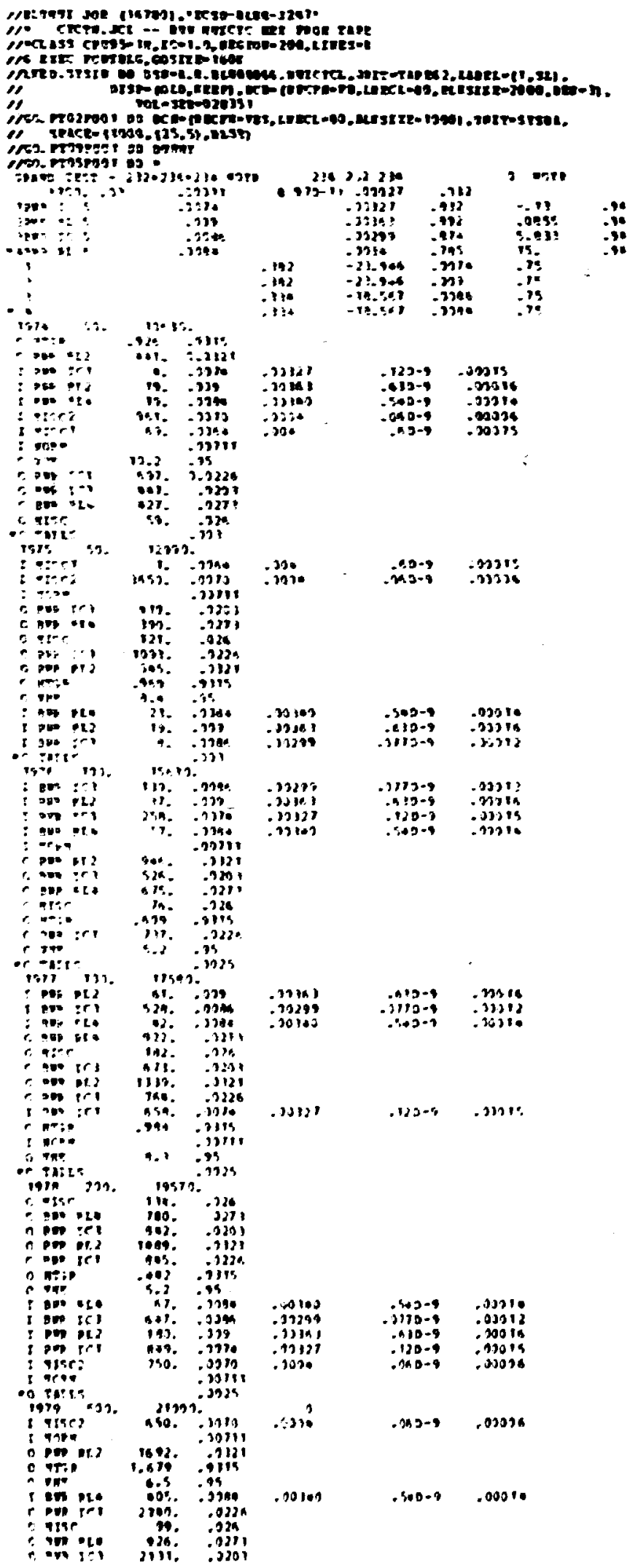

Fig. 4. Setup Deck for MUICYCL 


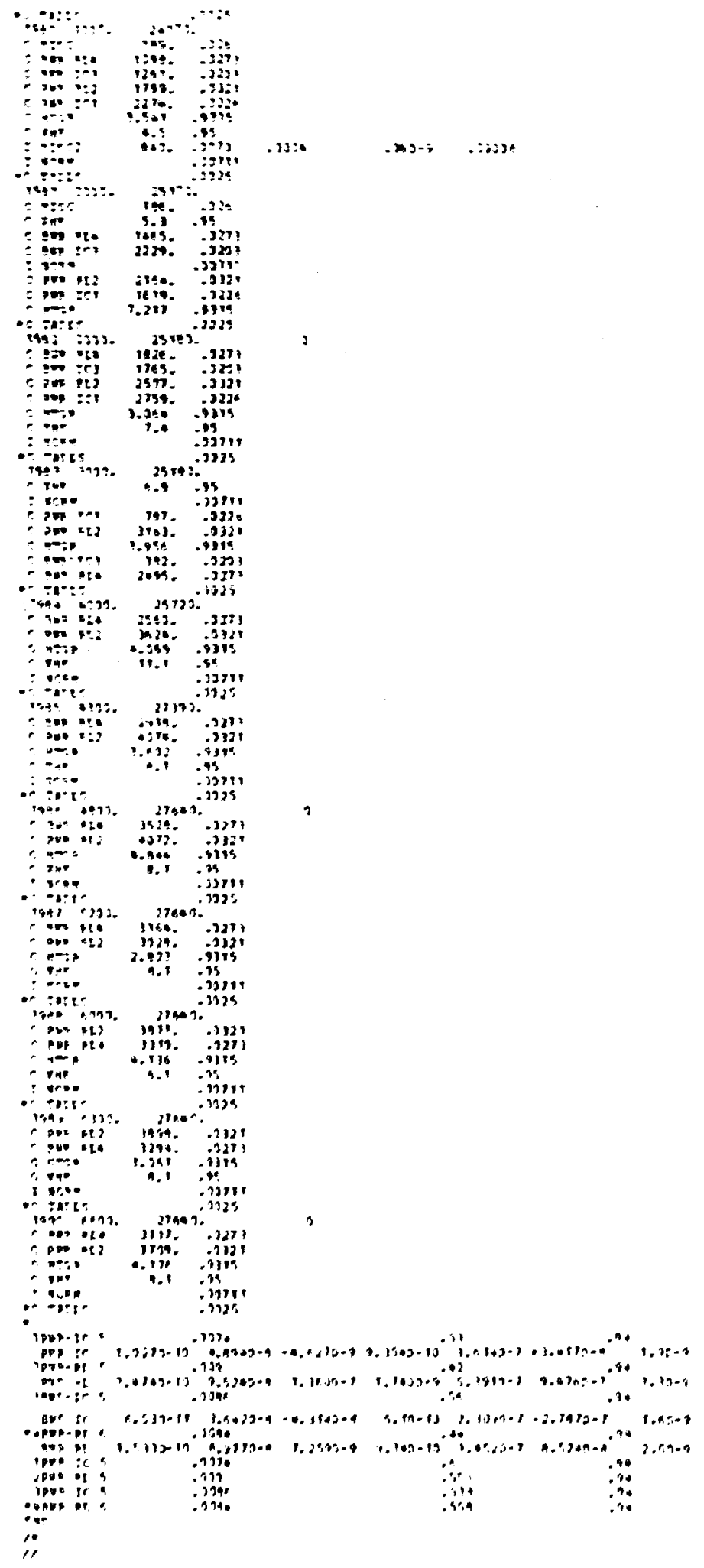

Fig. 4. Setup Deck for MUICYCL (cont'd). 


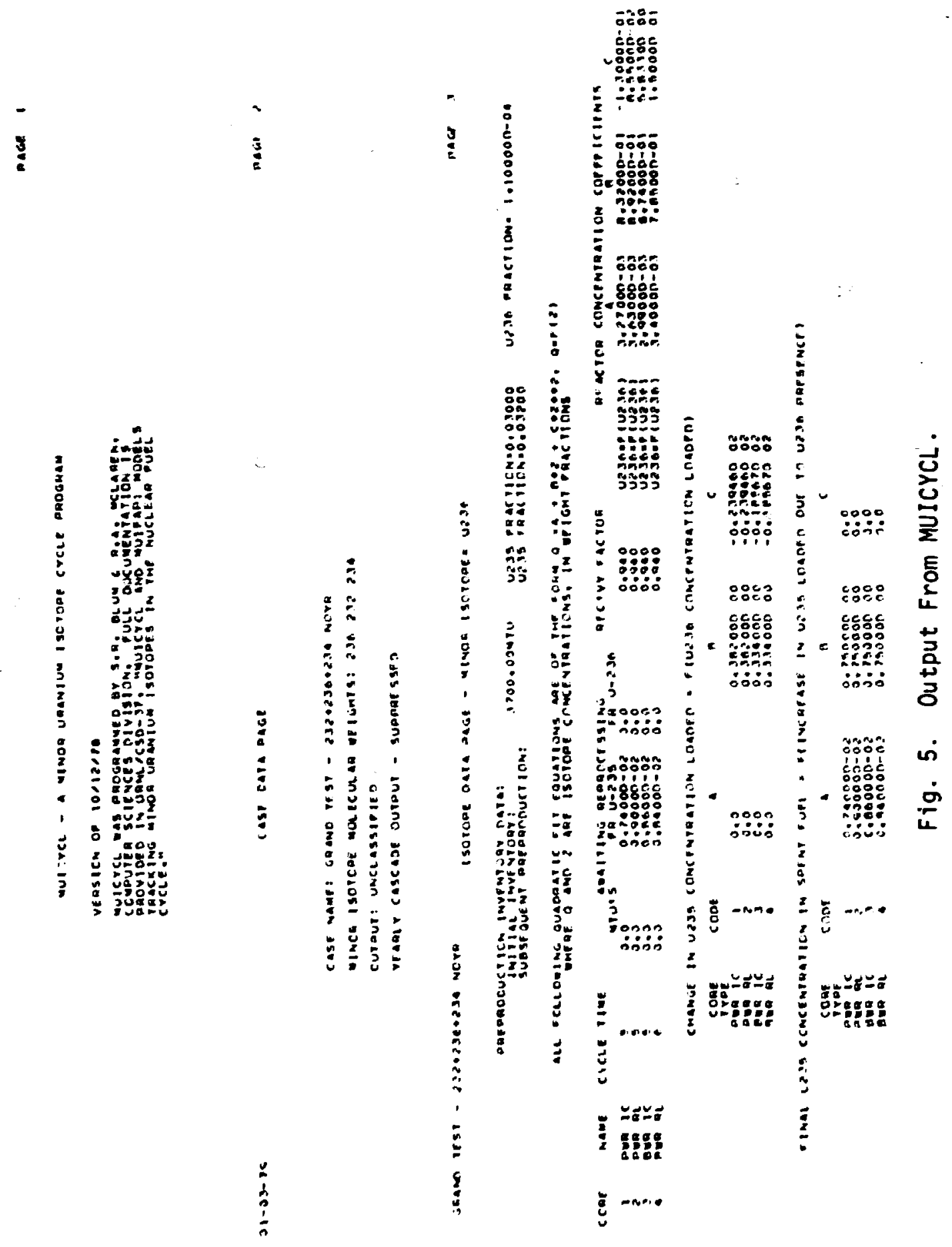




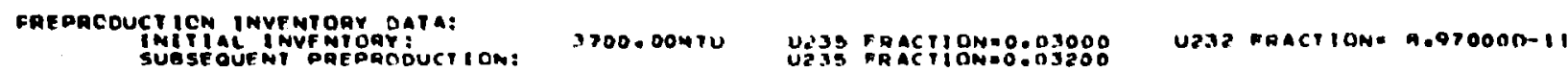

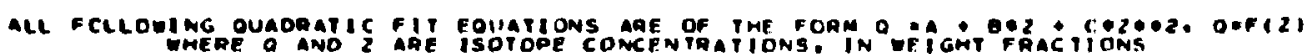

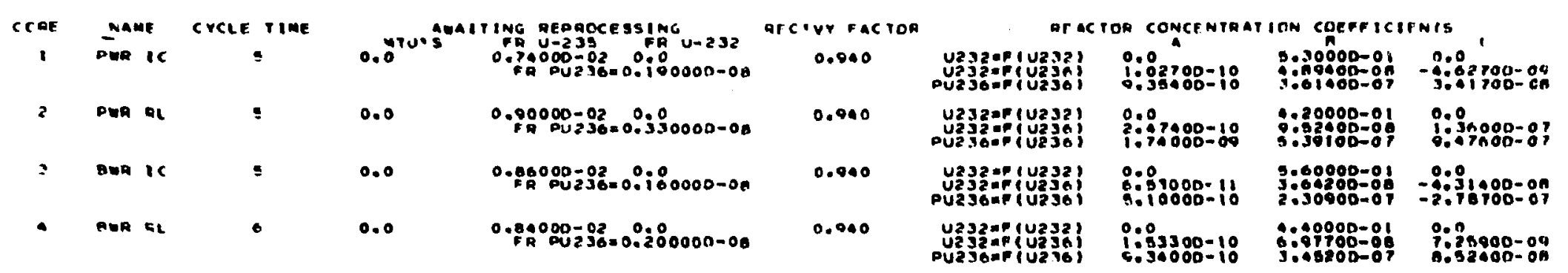

GRANO IEST - 2320536+234 NOYA

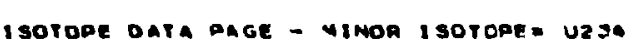

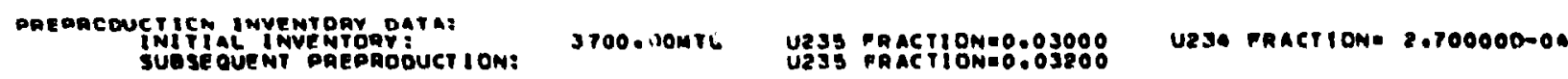

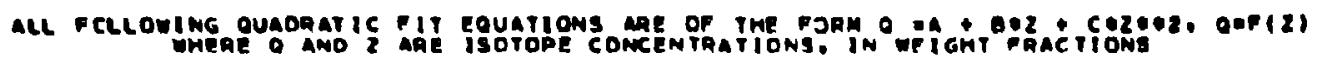
CCPF mame crece tine

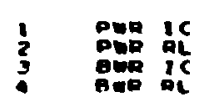
$\stackrel{3}{3}$

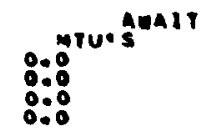

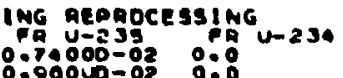
aeciur eac roh
De actora concentantion coemicionts
$\begin{array}{ll}0: 7000=02 & 0: 0 \\ : 9000=02 & 0: 0 \\ 0: 86000=02 & 0: 0 \\ 04000-02 & 0: 0\end{array}$
$0.94: 0$
$0: 90: 0$
0.940

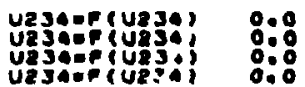

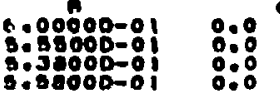

Fig. 5. Output From MUICYCL (cort'd). 

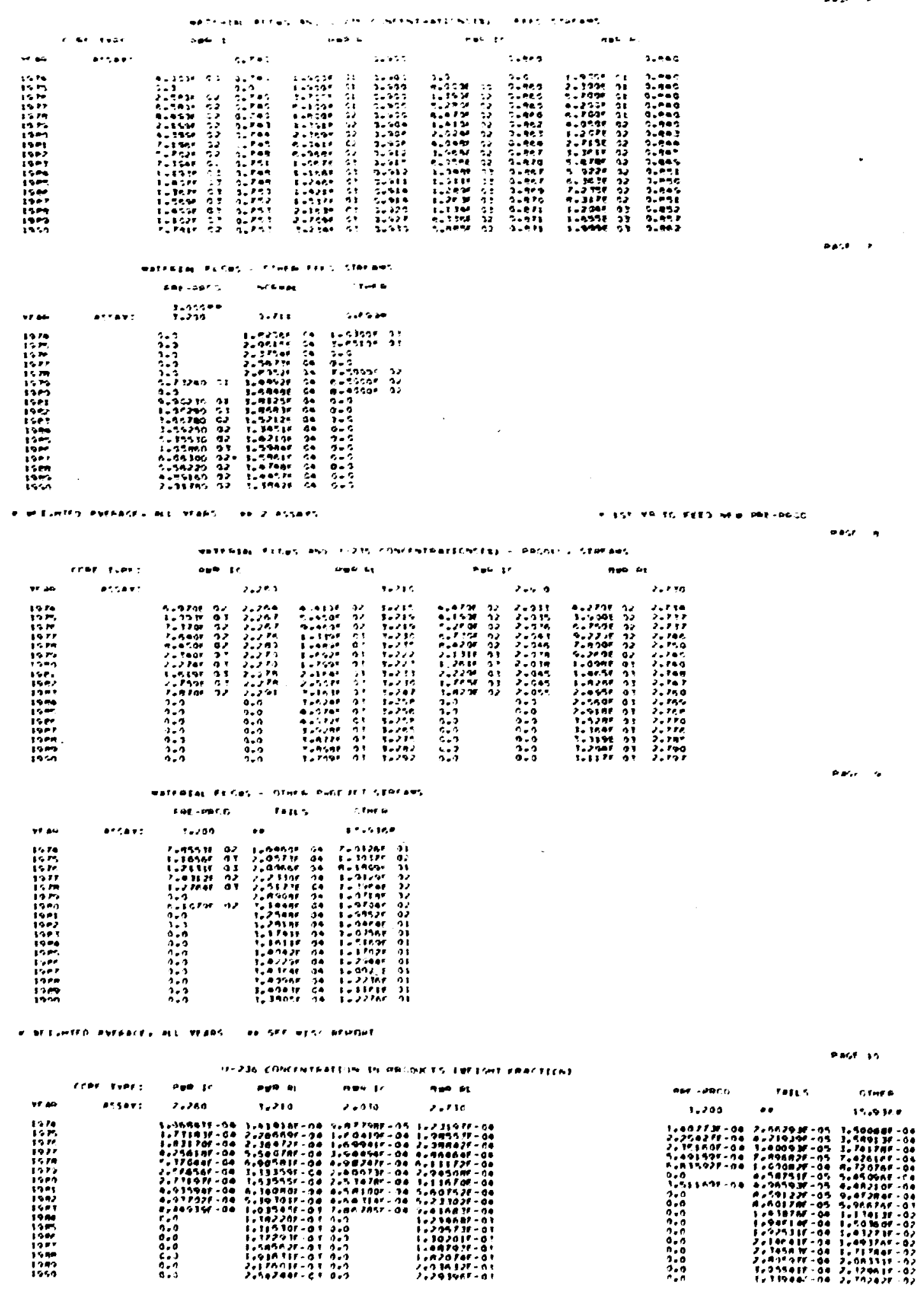

Fig. 5. Output From MUICYCL (cont'd). 

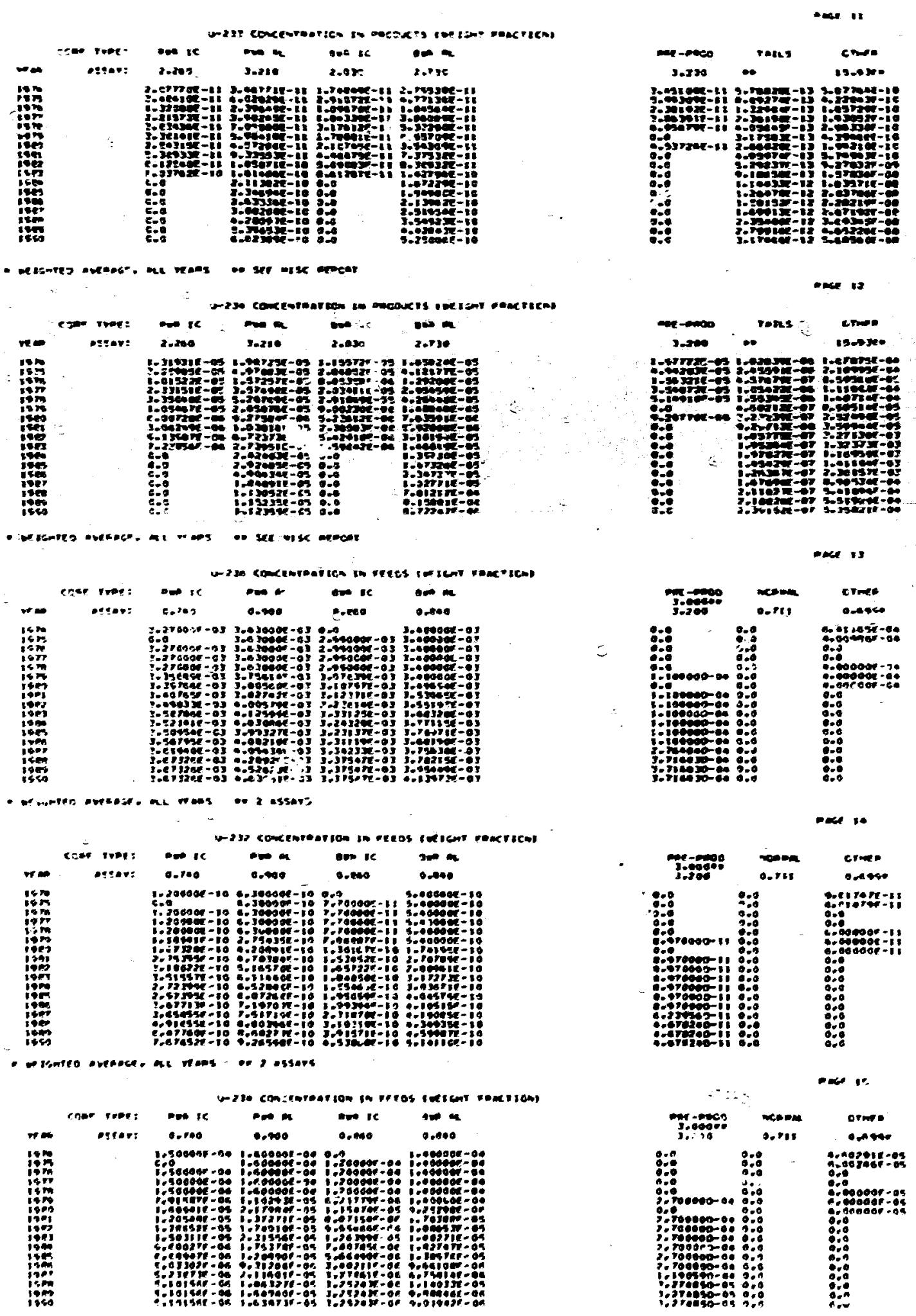

Fig. 5. Output From MUICYCL (cont'd). 


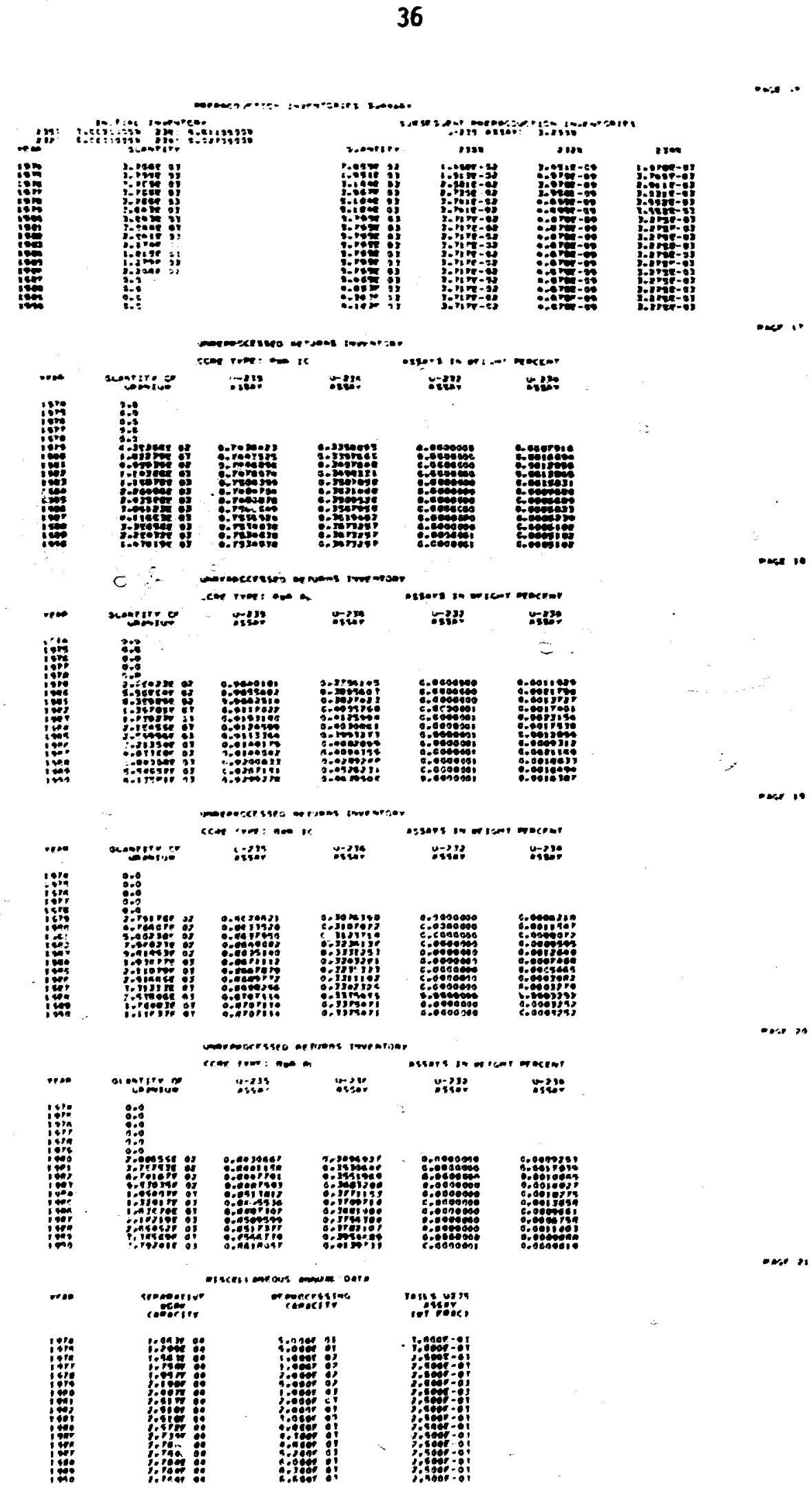

Fig. 5. Output From MUICYCL (cont'd). 
"I0" are sufficient for running several long cases in one job. A typical case requires less than 5 CPU seconds on the IBM 360/195.

The sample problem is an analysis of three minor uranium isotopes. $U^{232}, U^{2: 24}, U^{236}$, in a campaign from 1974-1990. Printout of annual reports was suppressed. A sample annual report is displayed in Fig. 3 or in the output from MUIFAP, Fig. 7.

\section{B. MUIFAP}

JCL setup, input, and output for a sample case solved by MUIFAP are presented here. Figure 6 displays the setup deck consisting of the JCL and input data, and Fig. 7 lists the full output.

The program is set up to run on the IBM $360 / 370$ class of machines. MUIFAP was written in IBM FORTRAN IV and is executed as an object module on a 1600 bpi tape. The resource requests of "CPU95 $=10 \mathrm{~S}$ " and " $10=1.0$ " are sufficient for running many successive cases. The sample case is an analysis of $\mathrm{U}^{232}$ in a five-stream cascade.
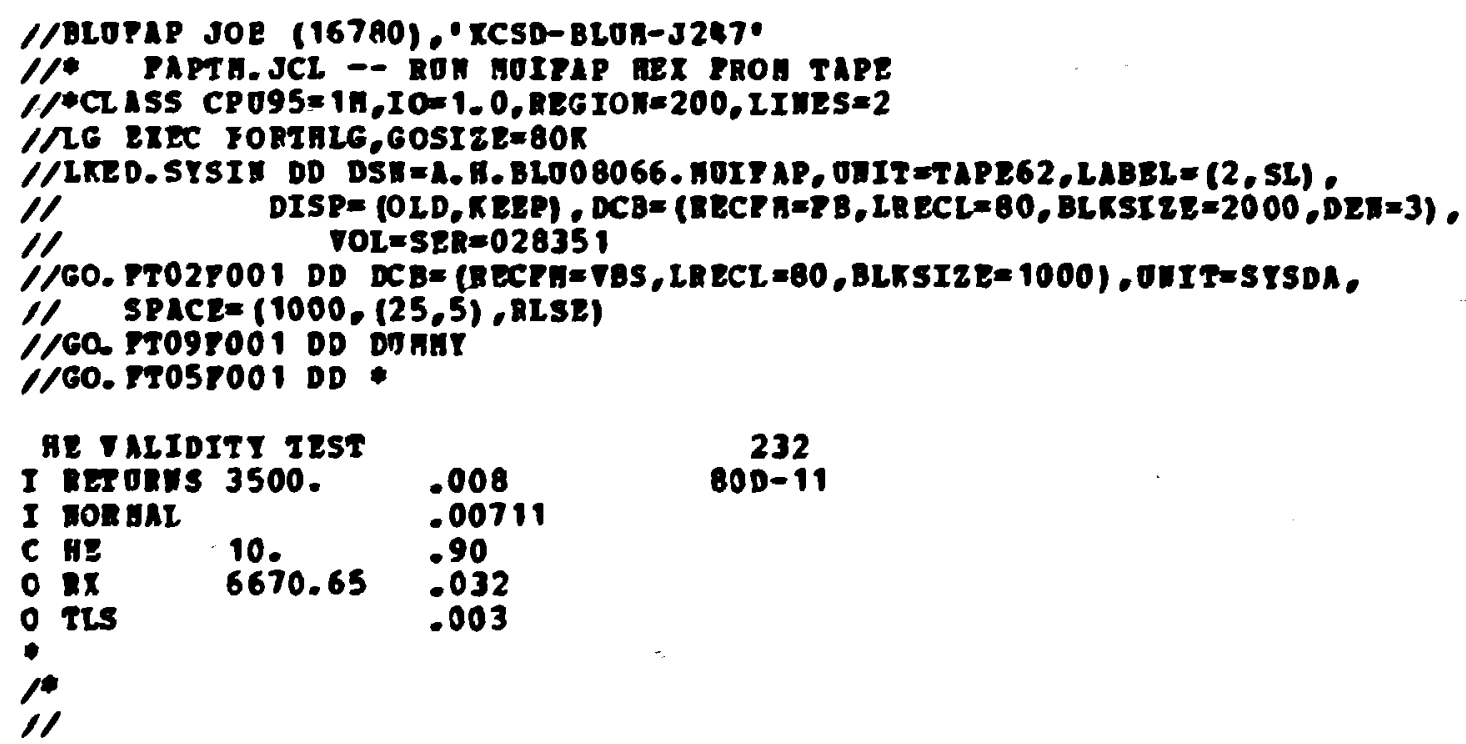

232

$800-11$

Fig. 6. Setup Deck for MUIFAP. 

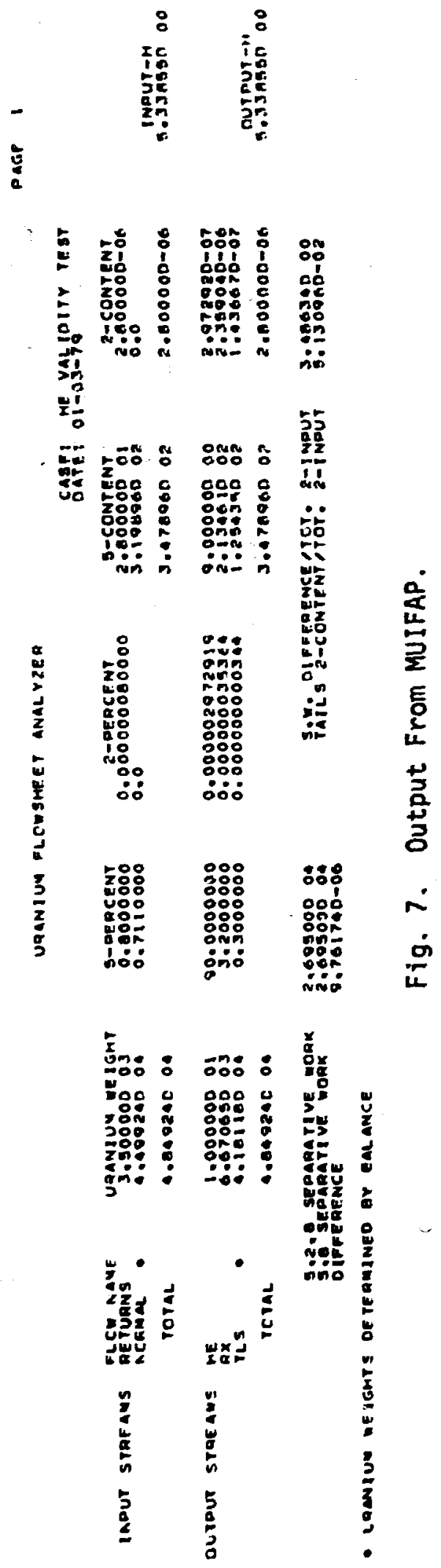
VII. INTERNAL PROGRAM ORGANIZATION

\section{A. MUICYCL Program Structure}

Referring to the program chart (Fig. 8), MUICYCL is organized into more than 20 routines most of which are called directly by MAIN. Communication of variables is accomplished largely by seven labeled common blocks containing over 100 variables.

As much as possible, each significant step in the model is partitioned into a separate subroutine or entry point. Foutines may be classified by the primary operation they perform - reactor use, reprocessing, enrichnent, and input-output.

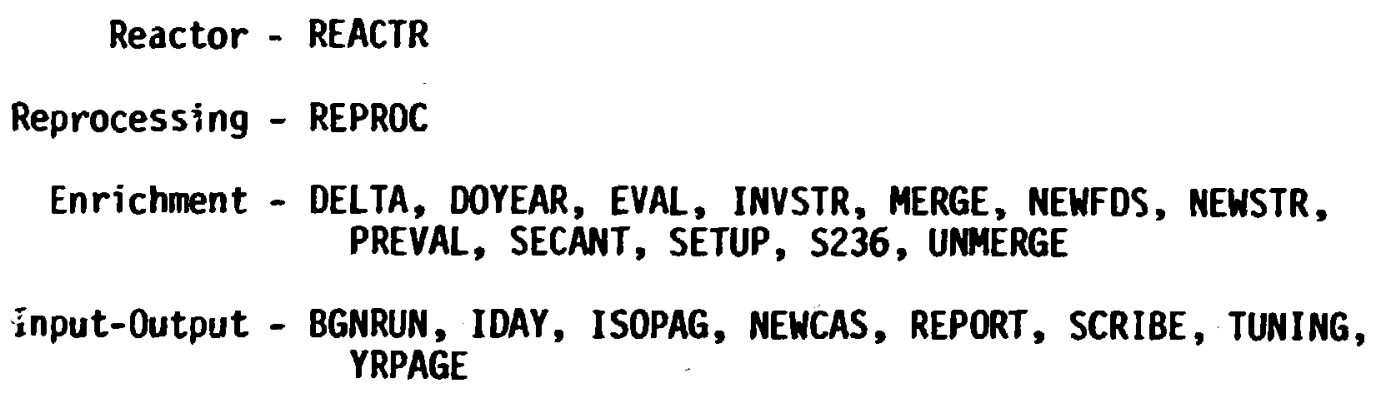
PREVAL, SECANT, SETUP, S236, UNMERGE YRPAGE

The enrichment phase contains several iteration procedures, described in Section $C$ following. The input-output, stage is organized by the type of data to be input, output, or prepared for output.

The evolutionary development of the program has resulted in an unusual structure for execution of a multiyear campaign with several minor isotopes: the full campaign is calculated for one minor isotope, and data are saved; then the full campaign is calculated for the next minor isotope, and similarly for a third minor isotope if one is present. This results in some repatition of calculations. For example, several reprocessing calculations are redone for each minor isotope rather than 
ORNL-OWG 79-8768

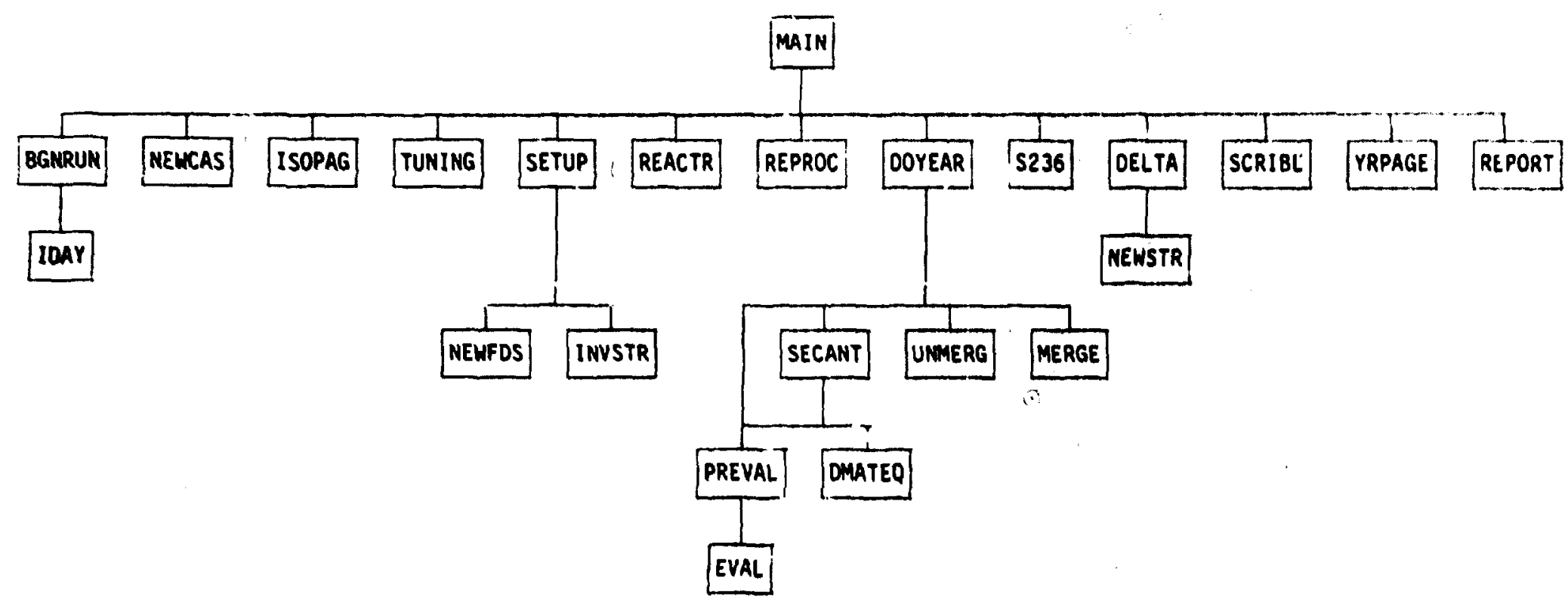

Fig. 8. MUICYCL Program Chart.

Routine $B$ is cailed by Routine $A$ if 11 ne segment(s) go down or across from Routine $A$ to Routine $i$, 
saving the data. The most time-consuming calculations, isotope iterations in the enrichment phase, are minor isotope specific and thus not redundant.

After each year is solved for the first minor isotope, all yearly data are written (by MAIN and YRPAGE) onto a temporary data set (FTO2) to be reread later (by MAIN, SETUP, and INVSTR) for enrichment calculations with the second and third isotopes if presert. A flowchart outlining program fl-w is provided in Fig. 9.

Documentation of individual routines follows. Documentation of variables is provided in a later section within this chapter. Mote also that extensive internal documentation exists in the two major routines, MAIN and DOYEAR. See the program listing, Appendix C.

The 24 MUICYCL routines are documented here by a short description of their use:

\begin{tabular}{|c|c|c|c|}
\hline Name & Description & Called by & Calls \\
\hline BGNRUN & $\begin{array}{l}\text { Prints the header page when executed } \\
\text { at the beginning of the run. }\end{array}$ & MAIN & - \\
\hline DELTA & $\begin{array}{l}\text { This routine calculates the difference } \\
\text { between target and indicated cascade } \\
\text { SH production and develops prepro- } \\
\text { duction stream rates for the next } \\
\text { iteration. Delta is called by MAIN } \\
\text { in each SW iteration. }\end{array}$ & MAIN & NEWSTR \\
\hline DMATEQ & Solves a system of linear equations. & SECANT & - \\
\hline DOYEAR & 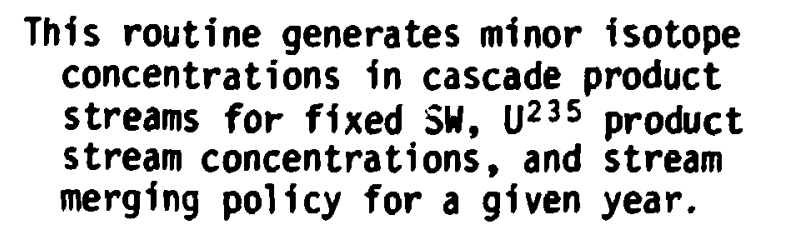 & MAIN & $\begin{array}{l}\text { PREVAL, } \\
\text { SECANT, } \\
\text { MERGE, } \\
\text { UNMERG }\end{array}$ \\
\hline EVAL & $\begin{array}{l}\text { This routine calculates the balance } \\
\text { equation values for given minor } \\
\text { isotope concentration values in } \\
\text { each cascade product stream. }\end{array}$ & PREVAL & - \\
\hline
\end{tabular}




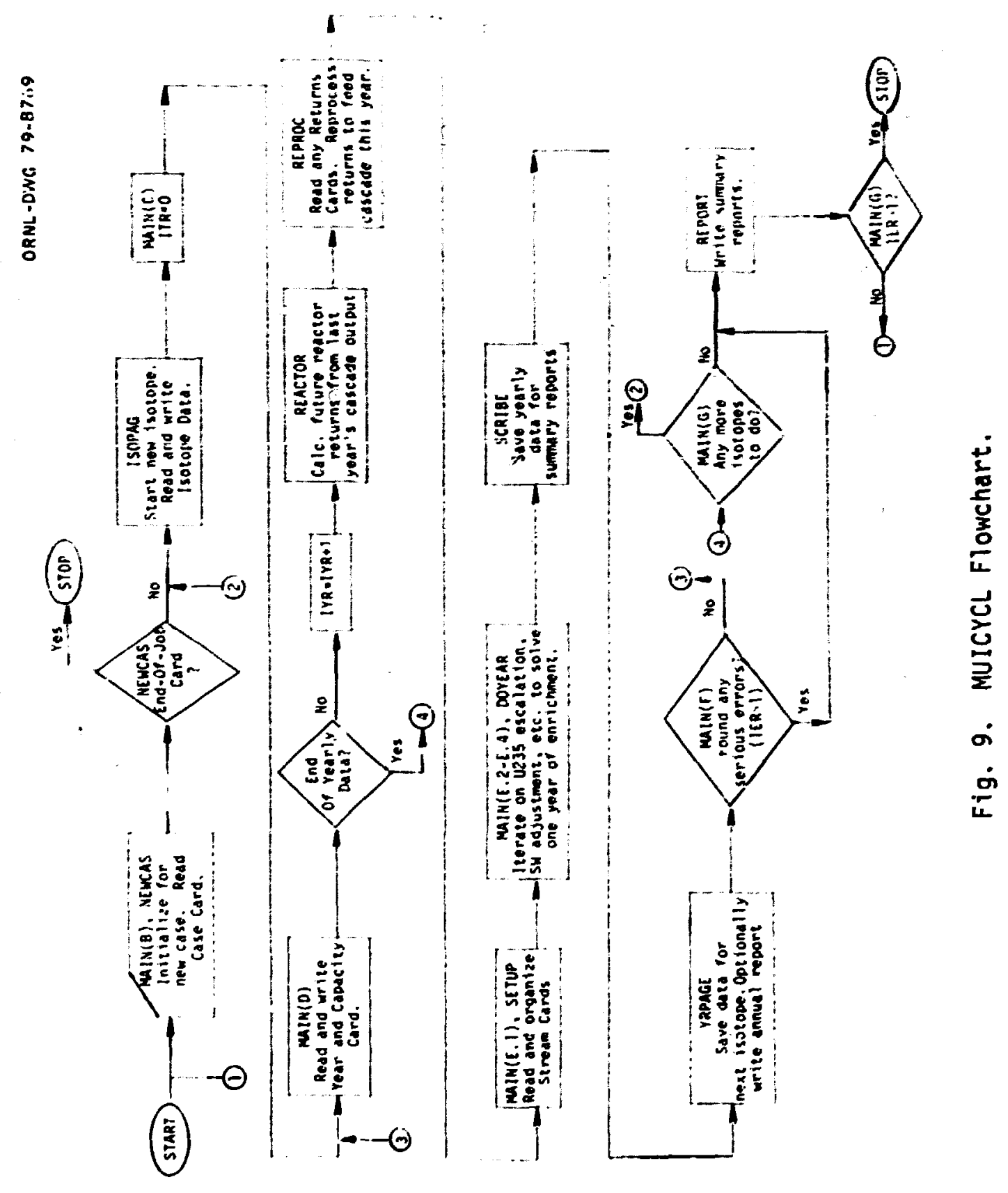




\begin{tabular}{|c|c|c|c|}
\hline Name & Description & Called by & Calls \\
\hline IDAY & $\begin{array}{l}\text { IDAY, a system routine, supplies the } \\
\text { present date for output. }\end{array}$ & BGNRUN & \\
\hline INYSTR & $\begin{array}{l}\text { This routine adds the three preproduction } \\
\text { streans to the cascade when called } \\
\text { by SETUP for each year. }\end{array}$ & SETUP & - \\
\hline ISOPAG & $\begin{array}{l}\text { ISOPAG generates the isotope data page } \\
\text { preceding the yearly data for each } \\
\text { minor isotope. ISOPAG reads } \\
\text { (rereads) the Preproduction Inven- } \\
\text { tory Card, reads the Reactor Fuel } \\
\text { Card(s) and the U235/U236 Card. }\end{array}$ & MAIN & $\pi$ \\
\hline MAIN & $\begin{array}{l}\text { Reads Year and Capacity Card, executes } \\
\text { SH and U235/U236 loops, and super- } \\
\text { vises all other processing. }\end{array}$ & - & $\begin{array}{l}13 \\
\text { Routin } \\
\text { See } \\
\text { Fig. } 8\end{array}$ \\
\hline MERGE & $\begin{array}{l}\text { This routine combines into one stream, } \\
\text { pairs of product streams having U235 } \\
\text { concentrations within tolerance } \\
\text { TOLMRG of each other. Merge is } \\
\text { selectively executed by DOYEAR to } \\
\text { aid in convergence. }\end{array}$ & DOYEAR & - \\
\hline NEWCAS & $\begin{array}{l}\text { This routine reads the Case Card and } \\
\text { generates the title page. }\end{array}$ & MAIN & \\
\hline NEHFDS & $\begin{array}{l}\text { This entry point adds to the cascade } \\
\text { any recycled feed streams when called } \\
\text { by SETUP for each year. Entry point } \\
\text { in INVSTR. }\end{array}$ & SETUP & \\
\hline NEWSTR & $\begin{array}{l}\text { Change the rate of a preproduction } \\
\text { feed stream or preproduction } \\
\text { product stream as part of the SW } \\
\text { iteration procedure. }\end{array}$ & DELTA & \\
\hline PREVAL & $\begin{array}{l}\text { This routine unscales the cascade } \\
\text { estimate, calls EVAL, then rescales }\end{array}$ & $\begin{array}{l}\text { DOYEAR, } \\
\text { SECANT }\end{array}$ & EVAL \\
\hline REACTR & $\begin{array}{l}\text { REACTR calculates concentrations in } \\
\text { future reactor output from last } \\
\text { year's cascade output. Call bj } \\
\text { MAIN Section D at the start of } \\
\text { each year. }\end{array}$ & MAIN & $\therefore$ \\
\hline REPORT & REPORT generates summary reports for & MAIN & \\
\hline
\end{tabular}
each case. Called by MAIN Section G. 
Name

Description

Called by Calls

REPROC REPROC reads any "Returns Cards",

MAIN

streams to feed directly to reprocessing this year. These are merged with reactor returns this year. Depending on capacity, a percentage of available material is reprocessed here (RETRN) to be fed to cascade this year.

5236

S236 escalates $U^{235}$ in cascade product to reactor due to the presence of $U^{236}$. It is called by MAIN in each $U^{235} / U^{236}$ iteration.

SCRIBE This routine stores information for the summary pages. Scribe is called at the end of each year by MAIN, Section $F$.

SECANT The SECANT routine finds the zeros of $N$ simultaneous equations in $N$ unknowns using the Newton formulation of the Secant method. SECANT is called here by DOYEAR to solve the cascade balance equations for each year.

SETUP SETUP generates a cascade stream table each year preparatory to solving.

\section{MAIN}

MAIN

DOYEAR

PREVAL

MAIN

NEWFDS, INVSTR

TUNING

With each new isotope in a case, MAIN calls TUNING to set the values of iteration parameters: These "parms" are set either by default or by input values and are always printed.

UNMERG This entry point in MERGE is a?ways executed at the end of the iterations in DOYEAR if any streams were merged at the start of the iterations.

YRPAGE YRPAGE records yearly data for the next isotope and generates a yearly cascade flowsheet:

HAIN

DOYEAR 


\section{B. MUIFAP Program Structure}

Referring to the program chart (Fig. 8), MIFAP is organized into a MAIN program and seven subroutines, most of which are called directly by MAIN. As in MUICYCL, communication of variables is accomplished mainly through the use of labeled common blocks (see Section D).

The routines are documented here by a short aescription of their use:

\begin{tabular}{|c|c|c|c|}
\hline Name & Description & Called by & Cal1s \\
\hline DMATEQ & $\begin{array}{l}\text { DHATEQ solves a system of linear } \\
\text { equations. }\end{array}$ & $\begin{array}{l}\text { SECANT, } \\
\text { START }\end{array}$ & - \\
\hline EVAL & $\begin{array}{l}\text { EVAL calculates the balance equation } \\
\text { values given minor isotope concen- } \\
\text { tration values for each cascade } \\
\text { product stream. }\end{array}$ & PREYAL & - \\
\hline IDAY & $\begin{array}{l}\text { IDAY is a system routine which returns } \\
\text { the present date as oucput. }\end{array}$ & MAIN & - \\
\hline MAIN & $\begin{array}{l}\text { MAIN reads the Header Card, calculates } \\
\text { the balance streams, builds the } \\
\text { initial estimate matrix to pass to } \\
\text { SECANT, calculates final data for } \\
\text { the output table and prints the } \\
\text { table. }\end{array}$ & - & $\begin{array}{l}\text { IDAY, } \\
\text { SETUP, } \\
\text { SECANT, } \\
\text { PREVAL }\end{array}$ \\
\hline PREVAL & $\begin{array}{l}\text { PREVAL unscales the present estimate, } \\
\text { calls EVAL, then rescales. }\end{array}$ & $\begin{array}{l}\text { MAIN, } \\
\text { SECANT }\end{array}$ & EVAL \\
\hline SECANT & $\begin{array}{l}\text { SECANT finds the zeros of } N \text { simul- } \\
\text { tarieous equations in } N \text { unknowns } \\
\text { using the Newton formulation of } \\
\text { the Secant method. }\end{array}$ & MAIN & $\begin{array}{l}\text { PREVAL, } \\
\text { DMATEQ }\end{array}$ \\
\hline SETUP & $\begin{array}{l}\text { SETUP reads all case data cards and } \\
\text { organizes the streams prior to } \\
\text { solution, setting up a stream table. }\end{array}$ & MAIN & $\longrightarrow$ \\
\hline START & $\begin{array}{l}\text { START generates the initial estimate } \\
\text { using a linear approximation to the } \\
\text { matched abundance ratio balance } \\
\text { equations. }\end{array}$ & MAIN & DMATEQ \\
\hline
\end{tabular}




\section{Enrichment Iteration Procedure}

As we discussed in Section V.C, Enrichment, as many as three levels of iteration are performed in the enrichment phase:

1) Determination of minor isotope concentrations in cascade product streams which will satisfy material balances and matched abundance ratio equations.

2) Iteration on $\mathbb{l}^{235}$ concentrations of reactor bound products.

3) Adjusting preproduction stream rates to attain the rated separative capacity value.

MIFAP executes the first level only. Each level is now discussed:

Determination of Minor Isotope Concentrations (Ievel 1)

In MUICYCL this iteration phase is performed almost completely in subroutine DOYEAR, but partially in MAIN, which calls DOYEAR.

This calculation is done for each minor isotope for each year. Assume the cascade has $M$ withdrawal streams and thus $M$ unknown minor isotope concentrations. The pertinent equations to be solved are $\mathbf{M - 2}$ sidestream $H$ balance equations of the form of (2-4) or (2-5), one cascade $H$ balance equation (2-3), and a minor isotope material balance equation. The two other material balance equations, $U^{235}$ and total uranium, are always satisfied at the beginning of this stage in COYEAR by adjusting two "balance stream" rates selected by the user. Thus, the mathematical system consists of $M$ nonlinear equations in $M$ unknowns. The system is solved by applying the Newton formulation of the Secant method [3]. Subroutine SECANT solves this system. An operationally identical version of SECANT is fully documented in [4], pp. 113-18 and 120-21. 
Among the arguments to SECANT are a matrix of $\boldsymbol{H}_{+1}$ initial estimates. This is built by $M$ perturbations on one initial estimate. The Ith estimate is generated by shifting variable $X(I)$ no more than $75 \%$ in the direction of $X(I+1) . X(M)$ is shifted by a fixed percentage of itself. Estimate $(n+1)$ is the initial estimate. This is generated by any one of three ways.

Method A: If this is not prior to the first iteration in the separative work calculation (ITERS>0), or if this is not prior to the first iteration adjusting $U^{235}$ assay due to $U^{236}$ presence (ITERS6>0), scale all concentrations up or down from the last returned values to satisfy the $U^{236}$ material balance equation.

Method B: !lowever, even if ITERS+ITERS6>0, but the previous solution appears very distant from the ultimate solution, or if ITERS + ITERS $6=0$, a heuristic method is used. The concentration of the highest product stream is estimated as $(1 / M)$ times its maximum by material balance considerations. All other successive concentrations are a factor times the estimated previous concentration:

$$
Y P(J)=Y P(J-1)\left(\frac{X P(J)}{X P(J-1)}\right)^{\operatorname{EXP}},
$$

where

XP is $U^{235}$ concentration

YP is minor isotope concentracion

EXP is a factor fixed for each minor isotope.

Method C: If ITERS+ITERS6=0 and streams were merged the previous iteration (IMERGE $=-1$ explained below), the previous solution is used.

Merging of streams is a procedure used to prevent convergence difficulties. The ordering properties of the $H$ balance equations results in nonlinearities when minor isutope concentrations do not maintain an ascending or descending relationship corresponding to their respective $U^{235}$ weight fractions. This difficulty is circumvented by temporarily merging into one stream any two product streams whose $U^{235}$ weight 
fractions are within a tolerance TOLMRG (default $=0.0005$ ) of each other. After reaching a solution, the two streams are separated, and their minor concentrations are shifted proportionately to their $U^{235}$ concentrations. During the merged period, IMERGE=1. For the iteration immediately following this, IMERGE $=-1$.

The MUIFAP level 1 procedure is considerably less complex. The initial estimate matrix is also built by perturbations on one initial estimate. However, the $I^{\text {th }}$ estimate is generated by reducing $X(I)$ by 50\%. The initial estimate is generated by solving a linear anproximation to the balance equations (subroutine START).

In both MICYCL and MIFAP, all estimate vectors passed to the SECANT program are normalized: the Ith component is divided by the value of the $I^{\text {th }}$ coriponent in the initial estimate. Thus, the initial estimate is always scaled to a vector of l's.

Iteration on $U^{235}$ Concentrations of Reactor Bound Products (level 2)

The presence of $U^{235}$ reduces the reactivity of $U^{235}$ in reactors. To compensate, the $U^{235}$ assay is escalated using a quadratic equation of the form of Equation (3-1). This is performed (in subroutine S236) when the minor isotope is $U^{236}$ and the user has not suppressed this calculation. This follows the previous level of iterations and is considered completed when each new $U^{235}$ concentration differs from the previous concentration by less than a tolerance of TOL235, whose default value is $5 \times 10^{-8}$. If not converged, or if streams must be remerged, the program performs fteration level 1 again. If converged, level 3, if applicable, is executed; otherwise, enrichment iterations for this year and isotope are complete. 
Adjusting Preproduction Stream Rates to Attain SW Capacity (level 3)

This calculation is performed unless the user has not entered a positive value for SWUCAP, the yearly separative capacity. Calculations. occur each year for which the minor isotope is $U^{236}$, and following the previous two iteration levels. Subroutine OELTA determines the quantity of preproduction which should be fed or produced in order to match the value of SWUCAP. The estimate is generated by a inear approximation to the rate of change in separative work for a change in pleproduction. Appendix $B$ derives the working equations.

If the relative difference between the calculated SH value and capacity is within tolerance $T_{0}$ : Si (default=10-4), the preproduction calculation is bypassed, and enrichment calculations for this year and isotope are complete. Otherwise, once a new preproduction stream rate is generated, the previous two iteration levels are recalculated and this phase is again executed.

Error Conditions (MUICYCL)

Error conditions within the enrichment iteration procedure in MUICYCL are denoted by the nonzero value of flag IER. Error conditions observed during iteration level $I$ (determination of minor isotope concentrations) result in negative values of IER, set in DOYEAR:

IER $=-1$ Indicates the concentration vector was not being moved significantly ("stall") al though convergence had not been attained.

IER $=-2$ Indicates one of two conditions, both noted by a warning message:
a) Convergence was not achieved within the maximum number of iterations, ITERMX $=30$, or
b) the system converged to a negative concentration. 
If another iteration level is to be executed next, IER is reset to zero in MAIN on the assumption that further iterations will resolve the difficilty. If iterations are completed, IER is set to its absolute value and more severe measures are taken, as explained below.

Two error conditions, involving iteration levels 2 and 3 , are noted in MAIN:

$$
\begin{aligned}
& \text { IER = } 2 \text { Indicates that the number of iterations in level } 2\left(U^{235}\right) \\
& \text { escalation) exceeded the limit of MXITR6=10. An input } \\
& \text { error is probably responsible for this infrequent error. The } \\
& \text { program will transfer to the end of the enrichment section. }
\end{aligned}
$$

At the end of the enrichment section each year, a value of IER>l results in termination of the run. Whenever IER>0 at this point, an error message is printed.

D. Common Blocks and Common Block Variables

Both MUICYCL and MUIFAP use labeled common blocks to communicate between routines. MUICYCL uses seven such blocks (EVALU, RECYCL, RECORD, CYCLE, SUMRY, COEFFS, and C0236) containing over 100 variables. Table 1 provides a cross listing of common blocks and the routines in which they are present. MUIFAP has two blocks, EVALU and RECORD, for 31 variables, nearly all of which are used similarly in MUICYCL.

Following is an alphabetized dictionary of all variables in MUICYCL common blocks. They are identified by common block name, dimension if appropriate, and type if different from the implicit specification. The implicit specification is that integer variables (first letter $I-N$ ) are typed INTEGER*4, and real variables (first letter $A-H$ or $0-Z$ ) are typed REAL*8. 
Table 1. A Cross Listing of Routines* and Common Blocks in MUICYCL

\begin{tabular}{|c|c|c|c|c|c|c|c|}
\hline & EVALU & RECYCL & RECORD & CYCLE & SUMRY & COEFFS & $\mathrm{CO236}$ \\
\hline MAIN & $\gamma$ & $\checkmark$ & $\checkmark$ & $\checkmark c$ & $\checkmark$ & & \\
\hline DOYEAR & r & & $\checkmark$ & & & & \\
\hline EVAL & $\checkmark$ & & $\checkmark$ & & & & \\
\hline INVSTR & & r & & $\checkmark$ & & & \\
\hline ISOPAG & $\checkmark$ & $\checkmark$ & $r$ & $\checkmark$ & & $r$ & 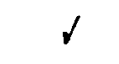 \\
\hline MERGE & d & & & & $\cdot$ & & \\
\hline NEWCAS & & & t & . & & & \\
\hline PREVAL & $\checkmark$ & & & & & & \\
\hline REACTR & $\checkmark$ & r & & & & $\checkmark$ & r \\
\hline REPORT & & $\checkmark$ & $r$ & & $r$ & & \\
\hline REPROC & ' & ' & & $\checkmark$ & & & \\
\hline S236 & & & & & & & $r$ \\
\hline SCRIBE & $\checkmark$ & $v^{\prime}$ & $j$ & & $\checkmark$ & & \\
\hline SETUP & $\checkmark$ & $\checkmark$ & $r$ & $\checkmark$ & & & \\
\hline YRPAGE & $\checkmark$ & $\checkmark$ & d & $\checkmark$ & & & \\
\hline
\end{tabular}

*Unlisted routines NEWFDS and UNMERG are entry points; IDAY is a system routine; BGNRUN, DELTA, DMATEQ, DOYEAR, NEWSTR, SECANT, and TUNING contain no common blocks. 
A5M SUIPRY, (40), $R \star 4$. This is the average $U^{2} \equiv$ concentration of all miscellaneous feed streams in a year, subscripted by year. Calculated in SCRIBE each year, it is then used in REPORT.

AM SUMRY, (3), $R^{\star} 4$. AM(A) is the concentration (weight fraction) of the $\mu^{\text {th }}$ minor isotope in the stockpile of original preproduction. This is set in SCRIBE and used in REPORT.

AMM SUMRY, $(40,3), R \star 4$. AMM(IYR, M) is the average weight fraction of the $M$ th minor isotope in QFM(IYR), the sum of all miscellaneous feed streams in year IYR. Calculated in SCRIBE, it is then printed by REPORT in the column, "OTHER".

AT5 SUMRY, (40), $R * 4$. This is the $U^{235}$ concentration in the cascade tails stream each year, subscripted by year. It is loaded in SCRIBE each year and printed by REPORT.

ATM SUMRY, $(40,3), R * 4$. ATM(IYR,M) is the weight fraction of the $M$ th minor isotope in the cascade tails stream in year IYR. It is loaded in SCRIBE and printed by REPORT.

C22 COEFFS, $(3,5) . C 22(K, I)$ is the $K^{\text {th }}$ quadratic coefficient in the first half of the equation (see Equation 3-2) which calculates the concentration of $U^{232}$ when fuel type $I$ is discharged from a reactor. This half quantifies the effect of initial $U^{232}$ concentration upon final concentration. It is input from the Reactor Fuel Card by subroutine ISOPAG and is used in REACTR.

C26 RECYCLE, $(3,6)$. C26 $(K, 1)$ is the $K^{\text {th }}$ quadratic coefficient in the second half of Equation 3-2 which calculates the weight fraction of $U^{232}$ when fuel type $I$ is discharged from a reactor. This half quantifies the effect of the initial $U^{236}$ weight fraction upon the final $U^{232}$ weight fraction. It is input from the second $U^{232}$ Reactor Fuel Card for each fuel type by subroutine ISOPAG and is used in REACTR.

C44,C66 COEFFS, $(3,6)$. C44 $(K, I)$ or $C 66(K, I)$ are the $K^{\text {th }}$ quadratic coefficients in the equation (see Equation 3-1) calculating the discharge weight fraction of $U^{234}$ or $U^{236}$ as a function of the initial weight fraction of $U^{234}$ or $U^{236}$ in fuel type I loaded into a reactor. These are input from the Reactor fuel Cards by subroutine ISOPAG and used in REACTR.

C55 RECYCL, $(3,6)$. C55(K,J) is the $K^{\text {th }}$ coefficient in the quadratic equation (see Equation 3-1) to define the weight fraction of $U^{235}$ in spent reactor fuel as a function of the $U^{235}$ escalation in a fuel type identified by $J$ loaded into a reactor. See definition of KNUM. It is input from the $U^{235} / U^{236}$ Card by subroutine ISOPAG and used in REACTR. 
CASE RECORD, (5). This is the case name, read from the case card by subroutine NEWCAS and printed by NEWCAS, ISOPAG, and YRPAGE.

COEF $\operatorname{Co236,}(3,6) . \operatorname{COEF}(k, J)$ is the $k$ th coefficient in the quadratic equation (see Equation 3-1) to define the change in $U^{235}$ assay reactor requirements as a function of $U^{236}$ assay in cascade product. J identifies the fuel type through use of $\operatorname{KNUM}(\mathrm{J})$. COEF is input from the $U^{2} 35 / U^{2} 36$ card by ISOPAG and used in S236.

COEFF COEFFS, $(3,6,3), \operatorname{COEFF}(\cdot, \cdot, 1),(\cdot, \cdot, 2)$ and $(\cdot, \cdot, 3)$ are equivalent to $\mathrm{C} 22(\cdot, \cdot), \mathrm{C} 44(\cdot, \cdot)$ and $\mathrm{C} 66(\cdot, \cdot)$. This arrangement permits easier input of these data by subroutine ISOPAG.

CONFID RECORD, $L * 4$. This variable takes a value of "true" if the user has requested output to be classified "CONFIDENTIAL" through use of an input field on the Case Card. CONFIS is initialized in NEHCAS and also acsessed in MAIN, DOYEAR, ISOPAG, REPORT, and YRPAGE.

CORNAM RECORD, (6). CORNAM(I) is the name assigned by the user to fuel type I. It is input by ISOPAG from the Reactor Fuel Cards for the first minor uranium isotope. Also used in MAIN, REPORT, SETUP, and YRPAGE.

CPU COEFFS, $(3,6)$. CPU(K,I) is the $K^{\text {th }}$ quadratic coefficient in the equation (see Equation 3-1) calculating the discharge weight fraction of $\mathrm{PU}^{23 E}$ as a quadratic function of the initial weight fraction of $U^{236}$ in fuel type I loaded into a reactor. This is input from the second $U^{232}$ Reactor Fuel Card for each fuel type in subroutine ISOPAG and is used in REACTR.

CYC SUMRY, (40), $R * 4$. CYC(IYR) is the input total reprocessing capacity for year IYR. This is loaded in SCRIBE and printed by REPORT.

CYCCAP RECYCL. This is the reprocessing capacity, input each year on the Year and Capacity Card in MAIN, and used in REPROC and SCRIBE.

DATE RECORD. This is the eight-character yearly date when the job is run. It is returned to subroutine BGNRUN by the system rout ine IDAY and is used in MAIN, NEWCAS, SETUP, and DOYEAR.

EVALU, (20). $F(I)$ is the weight of the Ith feed stream to the cascade in a year, ordered by $U^{235}$ concentration. Its value is loaded in SETUP each year for each isotope. The balance stream weight, $F(K F)$, is calculated in DOYEAR. At year-end, its value may be written onto temporary storage in YRPAGE for later use. Also used in MAIN, EVAL, DELTA, and SCRIBE. 
FEED5 SUMRY, $(40,6), R * 4$. FEEDS(IYR, IF) is the $U^{2}: \vdots$ concentration (weight fraction) of stream FEEDQ(IYR,IF). It is loaded in SCRIBE and printed in step REPORT.

FEEDM SUMRY, $(4 P, 6,3), R \star 4$. FEEDM(IYR, IF, M) is the weight fraction of the $H^{\text {th }}$ minor isotope in stream FEEDQ(IYR, IF). It is loaded in SCRIBE anci printed in REPORT.

FEEDQ SUMRY, $(40,6), R \star 4$. FEEDQ(IYR, IF) is the weight of the feed stream to the cascade in year IYR, representing returns from the reactor of core type IF. It is loaded in SCRIBE and printed in REPORT.

FNAM RECORD, (20). FNAM(I) is the name associated with the $I^{\text {th }}$ feed stream in a particular year, generated either from input on the Stream Card or the pertinent Reactor Fuel Card, or from the internal name assigned a "feed from preproduction" stream. FMAM is loaded in SETUP and used in DOYEAR and YRPAGE.

FSIN RECORD, (20). FSIN(I) contains a star, " $\star$ ", if the rate of the Ith feed stream to the cascade is to be calculated by material balance equations. Otherwise, FSIN(I) contains blanks. FSIN(I) is loareu from input in each year by SETUP and used in DOYEAR and VRPAGE.

FXF,FYF EVALU, (20). FXF(I) and FYF(I) are the quantity of $U^{2} 35$ and of the minor isotope, respectively, in the Ith feed stream to the cascade in a year. They are calculated in DOYEAR and used in the annual report (if not suppressed) by YRPAGE.

ICYCL RECYCL, (6). ICYCL(I) is the cycle time in years of fuel type I as input on the Reactor fuel Cards. The ICYCL values input with the first minor isotope are used with later isotopes. These data are input in ISOPAG and used in REACTR.

IFSTR RECORD, (20). IFSTR(I) is non-zero if the ith feed stream to the enrichment process represents a reactor sturn. If $\operatorname{IFSTR}(I)>100$, then IFSTR(I) -100 is the fuei type, and this stream card was entered by the user. If $I \leq \operatorname{IFSTR}(I)<100$, then IFSTR(I) is the fuel type, and this stream has been recycled by the program from the reprocessing plant. IFSTR is set in SETUP each year and is used in SCRIBE and YRPAGE.

IN EVALU. This is the total number of feed streams to the cascade in a year, calculated in SETUP for each year and each isotope. Also used in DOYEAR, EVAL, SCRIBE, YRPAGE.

IPSTR RECORO, (20). IPSTR(I) $=K \neq 0$ if product stream I is to be used as fuel type $K$ in reactors the following year. Note that IPSTR and IPTYP are "inverses". IPSTR is initialized in SETUP each year from input and used in SCRIBE and YRPAGE. 
IPTYP RECYCL, (6). IPTYP(K) is the product stream nimber of a cascade product stream which will be loaded in core type $k$ on reactors the following year. This is set in SETUP eash year from input and used in MAIN, REACTR, and S236.

ISTRM EVALU, (20). When subroutine MERGE is used temporarily to combine two adjacent cascade product streams into one, ISTRM handles stream number bookkeeping. Use of MERGE may mean there are $N-1$ unknown concentrations rather than $N$, but there are still data for the $N$ streams. ISTRM(I) is the product stream number assoitated with the solution YP(I). This is initialized to ISTRM(I) =I, possibly reset in MERGE, used in cascade calcuiations in DOYEAR and EVAL, and reinitialized in UNMERG.

IUNIT CYCLE. This is the logical number of the temporary data set onto which all yearly data are written while modiling the first minor uranium isotope (MKASE $=1$ ), and from which yearly data are read for the second or third minor isotopes. IUNIT=2 is set in MAIN, "endfiled" in MAIN, "rewound" in ISOPAG, and aiso used in INVSTR, ISOPAG, NEWCAS, REPROC, SETUP, and YRPAGE.

IYR EVALU. This variable tracks the elapsed years of the case up to and including the year being modeled. It is initialized and incremented in MAIN. Also used in REACTR, REPROC, and SCRIBE as a subscript for dimensioned data.

IYRMAX EVALU. This is the dimension on all yearly data arrays and, thus, the maximum number of years to be modeled. It is initialized in MAIN to 40 and used in initialization of dimensioned data in REACTR.

JYEAR SUMRY, (40). JYEAR(IYR) is the "calendar year" associated with the IYRth year in the run. It is loaded in SCRIBE each year and used in all the summary report pages by REPORT.

JYR EVALU. This is the actual calendar year, read from the Year and Capacity Card, presently being modeled. Input in MAIN, it is used for output operations in MAIN, DOYEAR, REACTR, SCRIBE, SETUP, and YRPAGE.

KF EVALU. KF is the subscript of the feed stream to the cascade whose weight, $F(K F)$, is to be calculated by closing the total material balance and $U^{23}$ balance equations. KF is identified from it,put in SETUP each year, and $F(K F)$ is calculated in DOYEAR. Also used in YRPAGE.

KNUM $\quad$ C236, $(6)$. KNUM(I) $=\mathrm{J}$ means that $\mathrm{C} 55(\cdot, j)$ are the appropriate C55 coefficients for reactor fuel type 1 . See the definition of C55. KNUM is calculated in ISOPAG and used in REAiTR and S236. 
RORES RECYCLE. This is the total number of fuel types, set in ISOPAG to the number of Reactor Fuel Cards. Also used in MAIN, HENFDS, REACTR, REPORT, REPROC, SCRIBE, and YRPAGE.

KP

EVALU. KP is the subscript of the cascade product stream whose weight, $P(K P)$, is to be calculated by closing the total material balance and $U^{235}$ balance equations. KP is identified from input in SETUP each year, and $P(K P)$ is calculated in DOYEAR. Also used in YRPAGE.

MAXKOR RECYCL. This is the maximum number of reactor fuel types permitted. It is set to 6 in MAIN and also used in ISOPAG and SETUP.

MKASE CYCLE. MKASE is the sequence number of the minor isotope presently being modeled. It is initialized in NELCAS and updated in MAIN. Also used in INVSTR, ISOPAG, REPROC, SETUP, and YRPAGE.

M2

EVALU. $M 2$ is the molecular weight of the minor uranium isotope being modeled. Its value is set in ISOPAG. Also used in MAIN, REACTR, REPROC, and SETUP.

N

EVALU. This is the number of product strcams from the cascade in a year, initialized in SETUP, and subject to change due to use of subroutine MERGE. It is equiva?enced to OUT. Also used in DOYEAR, EVAL, MERGE, PREVAL, SCRIBE, SECANT, SETUP, and YRPAGE.

MRYR SUMRY. The total number of years in the case. NRYR is loaded in SCRIBE and used in REPORT.

NUM EVALU, (20). For the Ith product stream from the cascade in a year, NUM(I) is the number of feed streams entered into the cascade above stream I. This is used by EVA! in modeling the cascade.

$P \quad$ EVALU, $(20) . P(!)$ is the weight of the $I^{\text {th }}$ product stream in the cascade in a year, ordered by $U^{235}$ concentration. Its initial value is loaded in SETUP (and DOYEAR for the balance stream) each year for each isotope. The preproduction product stream rate is recalculated in NEWSTR. At year end $P(I)$ may be saved in temporary storage by YRPAGE for laier use. Also used in MAIN, DELTA, EVAL, MERGE, REACTR, and SCRI.3E.

PA5M SUMRY, (40), $R * 4$. PA5M(IYR) is the averaged $U^{23}$ weight fraction in QPM(IYR), total miscellaneous cascade product flow in a year. It is calculated by SCRIBE and used in REPORT.

PAGE RECORD, I*4. This variable tracks the total number of pages being printed so that each page is numbered in compliance with security regulations. PAGE is initialized in BGNRUN, incremented and printed in MAIN, DOYEAR, ISOPAG, NEWC/AS, and REPORT. 
PAMA SUMKY, $(40,3), R * 4$. PAMA(IYR, $M$ ) is the averaged weight fraction of the $M^{\text {th }}$ minor isotope in QPM(IYR), total miscellaneous cascade product STow in a year. It is calculated by SCRIBE and printed by REPORT.

PNAM RECORD, (20). PMAM(I) is the name associated with the Ith product stream in a particular year, generated either from input on the Stream Card or from the internal name assigned a preproduction stream. PNAM is loaded in SETUP and used in DOYEAR, SCRIBE, and YRPAGE.

POT RECYCL, (6). POT(I) is the running value of the weight of fuel type $I$ awaiting reprocessing. It is initialized and updated in REPROC and used in MAIN, SCRIBE, and YRPAGE.

POTI EVALU, (6). POTI(K) is the initial stockpile weight of fuel type $K$ awaiting-reprocessing. This is read from the Reactor Fuel cards for the first minor isotope in subroutine ISOPAG and is used in REPROC.

POTPUI EVALU, (6). POTPUI(K) is the weight fraction of PU236 in the initial stockpile of fuel type $K$ awaiting reprocessing. It is input by subroutine ISOPAG from the second Reactor Fuel Card for $U^{2} \equiv 2$ and is used by REPROC.

POTXP RECYCL, (6). POTXP(I) is the present $U^{235}$ weight fraction in the stockpile of fuel type I awaiting reprocessing. This is variable over time because $U^{235}$ entering the reactors has been escalated due to $U^{236}$. Initialized (to XPKORS) and updated in REPROC, it is also used in MAIN, NEWFDS, SCRIBE, and YRPAGE.

POTYP RECYCL, (6). POTYP(I) is the running value of the weight fraction of the minor isotope in fuel type I awaiting reprocessing. It is initialized and updated in REPROC, used in NEWFDS to set the minor fraction in reprocessed streams fed back to the cascade, and also used in MAIN, SCRIBE, and YRPAGE.

POTYPI EVALU. (6). POTYPI(K) is the minor uranium isotope weight fraction in the initial stockpile of fuel type $K$ awaiting reprocessing. This is input by subroutine ISOPAG from the Reactor Fuel cards for each minor isotope ard is used in REPROC.

PREIL SUMRY, (40), $R^{\star} 4$. PREIL(IYR) is the weight of the original preproduction stockpile at the end of year IYR. It is loaded in SCRIBE and printed in REPORT.

PRE2FM SUMRY $(40,3), R * 4$. PRE2FM(IYR,M) is the weight fraction of the Mth minor isotope in stream PREIIF(IYR), the feed in year IYR from the "new" preproduction stockpile. This is set in SCRIBE and used in REPORT. 
PRE2L SUMRY, (40), R*4. PREZLiIYR) is the weight of the "new" preproduction stockpile is the end of year IYR. It is loaded in SCRIBE and printed in REPORT.

PREZM SUMRY, $(40,3), R * 4$. PREZM(IYR,M) is the weight fraction of the $M$ th minor isotope in the "new" cascade preproduction stockpile at the end of year IYR. It is loaded in SCRIBE and printed in REPORT.

PRE2P, SURRY, [(40), (40), (40,3)], R*4. PRE2P(IYR), PRE2P5(IYR), PRE2P5, PRE2PM and PRE2PM(IYR,M) are, respectively, the weight, $U^{235}$ weight fractioli, and weight fraction of $m$ th minor isotope in preproduction product from the enrichment cascade in year IYR. These data are loaded in SCRIBE each year and printed in the sumary reports by REPORT.

PREI SUMRY, (40), $R * 4$. PREI(IYR) is the weight of the cascade stream in year IYR consisting of feed from the original preproduction stockpile. This is set in SCRIBE and used in REPORT.

PREIIF SUMRY, (40), R*4. PREIIF(IYR) is the weight of the stream in the enrichment cascade in year IYR consisting of feed from the stockpile of "new" preproduction. This is set in SCRIBE and used in REPORT.

PROOM SUMRY, $(40,6,3), R^{\star 4}$. PRODM(IYR, ITYP,M) is the concentration of the $M^{\text {th }}$ minor isotope in cascade product stream PRODQ(IYR, ITYP), product to reactors. It is loaded in SCRIBE and printed by REPORT.

PROD5 SUMRY, $(40,6), R * 4$. PROD5 (IYR, ITYP) is the $U^{235}$ weight fraction in PRODQ(IYR, ITYP) the cascade product strean in year IYR to be used in reactor core type ITYP. It is loaded in SCRIBE and printed by REPORT.

PRODQ SUMRY, $(40,6), R \star 4$. PRODQ(IYR,ITYP) is the weight of the cascade product stream in year IYR to be loaded as fuel type ITYP in reactors. It is loaded in SCRIBE each year and printed in the summary reports by REPORT.

PSIN RECORD, (20). PSIN(I) contains a star, "*", if the rate of the Ith product stream from the enrichment process is to be calculated by material balance equations. Otherwise, PSIN(I) contains blanks. PSIN is loaded from input in each year by SETUP and is used in DOYEAR and YRPAGE.

PXP EVALU, (20). PXP(I) is the quantity of $U^{235}$ in the Ith product stream from the cascade in a year. It is calculated in DOYEAR and used in MERGE and YRPAGE. 
QFM SUMRY, (40), $R^{\star} 4$. This is the sum in a year of the weight of all miscellaneous streams fed to the cascade, i.e., streams other than normal feed, reactor returns, or feed from preproduction. Calculated in SCRIBE, it is then printed by REPORT.

QNORM SUMRY, (40), $R * 4$. This is the flow rate of the normal feed stream in a year, subscripted by year. This is set in SCRIBE and printed in REPORT.

QPM SUMRY, (40), $R * 4$, QPM(IYR) is the total weight in year IYR of all miscellaneous product streams from the enrichment process, i.e., all product streams except preproduction, product to reactors, or tails stream. It is loaded by SCRIBE each year and used in REPORT.

QTAIL SUMRY, (40), R*4. QTAIL(IYR) is weight of the cascade tails stream in year IYR. It is loaded in SCRIBE each year and printed by REPORT.

RETRN RECYCL, (6). RETRN(K) is the weight of fuel type $K$ which is reprocessed and ready to be fed to the enrichment plant this year. It is calculated in REPROC and used in NEWFOS.

RPU6 RECYCL, $(6,40)$. RPU6(I,IRYR) is the weight fraction of PU ${ }^{236}$ in fuel of core type $I$ when unloaded from reactors and ready for reprocessing in future year IRYR.

RR RECYCL, $(6,40)$. RR(I,IRYR) is weight of material from core type I when it is unloaded from the reactor and ready for reprocessing in future year IRYR. It is calculated in REACTR and used in REPROC.

RXP RECYCL, $(6,40)$. RXP(I,IRYR) is the weight fraction of $U^{235}$ in: fuel from core type $I$ when it is unloaded from the reactor and ready for reprocessing in future year IRYR. This calculation is performed in REACTR when the minor isotope is $U^{236}$. The data are used in REPROC.

RYP RECYCL, $(6,40)$. RYP(I,IRYR) is the weight fraction of the minor uranium isotope in fuel from core type I when it is unloaded from the reactor and ready for refrocessing in future year IRYR. It is calculated in REACTR and used in REPROC.

SECRET RECORD, $L * 4$. This variable takes a value of "true" if and only if the user has specified "SECRET" on the Case Card. The variabie is set in NEWCAS and aiso used in MAIN, DOYEAR, ISOPAG, REPORT, and YRPAGE.

SEP SUMRY, (40), R*4. SEP(IYR) is the input three component $\left(U^{235}\right.$, $\left.U^{236}, U^{238}\right)$ separative capacity of the enrichment plant in year IYR. It is loaded in SCRIBE each year and printed by REPORT. 
SHRINK RECYCL, (6). SHRINK(I) is the recovery factor for reactor fuel iype I, input from the Reactor Fuel Cards in ISOPAG. The factor is applied in REPORC each year to reactor output and to Returns Card output before adding to reprocessing pot.

TOTF5 EVALU. This is the total weight of $U^{235}$ in the feeds to the cascade in a year. It is calculated in DOYEAR and written in the annual report (if not suppressed) by YRPAGE.

TOTF6 EVALU. This is the total weight of $U^{236}$ in the feeds to the cascade in a vear. It is calculated in DOYEAR and used in the annual report (if not suppressed) in YRPAGE.

THOK This variable, calculated in ISOPAG for each minor uranium isotope, is used in the calculation of the H-balance (see Equation 2-2) and separative work (see Equation 3-3). Referenced in DOYEAR, EVAL, and YRPAGE.

UNQ,UN5, SUMRY, $[(40,6),(40,6),(40,6,3)], R \star 4$. UNQ(IYR, ITYP), UNM UN5(IYR, ITYP), and UNM(IYR, ITYP,M) are, respectively, the weight, $U^{235}$ weight fraction, and weight fraction of the $M^{\text {th }}$ minor isotope, in accumulated returns from reactors of core. type ITYP awaiting reprocessing at the end of year IYR. These data are loaded each year by SCRIBE and printed in the sumary reports bj REPORT.

WRT RECORD, $L * 4$. WRT=.TRUE, if the highest level debugging output is requested for the year being solved. This variable is set in iAIN from the values on input variables KASEPR and IYRPR. WRT is used in MAIN, DOYEAR, EVAL, MERGE, REPROC, REACTR, and SETUP.

XF EVALU, (20). XF(I) is the $U^{235}$ weight fraction in the Ith feed stream to the cascade in a year. It is loaded in SETUP, used in DOYEAR, EVAL, and SCRIBE, and may be saved in YRPAGE for later use.

XNORM5 SUMRY, $(40), R^{\star} 4$. XNORM5 is the $U^{235}$ weight fraction in nomal feed, subscripted by year. It is calculated in SCRIBE and printed [only XNORM5(1)] in REPORT.

XNORMM SUMRY, $(40,3), R^{\star} 4$. XNORMM is the minor isotope concentration in the normal feed stream, subscripted by year and minor isotope sequence number. This is loaded in SCRIBE and printed into summary data by REPORT.

XP EVALU, (20). XP(I) is the $U^{235}$ weight fraction in the $I^{\text {th }}$ product stream from the cascade in a year. It is loaded in SETUP, may be escalated in $\$ 236$ if targeted for a reactor, and at year end may be saved in YRPAGE for later use. Also referenced in MAIN, DOYEAR, EVAL, MERGE, REACTR, and SCRIBE. 
XPKORS RECYCL; (6). XPKORS(I) is the weight fraction of $U^{235}$ in the intitial stockpile of fuel type I awaiting reprocessing. This is input from the Reactor Fuel Cards for the first minor isotope by subruutine ISOPAG. Also used in REPORT and REPROC.

YF

EVALU, (20). YF(I) is the mincr isotope weight fraction in the Ith feed stream to the cascade in a year. It is loaded in SETUP each year for each minor isotope value. Also used in DOYEAR, EVAL, SCRIBE, and YRPAGE.

YP EVALU, (20). YP(I) is the weighi fraction of the minor isotope in the Ith product stream from the cascade in a year. It is initially estimated in DOYEAR, calculated as part of several iteration procedures in EVAL, adjusted in MERGE-UNMERG, and may be written onto temporary storage by YRPAGE for use with later minor isotopes. Also referenced in MAIN, REACTR, S236, SCRIBE, and SETUP.

YP6 EVALU, (20). If the minor isotope being modeled is $U^{232}$, SETUP loads YP6(I) with the $U^{236}$ roncentration of the Ith product stream. Subroutine REACTR requires these data to calculate discharge $U^{232}$ concentrations (see Equation 3-2).

\section{LIMITATIONS OF THE MODELS}

Use of a small set of mathematical equations to model a dynamic and complex enrichment process must inevitably limit the applicability of the model. A crucial assumption of the matched abundance ratio model, as implemented in both MUICYCL and MUIFAP, is that the minor uranium isotopes may be modeled independently of each other. While generally true, this assumption is invalid when analyzing cascade products highly enriched in $U^{235}$. Significant inaccuracies may begin to occur when the $U^{235}$ enrichment increases beyond $90 \%$, ultimately causing the sum of the top product concentrations to exceed $100 \%$. All other model limitations are explicitly defined, e.g., single enrichment and reprocessing plants, MUICYCL restriction to a subset of three specific iUI's and fixed cycle times. 


\section{REFERENCES}

1. A. de la Garza, G. A. Garret, and J. E. Murphy, "Multicomponent Isotope Separation In Cascades", Chemical Engineering Science, 15:188-209, September 1961.

2. J. M. Friend, Functional Relationships for Minor Uranium Isotopes in PWR and BWR Spent Fuels, Oak Ridge Gaseous Diffusion Plant, Union Carbide Corporation, Nuclear Division, Report K/OA-2762 Revised, November 1975.

3. J. M. Ortega, and H. C. Rheinboldt, Iterative So Iution of Nonlinear Equations in Several Variables, Academic Press, Inc:, New York and London, pp. 194-97, 1970.

4. S. R. Blum, NEWFIX - A Multicomponent Fixed Plant Productivity Code. Users Guide, Union Carbide Corporation, Nuclear Division, K/OA-4158, July 1978. 
APPERDIX A

FORMULATION OF PU $236+U^{232}$ DECAY EQUATION 
FORMULATION OF PL'236 $+U^{232}$ DECAY EQUATION

From [2], P. 7, the formula for $1^{232}$ concentration, in the presence of $\mathrm{PU}^{236}$, over time is

$$
y_{t}=y\left(t, y_{0}, p\right)=y_{0} c^{t}-k p\left(d^{t}-c^{t}\right),
$$

where

$$
\begin{aligned}
& t=t \text { ime in years after discharge from reactor } \\
& y_{t}=U^{232} \text { concentration at time } t \text {, wt. fr. } \\
& y_{0}=U^{232} \text { concentration at discharge, wt. fr. } \\
& p=P U^{236} \text { concentration at discharge, wt. fr. } \\
& c=e^{-.009627} \\
& d=e^{-.2432} \\
& k=1.02357
\end{aligned}
$$

After slight rearrangement

$$
y_{t}=\left(y_{0}+k p\right) c^{t}-k p d^{t}=v_{t}-w_{t} .
$$

$V_{t}$ and $W_{t}$ are identified in the computer as yearly values of POTV(I) and POTW(I), where I identifies the reactor fuel type. They are updated by

$$
\begin{aligned}
& v_{t+\tau}=v_{t} c^{\top} \\
& u_{t+\tau}=w_{t} d^{\tau} .
\end{aligned}
$$

It will be shown that, when two streams of the same fuel type are combined by merging their $V_{t}$ values and $W_{t}$ values, the resultant $U^{232}$ concentration over time is identical to the weighted sum of the concentration of uncombined streams. Thus, all material of one fuel type awaiting reprocessing 
may be accounted for by updating one pair of values, POTV(I) and POTW(I) each year.

Let quantity $Q_{0}$ of material be discharged from the reactors at time $t_{0}=0$, and quantity $Q_{1}$ be discharged at time $t_{1}$.

Then for time $t_{j}>0$

$$
y_{0, j}=v_{0,0} c^{t_{j}}-w_{0,0} d^{t_{j}},
$$

and for $t_{k}>t_{l}$

$$
y_{i, k}=v_{1,1} c^{t_{k}-t_{1}}-w_{1,1} d^{t_{k}-t_{1}}
$$

where

$$
\begin{aligned}
& y_{i, j}=t^{232} \text { concentration in } Q_{i} \text { at time } t_{j}, \\
& v_{i, j}=v_{t} \text { value of material } Q_{j} \text { at time } t_{j}, \\
& W_{i, j}=W_{t} \text { value of material } Q_{j} \text { at time } t_{j} .
\end{aligned}
$$

Combining these streams at time $t_{\alpha} \geq t_{1}$, the weighted $U^{232}$ concentration is (subscript $z$ indicates combination)

$$
\begin{aligned}
y_{z, \alpha} & =\left(Q_{0} y_{0, \alpha}+Q_{1} y_{1, \alpha}\right) /\left(Q_{0}+Q_{1}\right) \\
& =\left(Q_{0} v_{0,0} c^{t_{a}}+Q_{1} v_{1,1} c^{t_{\alpha}-t_{1}}-Q_{0} W_{0,0} d^{t_{a}}-Q_{1} W_{1,1} d^{t_{\alpha}-t_{1}}\right) /\left(Q_{0}+Q_{1}\right) \\
& =\frac{Q_{0} V_{0,1}+Q_{1} v_{1,1}}{Q_{0}+Q_{1}} c^{t} c^{-t_{1}}-\frac{Q_{0} W_{0,1}+Q_{1} W_{1,1}}{Q_{0}+Q_{1}} d^{t-t_{1}}
\end{aligned}
$$


Setting $t_{\alpha}=t_{1}$ we produce the formulae for updating $V$ and $W$ values by combination of material at time $t_{1}$,

$$
\begin{aligned}
& v_{z_{1}}=\frac{Q_{0} v_{0,1}+Q_{1} v_{1,1}}{Q_{0}+Q_{1}} \text {, and } \\
& W_{Z_{1}}=\frac{Q_{0} W_{0,1}+Q_{1} W_{1,1}}{Q_{0}+Q_{1}} .
\end{aligned}
$$

This combined stream will have, at time $t_{2}>t_{1}$,

$$
y_{z, 2}=v_{z, 1} c^{t_{2}-t_{1}}-H_{z, 1} d^{t_{2}-t_{1}},
$$

which is identical to the value of $y_{z, \alpha}$ when the material is combined at $t_{\alpha}=t_{2}$. 
APPENDIX B

DERIVATION OF PREPRODUCTION ESTIMATE 
73

DERIVATION OF REPRODUCTION ESTIMATE

Objective: Given SH, the value of separative capacity within

a year, determine the increment in preproduction feed or product to attain the rated capacity.

Let

$$
\begin{aligned}
P, F= & \text { unsigned rates of the product and feed balance streams } \\
R= & \text { rate of preproduction feed or product stream (negative } \\
& \text { if feed) } \\
x_{P}, x_{F}, x_{R}= & \text { corresponding } U^{235} \text { concentrations. }
\end{aligned}
$$

The following algorithm is used:

$$
\Delta R=\Delta S W / \frac{d S H}{d R} \text {, }
$$

where

$$
\begin{aligned}
\Delta S W & =\text { the required increment or decrement in SW to attain capacity } \\
S W & =\operatorname{Pv}\left(x_{P}\right)-F v\left(x_{F}\right)+R v\left(x_{R}\right)+\text { constants } \\
\frac{d S W}{d R} & =v\left(x_{P}\right) \frac{\delta P}{\delta R}-v\left(x_{F}\right) \frac{\delta F}{\delta R}+v\left(x_{R}\right) .
\end{aligned}
$$

The balance streams are calculated by

$$
\begin{gathered}
P-F+R+K_{1}=0 \\
P x_{P}-F x_{F}+R x_{R}+K_{2}=0
\end{gathered}
$$

where $K_{1}$ and $K_{2}$ are terms involving other streams. Using substitution and implicit differentiation on the above,

$$
\frac{\delta P}{\delta R}=\frac{\delta F}{\delta R}-1
$$


and

$$
\frac{\delta F}{\delta R}=\frac{x_{P}-x_{R}}{x_{P}-x_{F}}
$$

Therefore,

$$
\frac{d S W}{d R}=\frac{\left[v\left(x_{P}\right)-v\left(x_{F}\right)\right]\left(x_{P}-x_{R}\right)}{x_{P}-x_{F}}+v\left(x_{R}\right)-v\left(x_{P}\right) .
$$


APPENDIX C

MUICYCL PROGRAM LISTING 


$$
\text { I:G :c }
$$

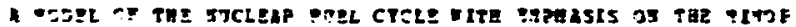

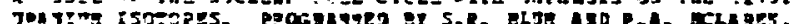
copt. Covipe-

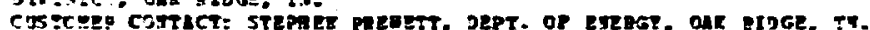

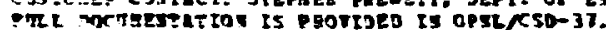

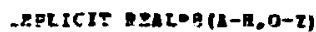

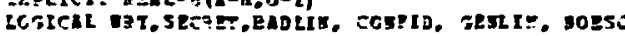

ITPEE PAGE

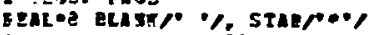

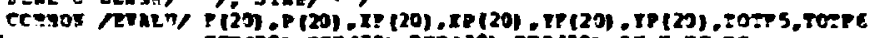

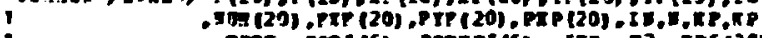

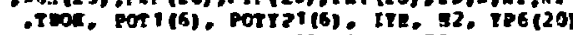

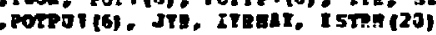

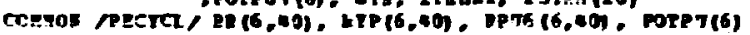

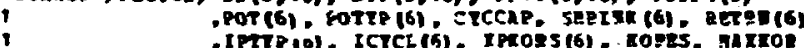
POTXP I6). EXP(6,-10)

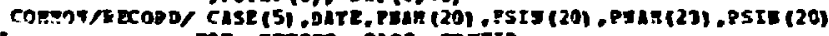

!

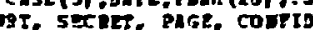

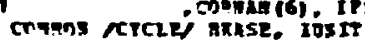
Connos /Soge/ PBost 3072

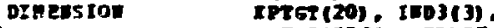

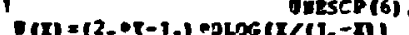

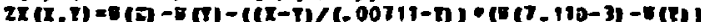

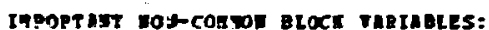

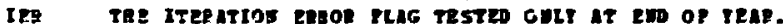

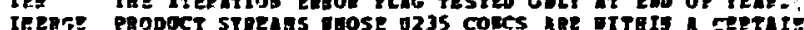
Tocenece or sic ose

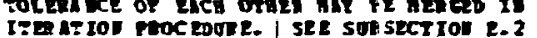

I01 3 1003 (1)

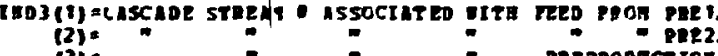
- : Pepaodiction.

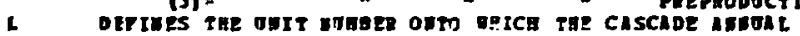

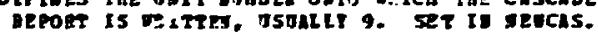

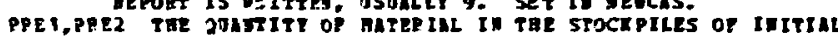
PAE PAODJCTIOT ADO SOBSEOJET PEEPEODOCTIOS ERSECTIVEL

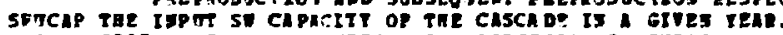

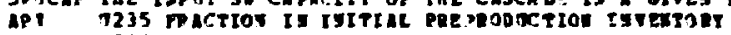

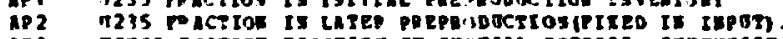

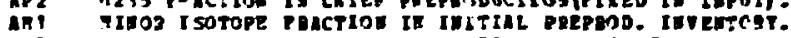

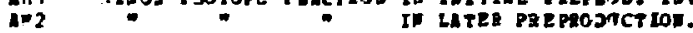

SECT TOA A- IATTIALIZATIOA

ZzPO $=0$.

Mxtro. 10

nIrT:6 $=0$

$\operatorname{sxr}=10$

SEn $=100$

ITPGix $=0$

$\operatorname{limix}=0$

$\operatorname{corrog}=6$

CALL EGROE (DATE,PAGE)

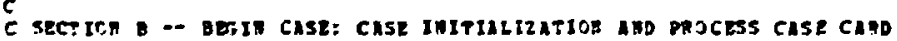

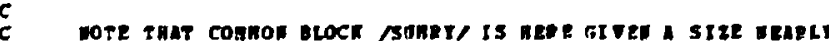

25 Tes eOCe 2x

contisne

$\operatorname{lin}_{0}=0$
$001-1,3072$

0 Do 00 T-1,

in $6011=1,6$

O

$c$

ARAD CASE CABD AND GETRATE TITLE PMGE

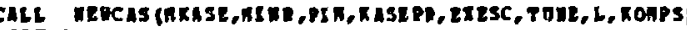
CSATEL

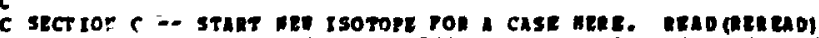

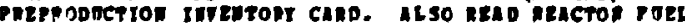
CAPD (3) ANO $1235 / 7236$ CARD. PHoCess AND PHINT ISOTOPR DATA PAGE. HLL THIS IS DOTE IU ISOPIG.

so contrinue

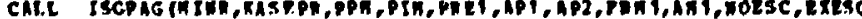

$1)$

in $-22-230$

RI $=(142-230) / 2$

P.:20.0.

$\rightarrow x^{2}=0$.

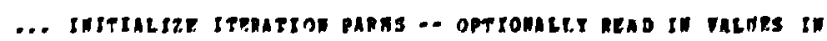




$$
\text { BLANK PAGE }
$$




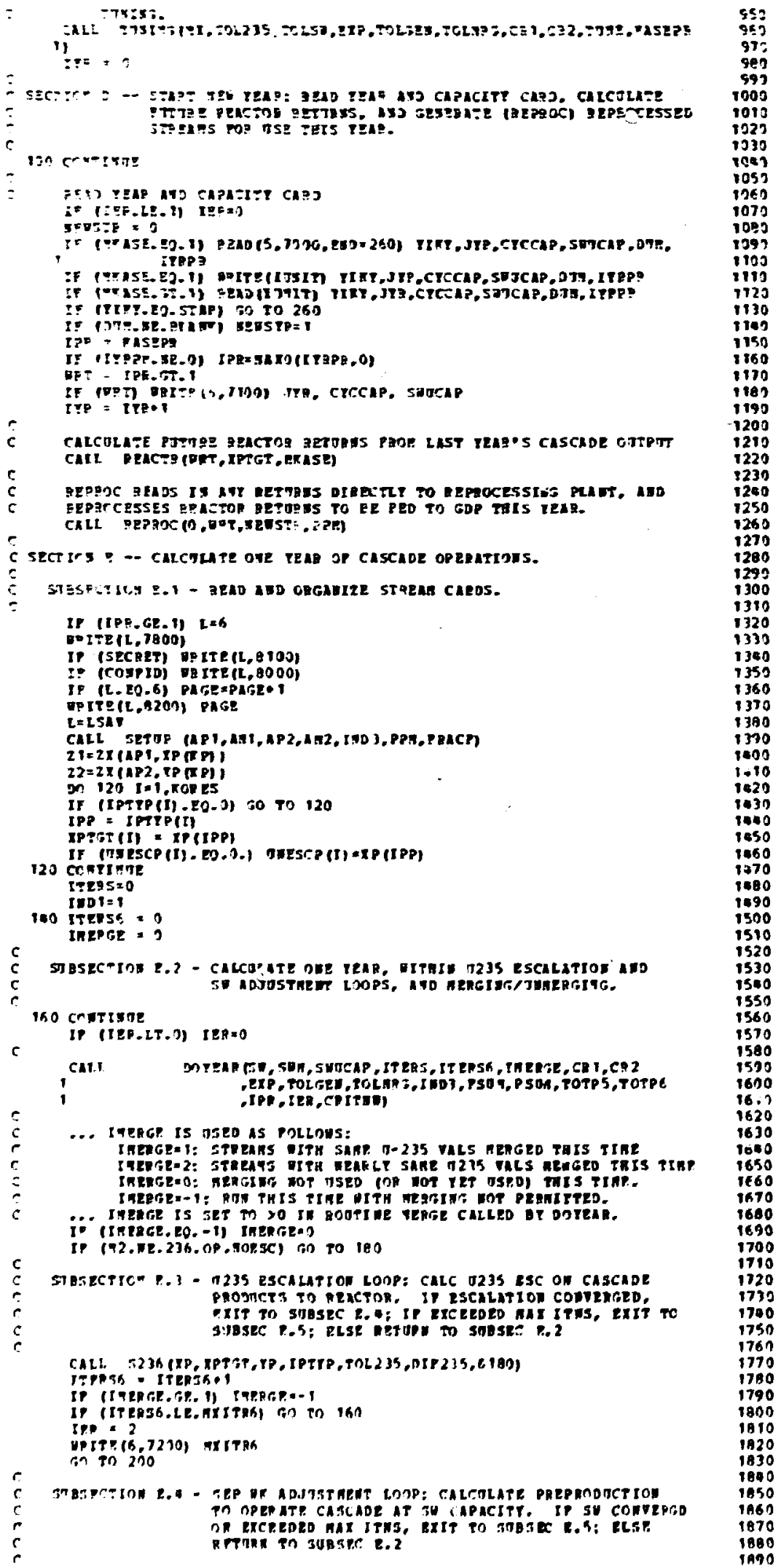




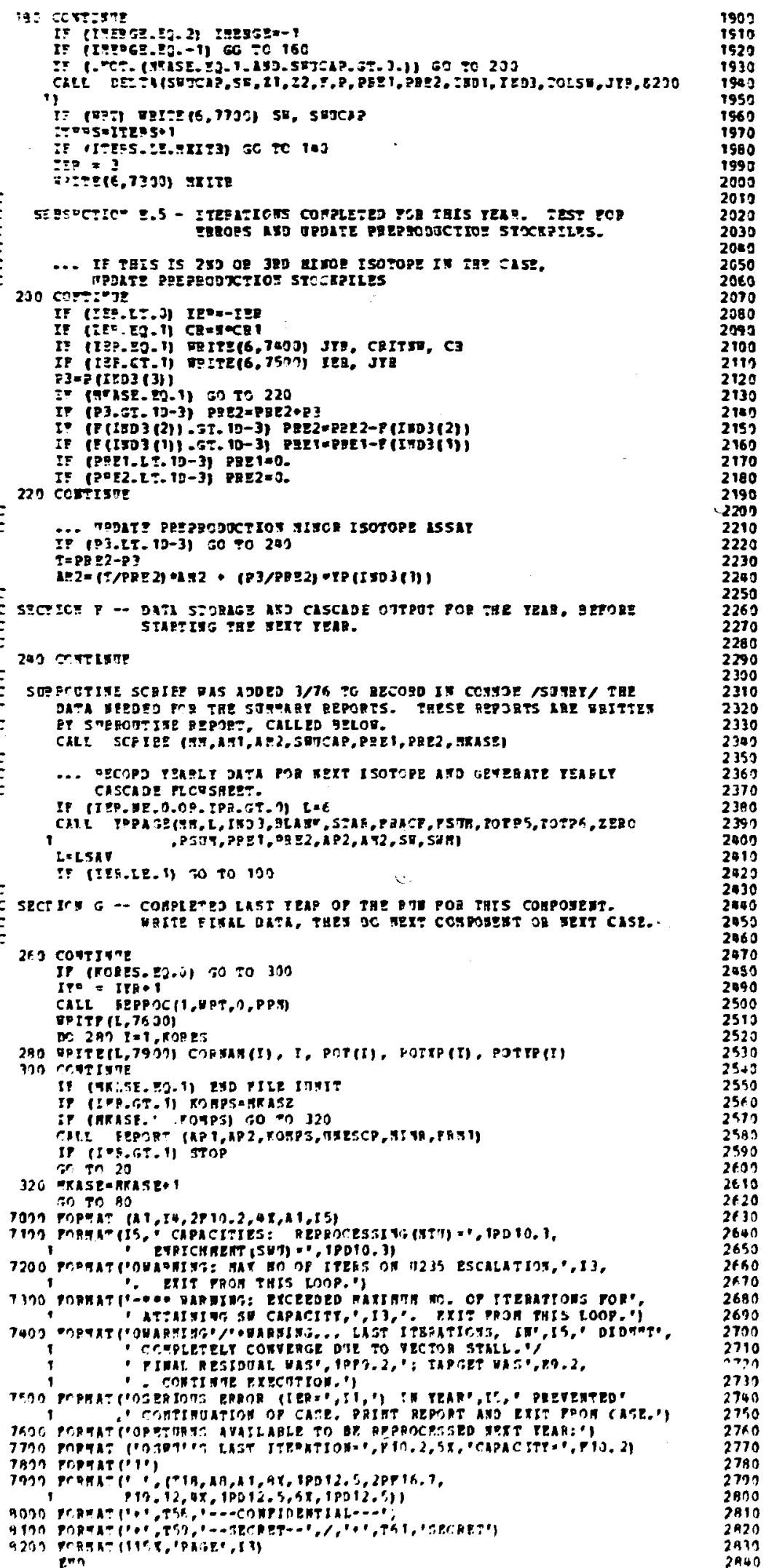




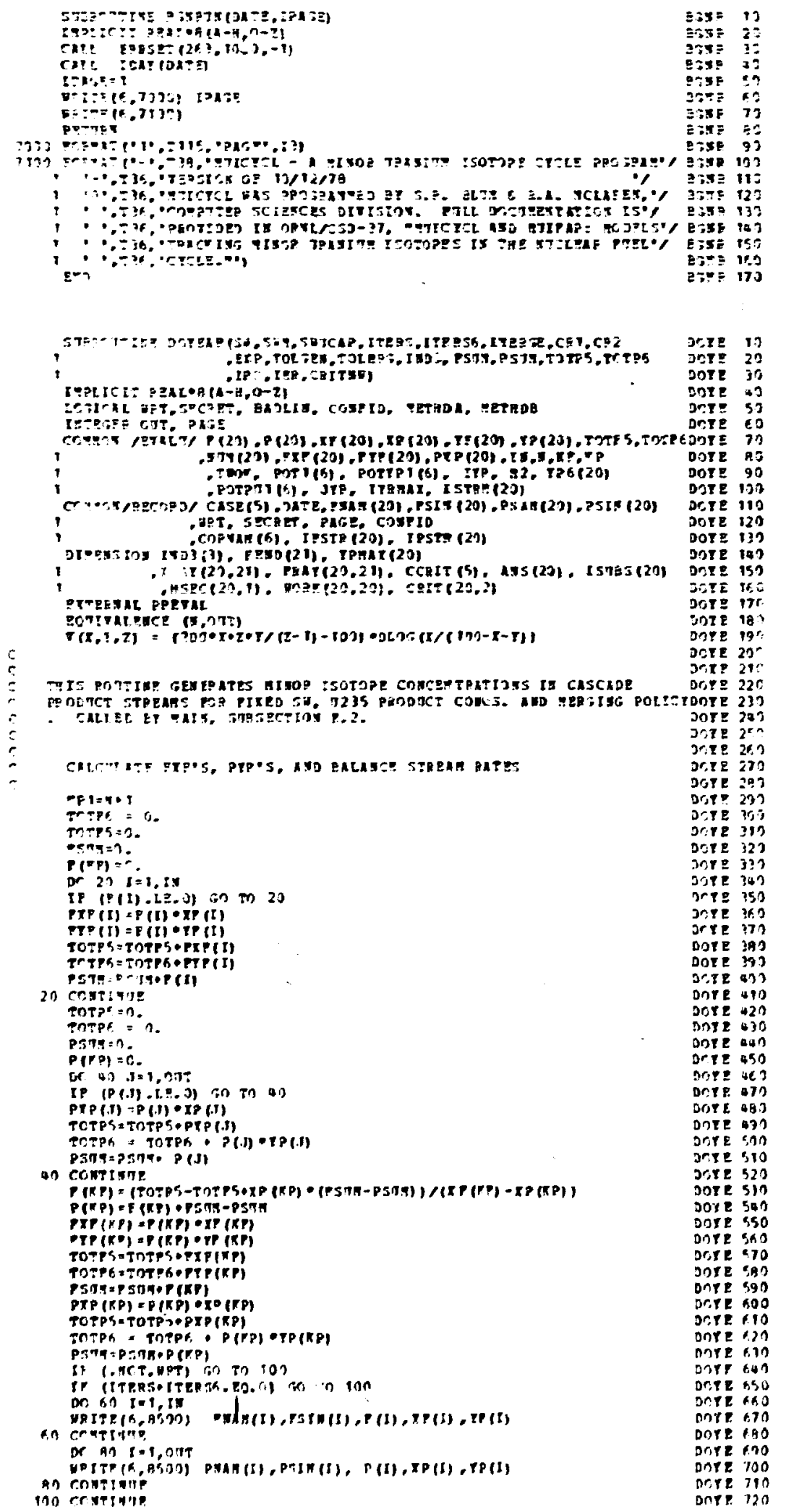




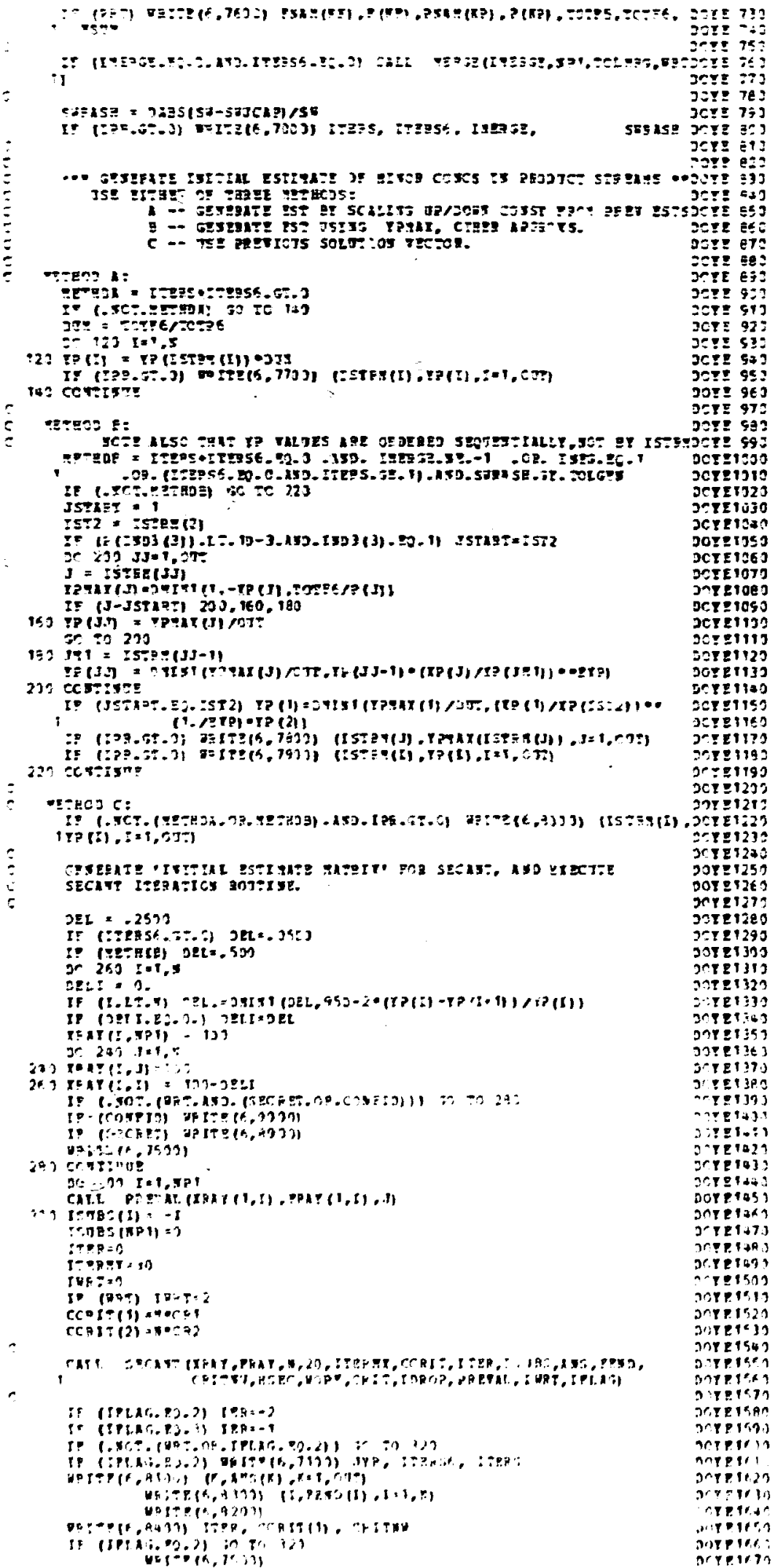




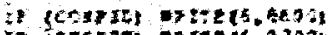

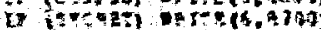

potopisel

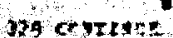

$$
\text { atrit. Apon pare }
$$

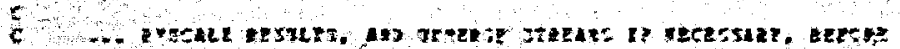
ist ot Hes caletúf rans.

Tixtis

Ore?tas

arevisa

$=0,5=1$

ing retan

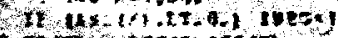

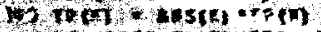

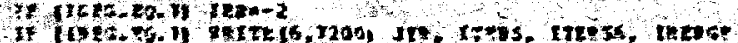

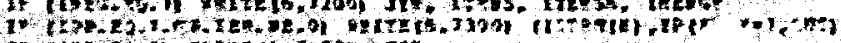

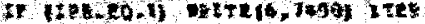

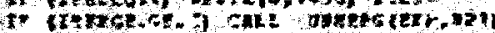

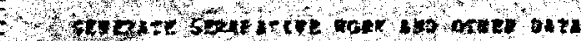

350

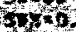

$30 \mathrm{xr}+\mathrm{N}$

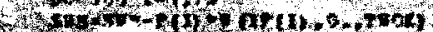

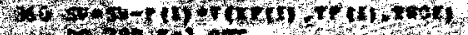

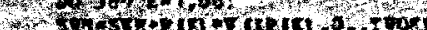

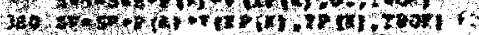

trints

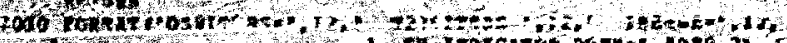

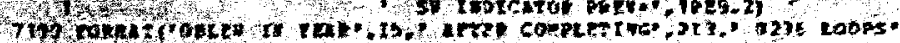

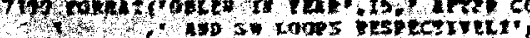

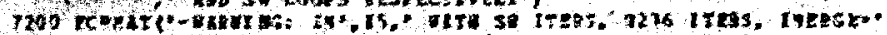

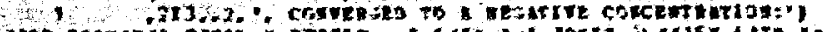

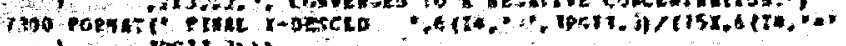
$(10,1,3)+$

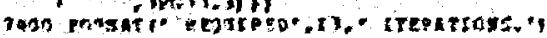

7500 preath ("1")

bortzo7o

oxtorn:

$20 r e+70$

yerning

soreles

1.? 102

$\operatorname{ser} 103$

artent

n.eres?

ogrates

miver:

waters

Daretsos

ootrtars

bateviso.

voctersin

Doristso

000 eses

D.

vor

ares.

dexevs

Dar

20re2s

s.pexa?

Invas?

orezas?

ortezoto

virezoes

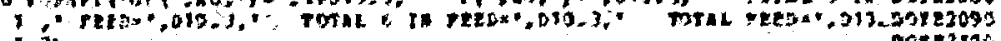

1) Pi

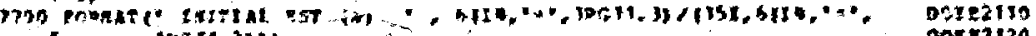

ontezing

Dortziso

Dareziso

otrezies

ontezin?

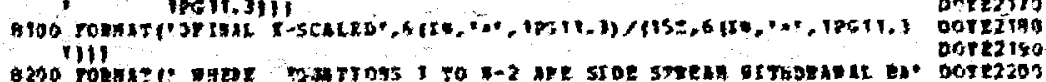

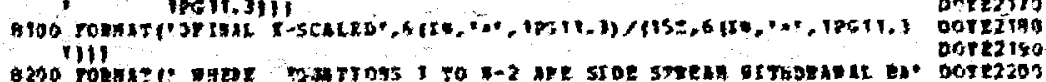

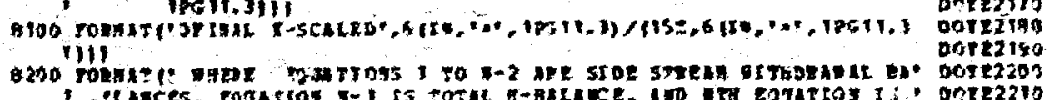

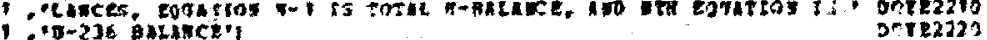

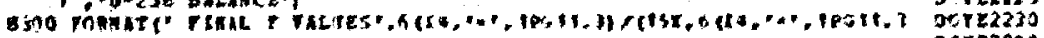

ili)

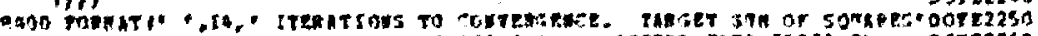

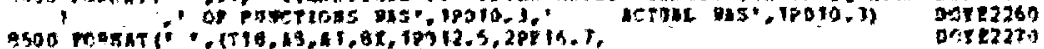

$$
1 \text { (12, } 12,0 x, 1 P D 12,5,61,10012,5)
$$

ando rongte...

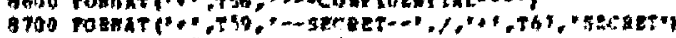

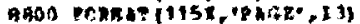

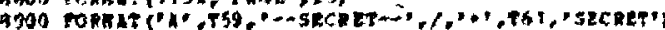

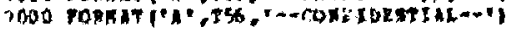

10

OOT 2200

ante2290

an1 12305

Dot 2310

bort? 200

onrt2 330

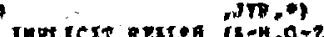

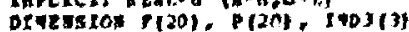

c

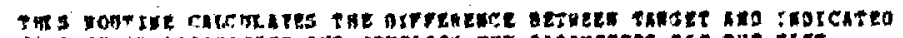

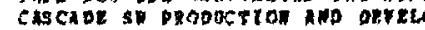

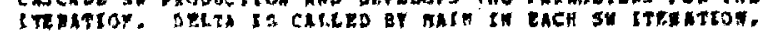

DEtP $\times$ SThCAP-SH

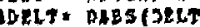

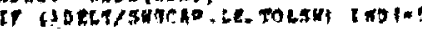

an to $(20,400,950,180,200)$, Ind

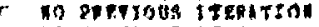

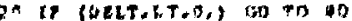

naephotect

Antonotite?

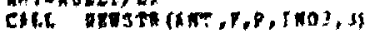

ppeinpteran?

cuniog

etras

I ERD PARPRDilter IO

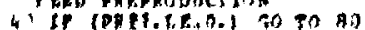

nete io

Detr. 20

Det. 30

Dels 0

DeLT 30

DELT 60

get 10

Det? 80

Dews 90

5elt 100

Dext 110

2423130

DEtT IIT

DxIT 150

beet teo

DELT tro

Det? IAS

DELT 190

Dete 200

oste 2190

Dat. 210

DeET ing

गII: 250 
84

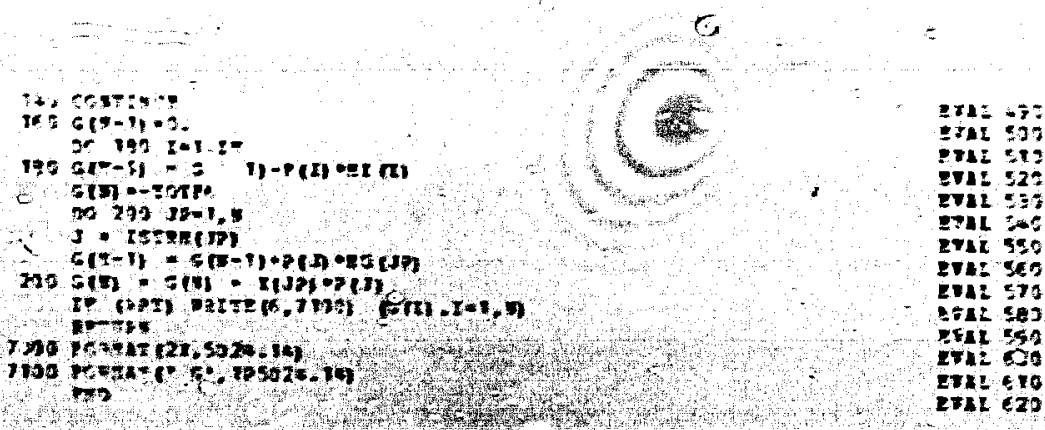

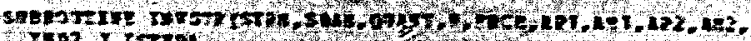

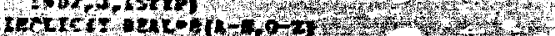

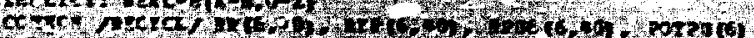

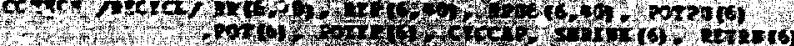

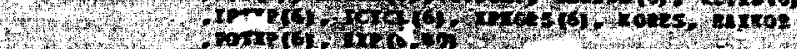

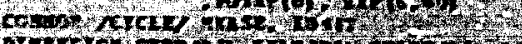

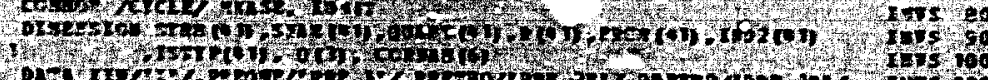

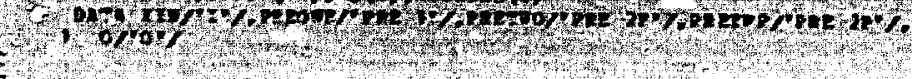

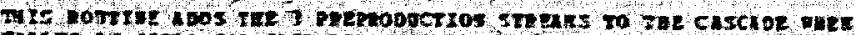
alles ex sats ons nre the

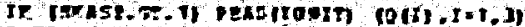

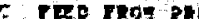

STER(j) $=\mathrm{Rt}$

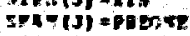

$\cos x+(\pi)=0-6$

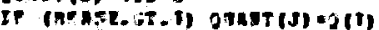

2 (J) $*$ apt

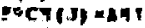

$(=25(3)=1$

ISTYPe-1)

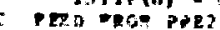

T.M.

$\operatorname{sip}(1,3)=x[x$

3Wh

onche (7) =1.p-a

IP (nrise-G-1) gonv8(J)=J(2)

$x(J)=R P ?$

$\sin (\cos )=1,45$

$(\operatorname{mos}(N)=2$

(15)

$3 \times x+1$

$\operatorname{stan}(J)=0$

SEAM $(x)=82 E T$ DP

GMAT (d) $=1, n-6$

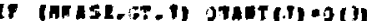

$x, 1=182$

$\operatorname{mim}_{t \rightarrow n}(J)=0$.

imtinges.

$\dddot{2}$

ตrratin

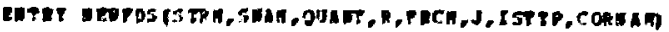

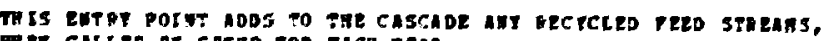

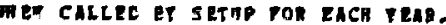

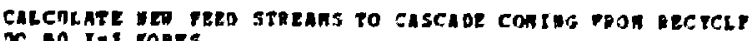

$x \in 0 \quad I=1, \operatorname{Rog}$

IP (ReTan $(l), E 0.0$.$) 60 ro.$

$x=\pi+1$

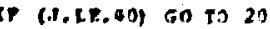

verto(t,, $100 \mathrm{~N})$

CALE ERTt

20 complate

iren (II) . पis

SEAR (I) - CORHARII

onan? (S) - prepex(I)

Q(.I) - ootxp(I)

vorin (in. potre(t)

(ITtP (,I) * -

Q A comtrutr.

protop

7000 monht Hn

15512

strs 2

Cars 3

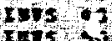

ive 6

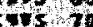

$1+5 \mathrm{sit}$

$4=5,190$

$+1518$

twos 100

zats 100

rists rso

$7+x^{2}$

riv

Ins 180

Inv 190

IETS 202
IETS 210

IEVS 210
InVS 220

I 475230

IतTs 280

I0T5 250

-5Ts 200

Iिए5 210

जT: 240

Tतs 250

Ints 300

:575 310

t5VS 320

I 175350

IETS 30J

IEvs 350

IDVS 363

I7V5 17?

IFvs 390

ings 390

res 330

Tr5 2 क

195 212

167. 429

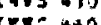

leve nat

Ixvs 950

IDVS WE.

xणs of?

InTs 4a?

5 Th5 497

Invs iol

जब 510

1005522
1075330

[DTE 540

ov 550

ivis 500

Tणv5 570

nTS 580

IDV 590

5T) 600

INTS 6.10

InTS 020

[7Ts 630

IEVS 640

ITVS 650

Invs tho

ITVJ 4.79

INOS he?

1403190

IHVS 700

InV: 110

INDS 720

4085 793

1 173502

IMPS 779 


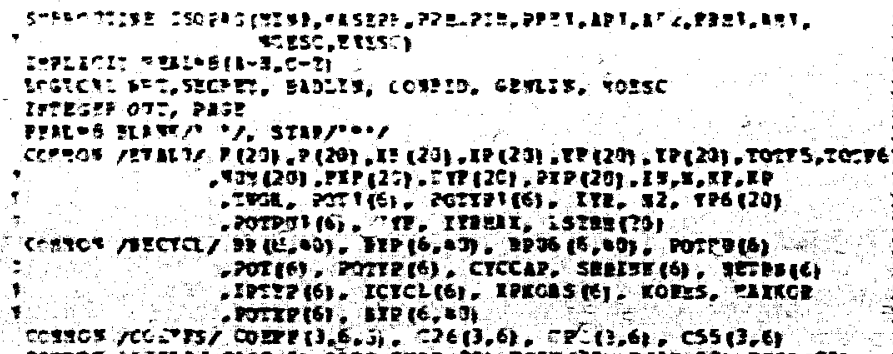

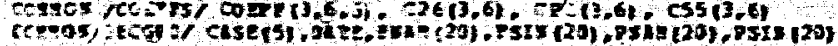

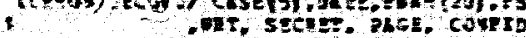

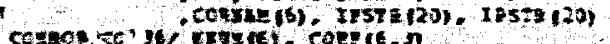

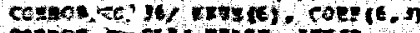

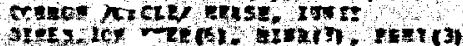

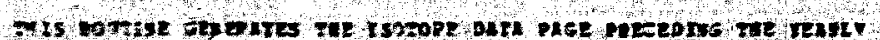

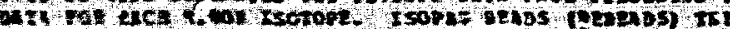

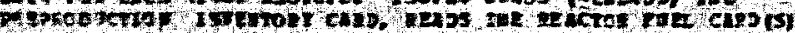

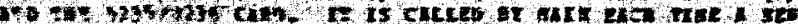
sschet 8 so te recess th

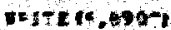

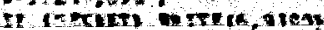

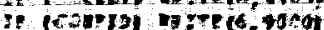

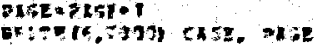

Gi:

vit-pro,7ing

now in: in

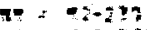

$\because+(2-23) 12$

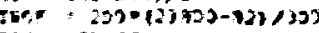

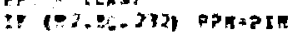

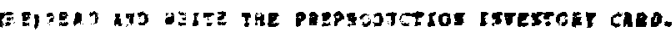

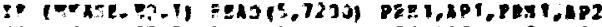

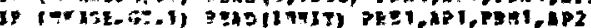

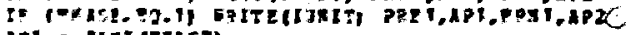

1+1 = EnT (TRKSE)

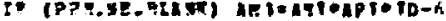

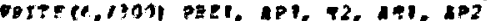

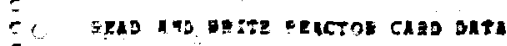

$\operatorname{Deg}(6,7+2 x)$

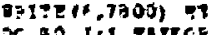

$=50 p \quad 12$

İop 20

Isop et

152
150

$\operatorname{sct} 60$

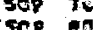

$\cos 6$

$\operatorname{sen} 100$

$=50 p 100$

507110

1502120

25150

$70 r$ Ito

2508 ist

isep 170

3 seg 180

op 190

sor 200

TSE 210

$\csc 220$

7507230

$1500 \mathrm{Ac}$

150825

ISor 20

rant2

$\operatorname{csop} 2 \mathrm{z}$

150870

$x=0$

t 300310

$=-2 \leq=$

Isor 330

Isap 340

se. 35

sop 360

sor 370

1508364
1500370

1500
I5T.
I50

ISTP

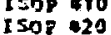

$1507 \quad 20$
I $509 \quad 30$

I SOP 10

150940

I 50.950

sop 170

sop ato

500490

sop 500

500510

sop 520

sop sed

ISOP 550

tsor 560

I 150 \% 570

1508 580

IF (20)

1.

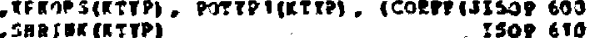

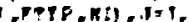
SHRTEK (KTTP)

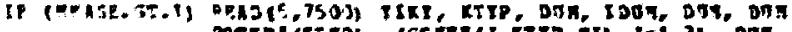

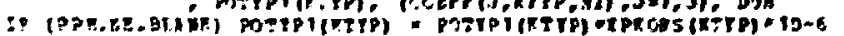

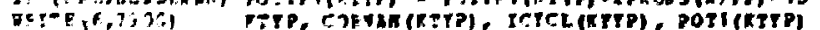

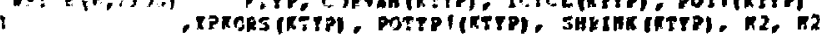

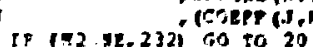

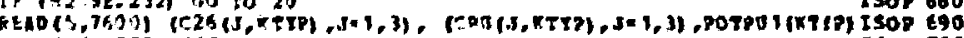

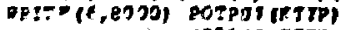

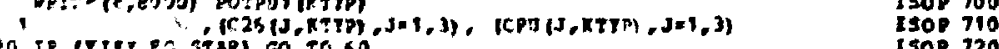

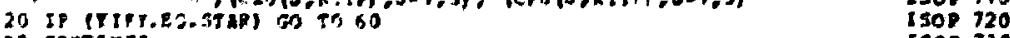

an contente

DEtTz $(6,7703)$ antrop

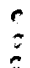

6) ETRE: - I

ISOP 730

Isop 740

Isop 750

Isos 760

ISOP $\cdots$ -

1308100

1508790

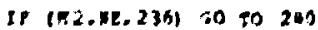

II 00

B) $I I=15=1$

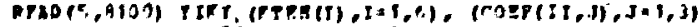

(r.ss, $1,(8), .1 \times 1,3)$

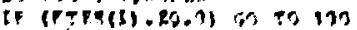

Knin (Kten (1) : II

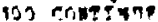

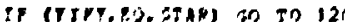

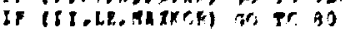

WH:TE (T. B201)

ritil ivit

(2) conetor.

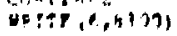




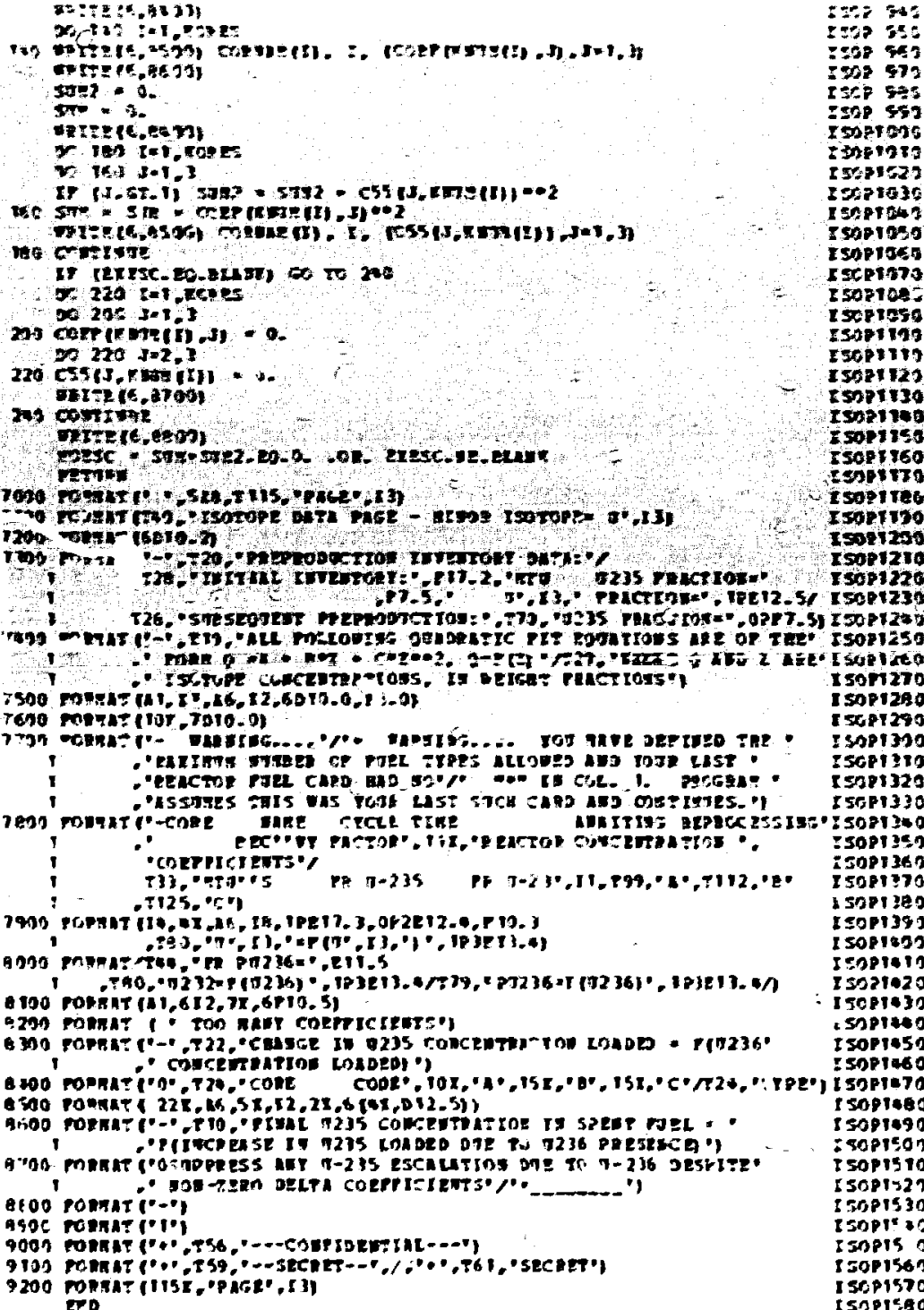

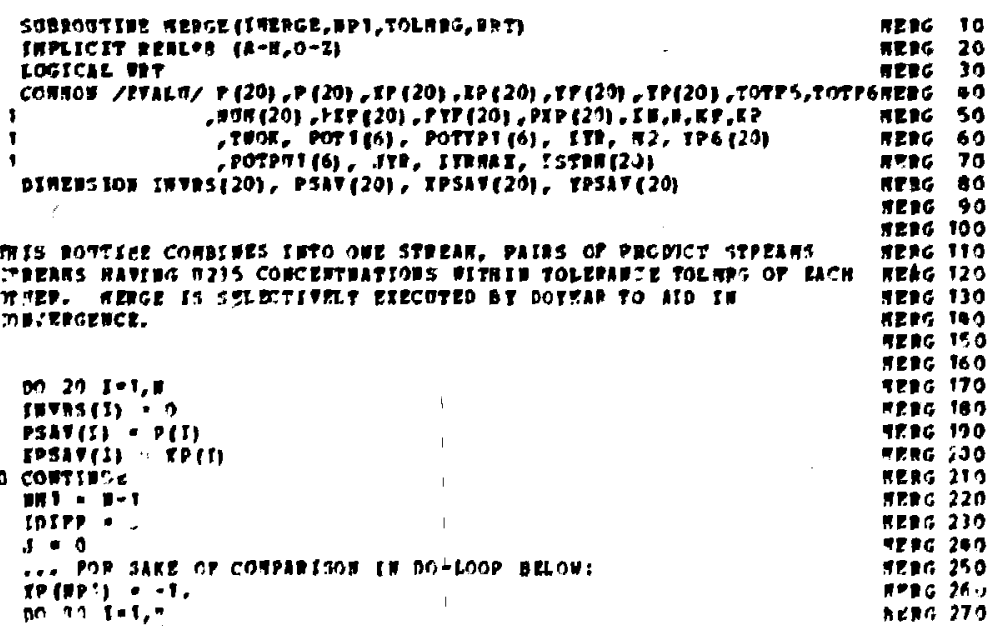




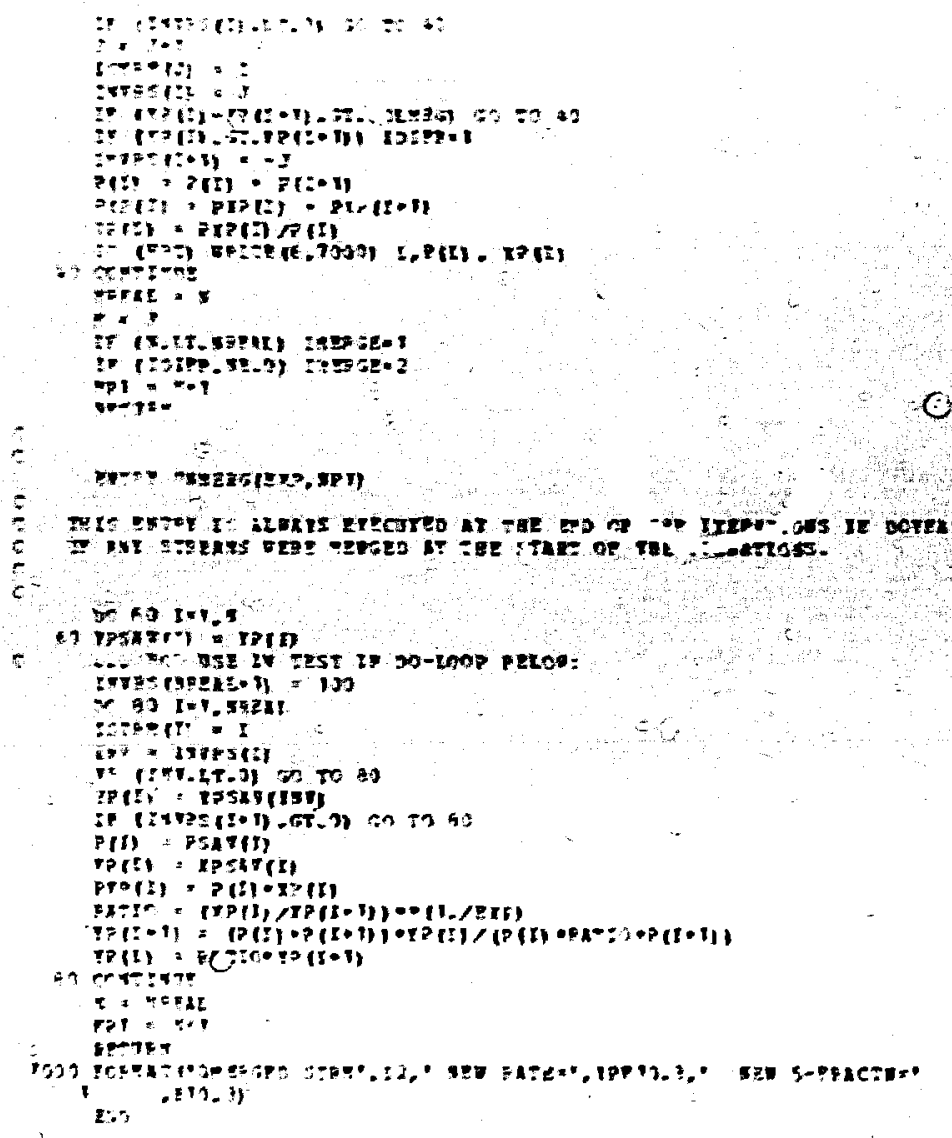

in:

-

-

reac

-6 .

$x=0$.

Trus 35

-

7 ?

ate 37

of 30

ate tos

enc elo

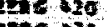
pate 2 응

axt as

E24 650

sene 40

sec 70

ates aso

SES $\$ 9$ Hexe 500 nes sita serc 520 चare 530 7ate 56 ates 550 Heac 569 tac 39 - gac a 90 TEरी 55 : - 600  Ixec IDor

7.26 650

列 Teg6 7. are 690 7esc 130 PES I30 "IEG 710 NER6 733 ज216 723 inge 790

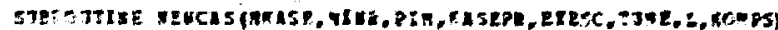

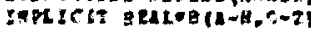

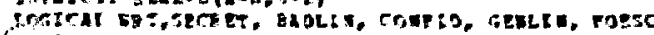
Go+geF nTi, baits

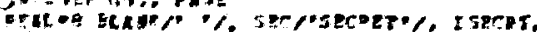

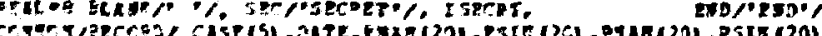

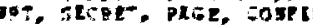
(3)

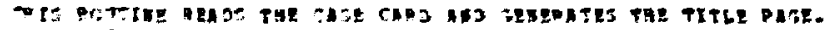
Q 07 ?

This: $* 1$

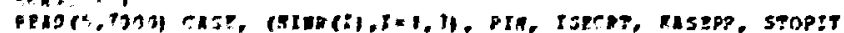

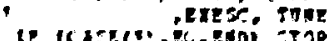

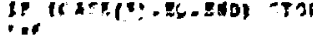

sits

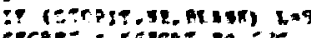

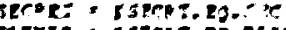

- 1 secat.

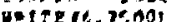

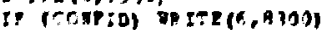

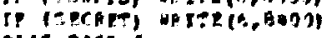

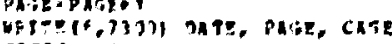

rexp: 0

52911,3

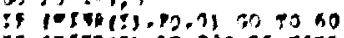

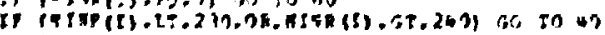

penpt i keqpats

rentimp

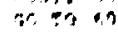

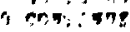

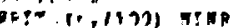

rei: OxtT

, 3 :

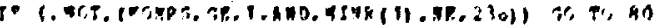

noete+1,.7>311

2 retertis
Iexc $10=$
aec $20=$

SIDC 30

उewc

$320 \mathrm{C} 0$

vewc 69

IEe 10

troc in

gerc ros

$\operatorname{TEC} 110$

IES 120

I2EC 130

veve 130
verc 150

ज200 190

IEde 150

320C 160

Texc 170

erac 190

जerc 210

जEDC 210

vere 220

VIDC 235

TENC. 240

TERC 250

verc 260

जetC 260
wegc 210

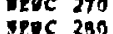

जPC 285

T2ú 290
Feuc 300

resc 310

Eeve 320

TETC 30

जenc 39

Teve 190

vepc is?

जedc 170

Teac ign

TEบC 390

Neve 4 tho

*⿻一𠃋 410

जeVC 420 


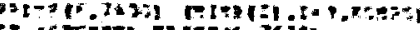

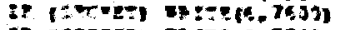

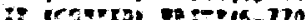

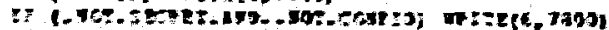

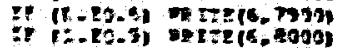

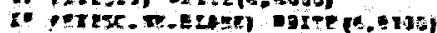

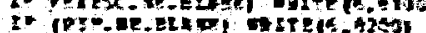

antiog

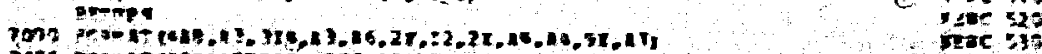

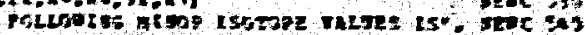

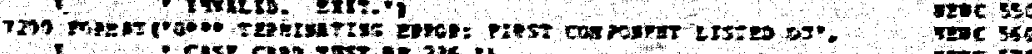

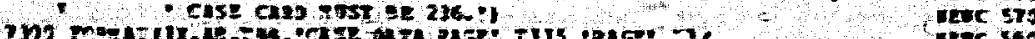

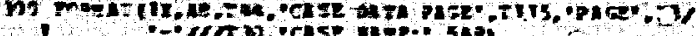

-

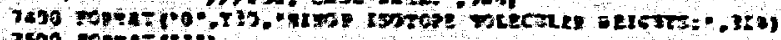

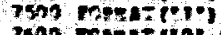

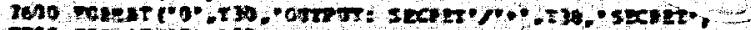

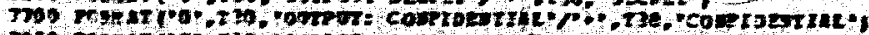

20000 rama

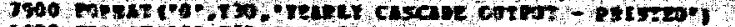

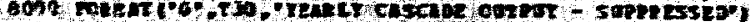
furingres: wex 670

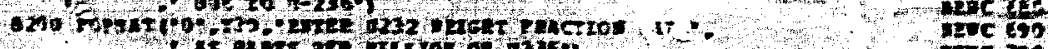

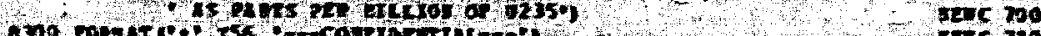

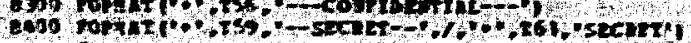

ans

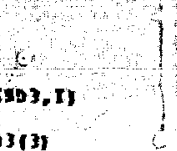

$5 \mathbf{s e c} 210$

यer

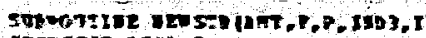

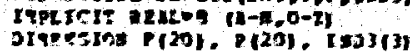

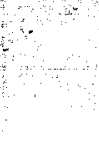

3ros 10

$\operatorname{sen} 25$

$7 z=30$

5

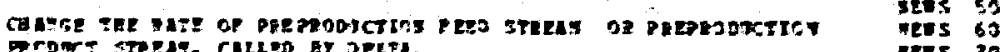

iess 63

uEs 70

nzos :3

32537

$[1-1-3)(1)$

$\cos (20,4), \alpha, n)$.

chanto pers or so

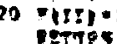

6 Cas sce reed op poot

on E(ri)=f(II)

mpte

c cante paeproduct bos peodot

ho P(II) OP(II) PAn?

move

Q205 110

TEX 5 . 12

$\operatorname{ces}$ in

sees ing

3005
760

eno

revs 770

ins is:

iess 290

vens 210

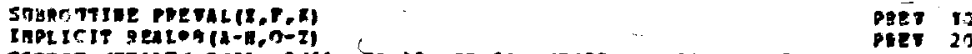

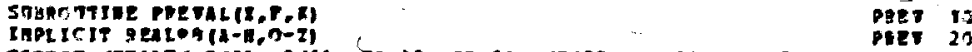

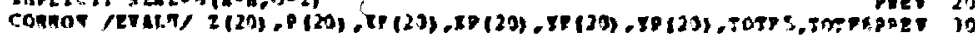

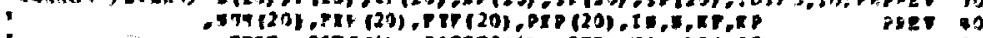

1
1

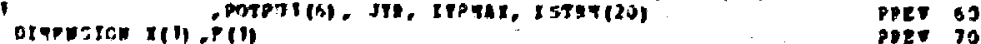

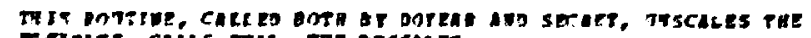

ETrThTE, CaLS EThL, THE RESCALES.

DO $203 \times 1,0$

20 (II) * I(t)etp(t)

CALL LYL $(x, F)$

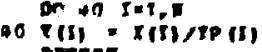

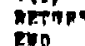

PaEr

Pier

PEeT

piner ir.

PIET 120

pher 130

pnet 100

peer 150

PEet 160

PAET 170

POET 100

piet 190

puet 200

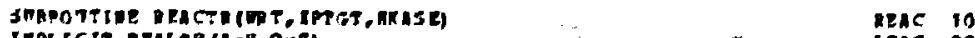
IHPLCCTP PEALER(A-H, O-Z) - REAC 20

chrorcht WPS

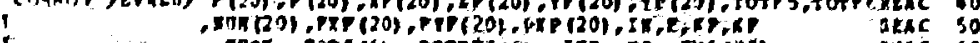

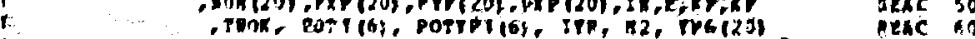

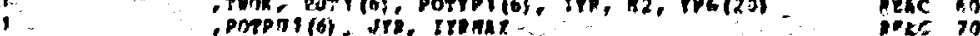

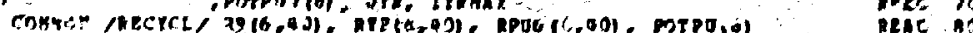

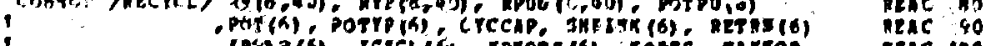

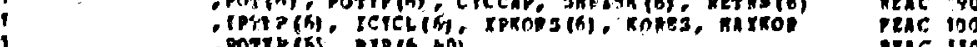

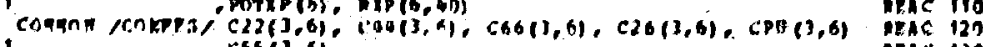
'

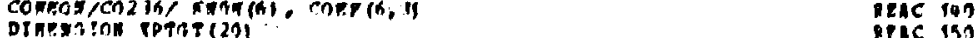




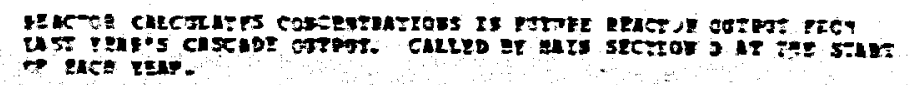

QE⿰冫欠 730

Exac 720
iEac 730

iRAC 790

seic 750

ReAc 760

azac 770

Beac 700

inc 790

DEA 800

Etac 820

azac ajo

Tenc dad

izic 850

izic 870

IEAC 080

nesc 890

Rec 900

REAC 900

21098

FEAC 920

Rac 930

Penc 950

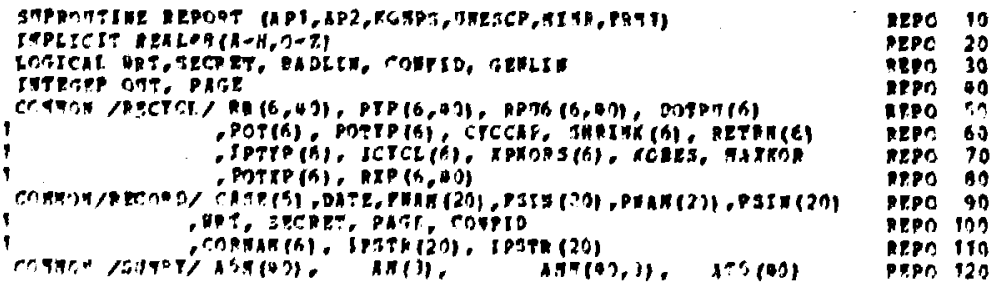




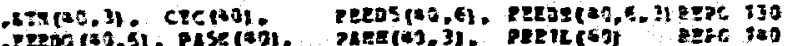

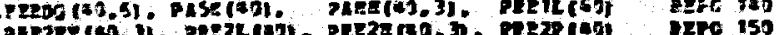

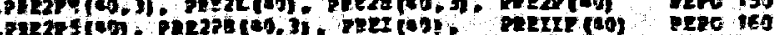

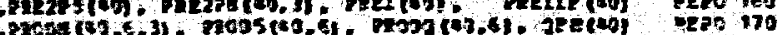

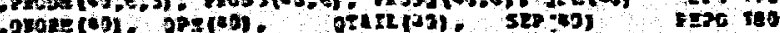

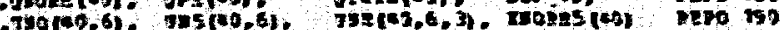

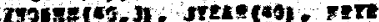

Trpe 290

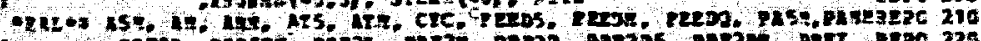

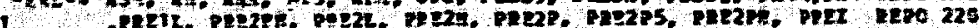
1212.

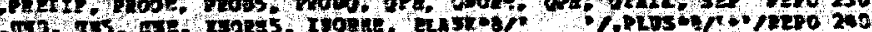

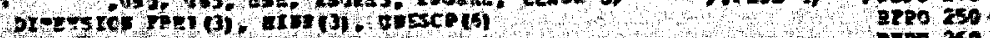

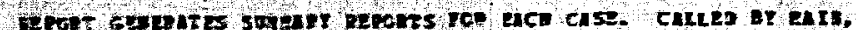
Sterros o.

270

$\lim _{x \rightarrow 0}$

Eepo 700

1280 ato 320

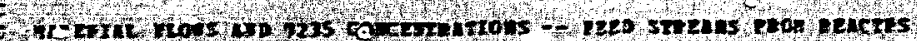

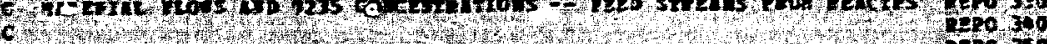

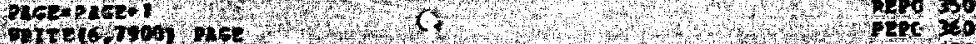

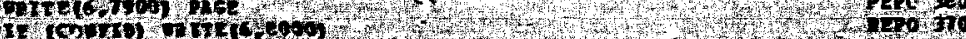

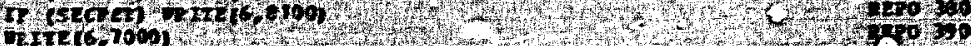

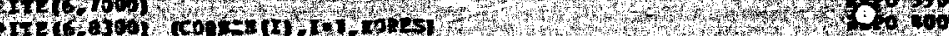

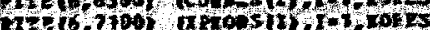
nive (e, es00)

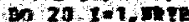

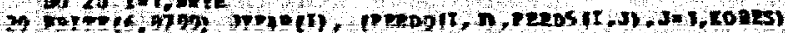
PFIFE (6.8600)

Detrefriono

IF (CESTID) IPITE(6, DOSO)

$\dot{c}$ MTEPTAL TLOE - OTWEE rEEo sTHEATS

puriz=psezer

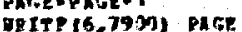

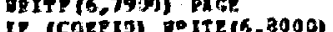

If (STeCET) ga I*E(K,BIDO)

If (SRCBET)

prtef6,7300:

Priticte.7303)

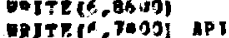

DorTiof.

$\operatorname{tot} 2=1$.

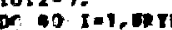

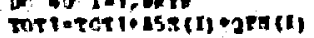

$00 m-2=2022+\operatorname{crs}(1)$ -

isz=0.

IF (totz-20.0.) to to 60

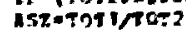

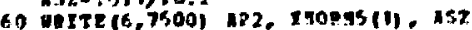

DRIT $=16,8 B 00)$

$\cos =0$

CHAP $=B L A T$

$x$ ind $1-1$, Tot:

If (PPEIIPII) 10.0t.100.67. ol Go th ho

isoet

CRevipens

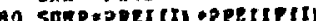

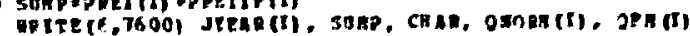

cricection

10n cominge

DetTE $(6,9200)$

exte 47001

1F (I) 20,1$)$ ve17e $(6,7800)$

IP (Comioi or IT: $(6,8000)$

c

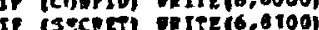

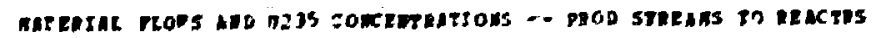

PLEEnpIGEN

Dite(6,7900) PACE

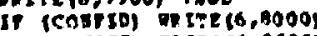

if (secent)

DPITP(o,8200)

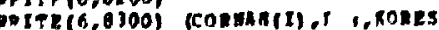

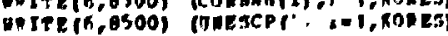

wite 16,8400$)$

$00120 i=1$, 1 ier

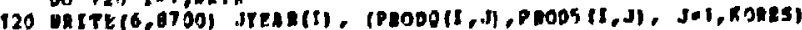

WPITE 16,8600$)$

antrecte 11000 )

if (chorid) unire $(6,8009)$

c

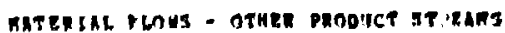

PACEAPARE! I

OArTe(h, TMDO) DHat

tow 45

$0+1020$

480030

pepo 180

$2820 \quad 450$

ptra ue

eE20 790

TEPO 495

Eepo 50

BEPS 510

sepo 523

EEPS 530

PEP, sen

FEPG 350

Eepe 553

PEPC 570

PEPT SAO

RTPO S40

aepc cos

REPO 610

REPO 620

PEP 630

PEPO 640

DEPO 65

व2PO 601

aEpe 670

PRPO $69 \mathrm{C}$

SRPS 700

2EPC 710

PEPC 720

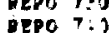

IEPO T:5

PRPn 7E?

BRPC 770

AEpo 780

kepo 800

Repo 110

repo 220

EEPO 830

RTPO OA0

Repo 050

RTD 60

LED 670
TEPO 690

EEPO 690

Repn 90 ?

Reo 910

17P0 920

REPO 310

IEPC X150

nEP 95

ReP0 370

repo 985

pepn 390

REPOTUNo

Prpolato

Depolnzo

expeioin

TEPO 104

RPPO1051,

mpry:06s 


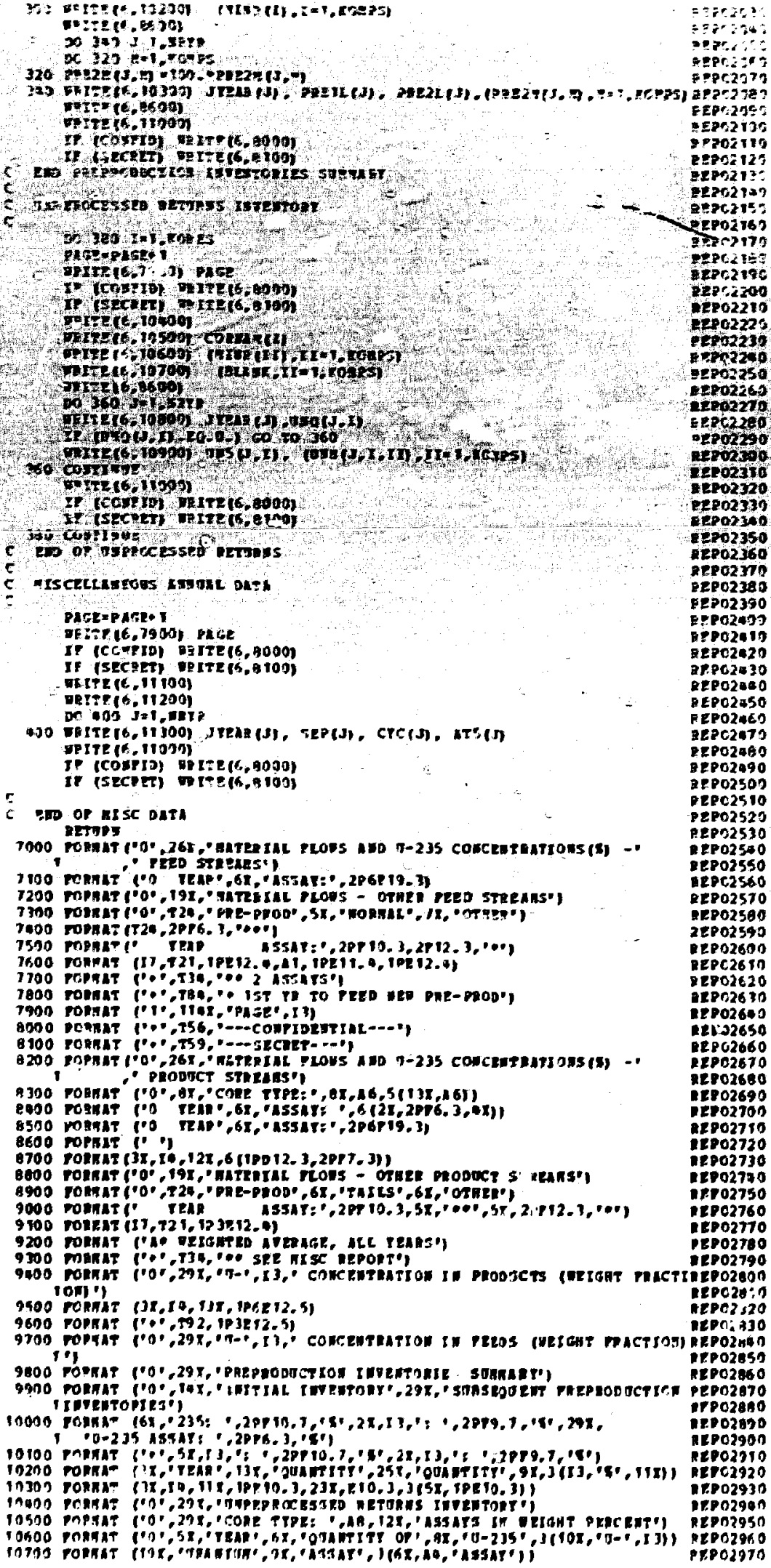




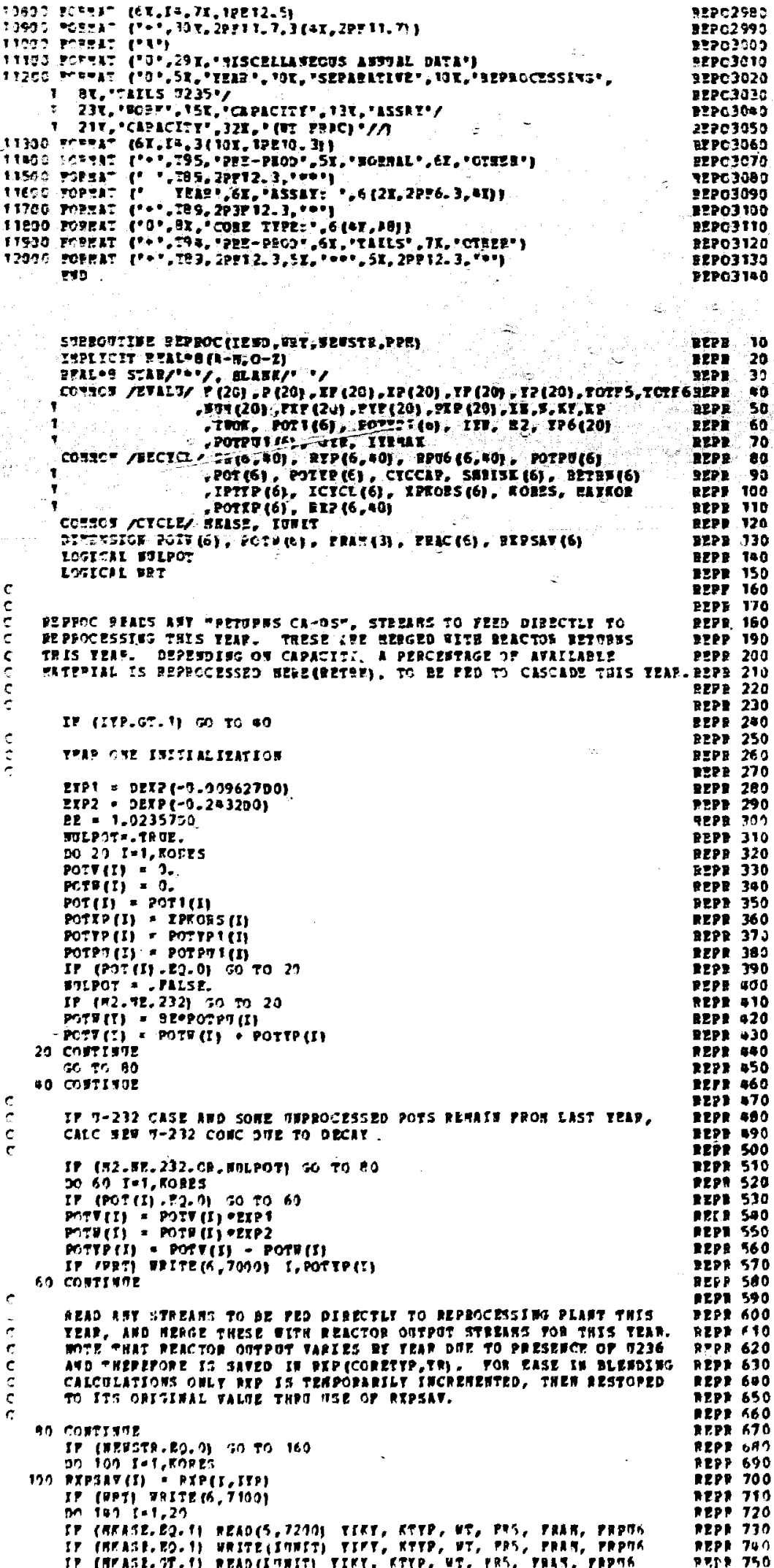




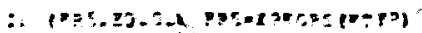

B.

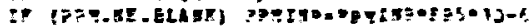

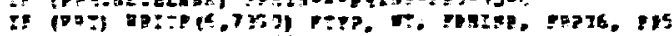

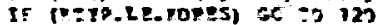

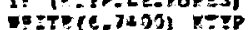

ThLE Ext?

-

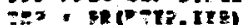

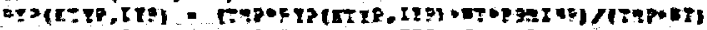

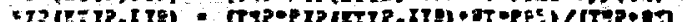

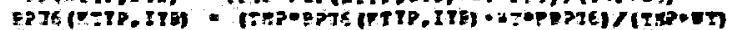

se tetry,

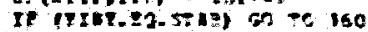

18) extritge

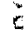

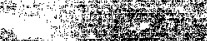

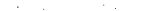

iet corrant

an $200 \mathrm{~T} \cdot 1, \operatorname{tos} 25$

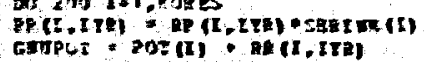

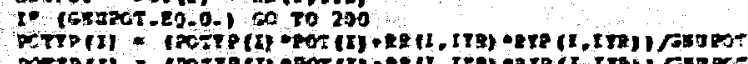

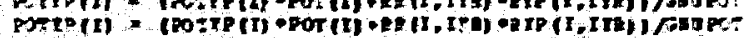

PCTtI $=$ syopot

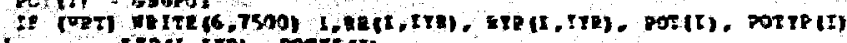

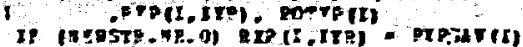

275 costriste

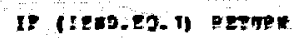

i sppoceserso step

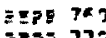

Sert 72

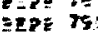

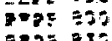

fige 4 S

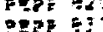

EZPF $5=2$

SEPE ess

ERPF $4<0$

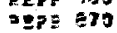

-zre zas

P.ie esa

DEPE 425

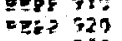

EZ25 55

PPP GE?

도ำ

EDPE

PEPE 970

EEPE SSI

ZEPET:30

PEPF1019

BEPTYOS

PEPPISTS

$0 D P \equiv 1350$

SERETGEO

poppisic

rerelogo

2EPEiss:

PEPEITS

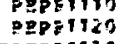

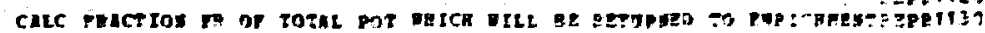

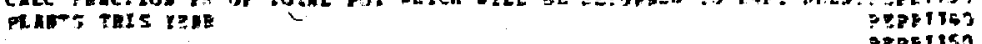

PEPETisn

perat $=0$

DOT220 Iai, meE

Pence? $x$ ?

22, potot: pmro: - poteI

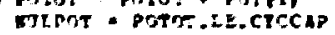

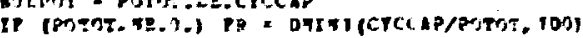

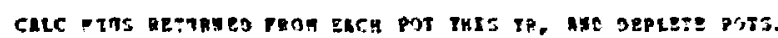

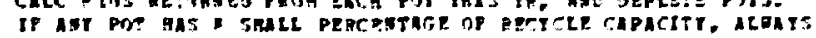
ECTCLE It CCOPLETELT.

EP?

REPFI159

cepprisn

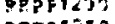

PEPDIZ1T

TEPET22?

EEPQ1215

PePrize?

SEPF125.5

9EPP1263

PRP 1270

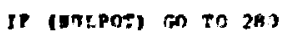

Reps 1285

PPEFEO - 1.000

$c$

PRTPER $=.0200$

prest $=0$.

कo $240 \quad t=1,80 \% 5$

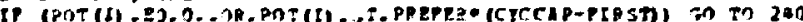

TFAC (I) a ino

ITRST = PIAST + PM(E)

240 costiont

IP (rIPSt.e0.n.) wo to $2 \mathrm{an}$

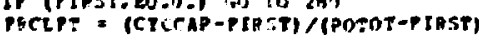

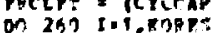

260 IP (PRAC(b) - EO. J.) PGACGL)=PPCLPT

280 comrang

DO 305 I $5=3, \pi 0 R=5$

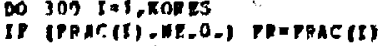

IP IPRAC (I) - WE-O-J PRE

REPRE (I) PM०POT(I)

IP (pnT (I) - ED.n.) ro To 100

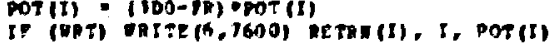

Mo colvinto

LPET?

REPGT3T

PEPET3ZT

$B=P Q 1310$

enspisan

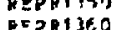

FEPE1370

TOPIIST

oppisiog

RePGiajo

AEPBing?

REPRT+10

QEPRT120

PEPR1730

EPE1450

REPP1450

EPQ1560

250.

REPRT4:J

TPRTY9?

exprs?0

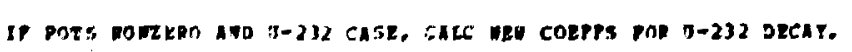

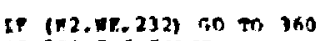

on $3 \times 1, T=1$, KORES

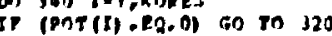

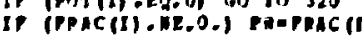

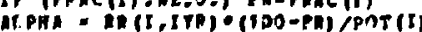

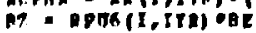

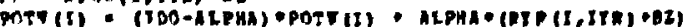

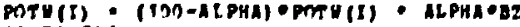

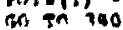

32.) contine

BकT (I) *

Mrofi:

300 coming

Jo cont Inne

METIRT

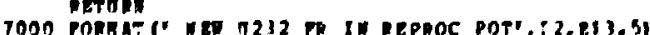

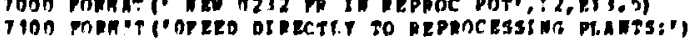

1200 mant at (AT, IT,8X,6810,0) 


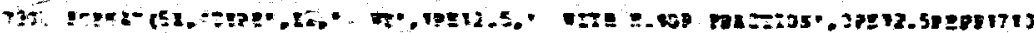

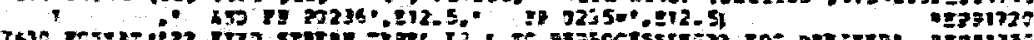

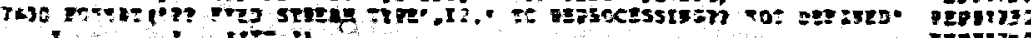

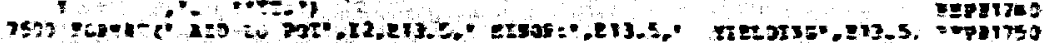

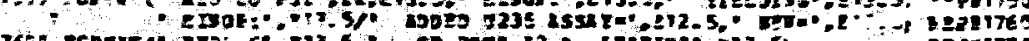

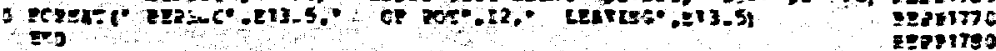
t.

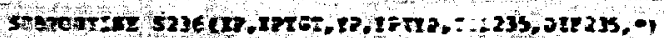

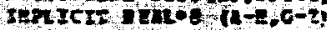

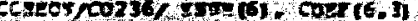

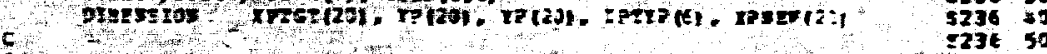

(t) $2 \geq 236$

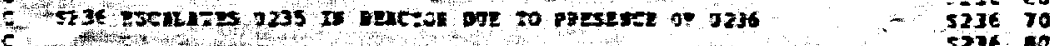
- w

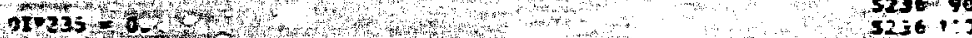

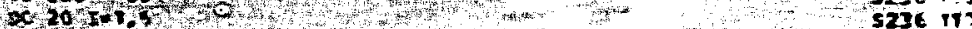

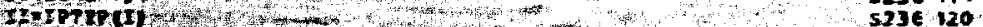

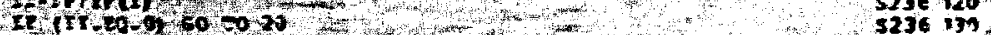

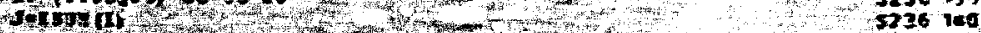

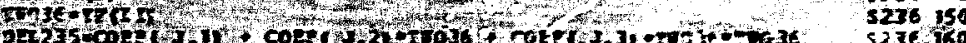

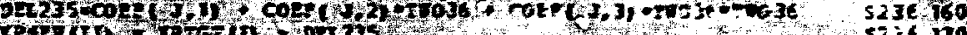

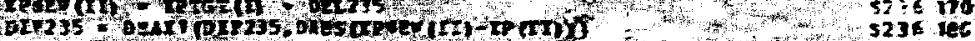
29 cos 5236 iec

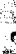
5

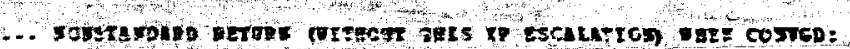
5236200

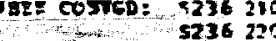

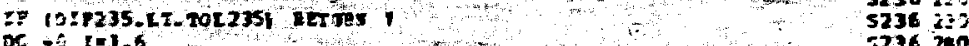

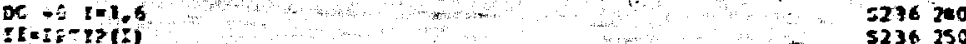
$1:(::-2-0)$ GCTO

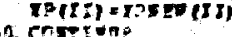

$\operatorname{coseg} 20$

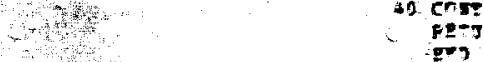

5236260

s33e 270

5236269

s236 290

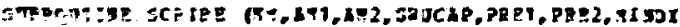
IAPLICIT gEALE $\left(k-\mathrm{R}_{0} 0-1\right)$

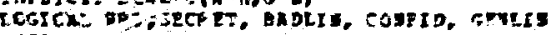
ISERG ONF. PACE

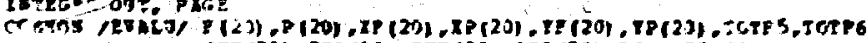
$\operatorname{seg} 20$ $\begin{array}{lll}3 C B I & 30\end{array}$

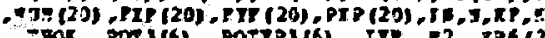

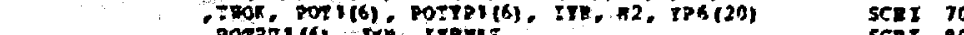

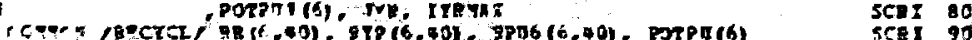

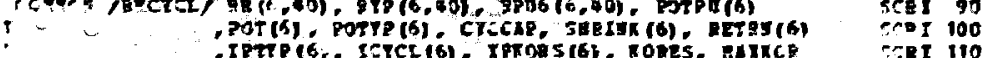

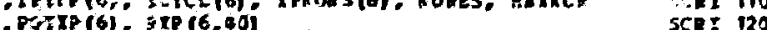

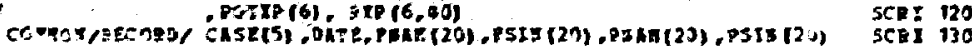

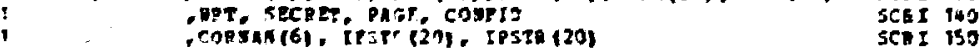

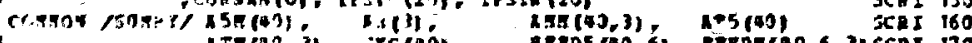
1
1

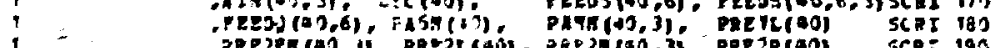

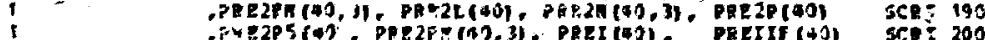

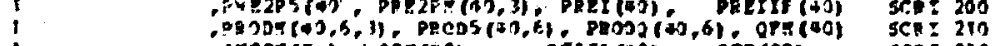

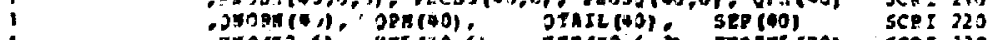

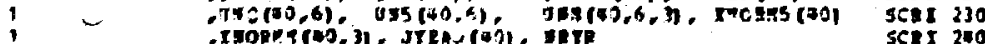
pete $45 \mathrm{x}, x^{\prime}$,

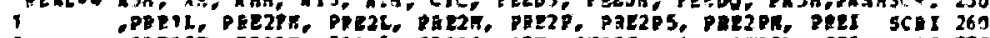

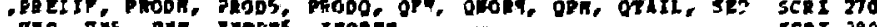

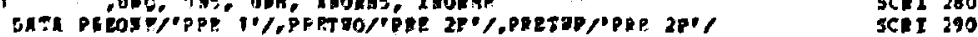

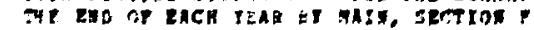

Pezo sTPEATS:

CPE $(15 T)=0$

o.

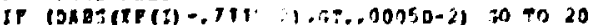

OUOB $(1, P)-P 1^{\circ}$

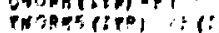

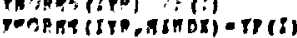

on $\mathrm{Te}^{\mathrm{i}}$ ing

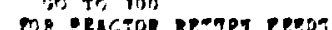

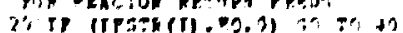

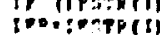

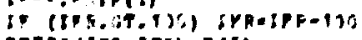

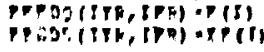

SCEI 290
SCAI 130

$\operatorname{sen} 310$

SCR 130

sert 100

SCP 350

scr I jo

sCer JTo

SCEI 390

ICE

उCE 110

उCR: 420

3CR 350

3CEI 490

scP! 450

TCK: $4 \mathrm{CO}$

उCE 47 ?

Tren की

gent
grent

उदR 510 


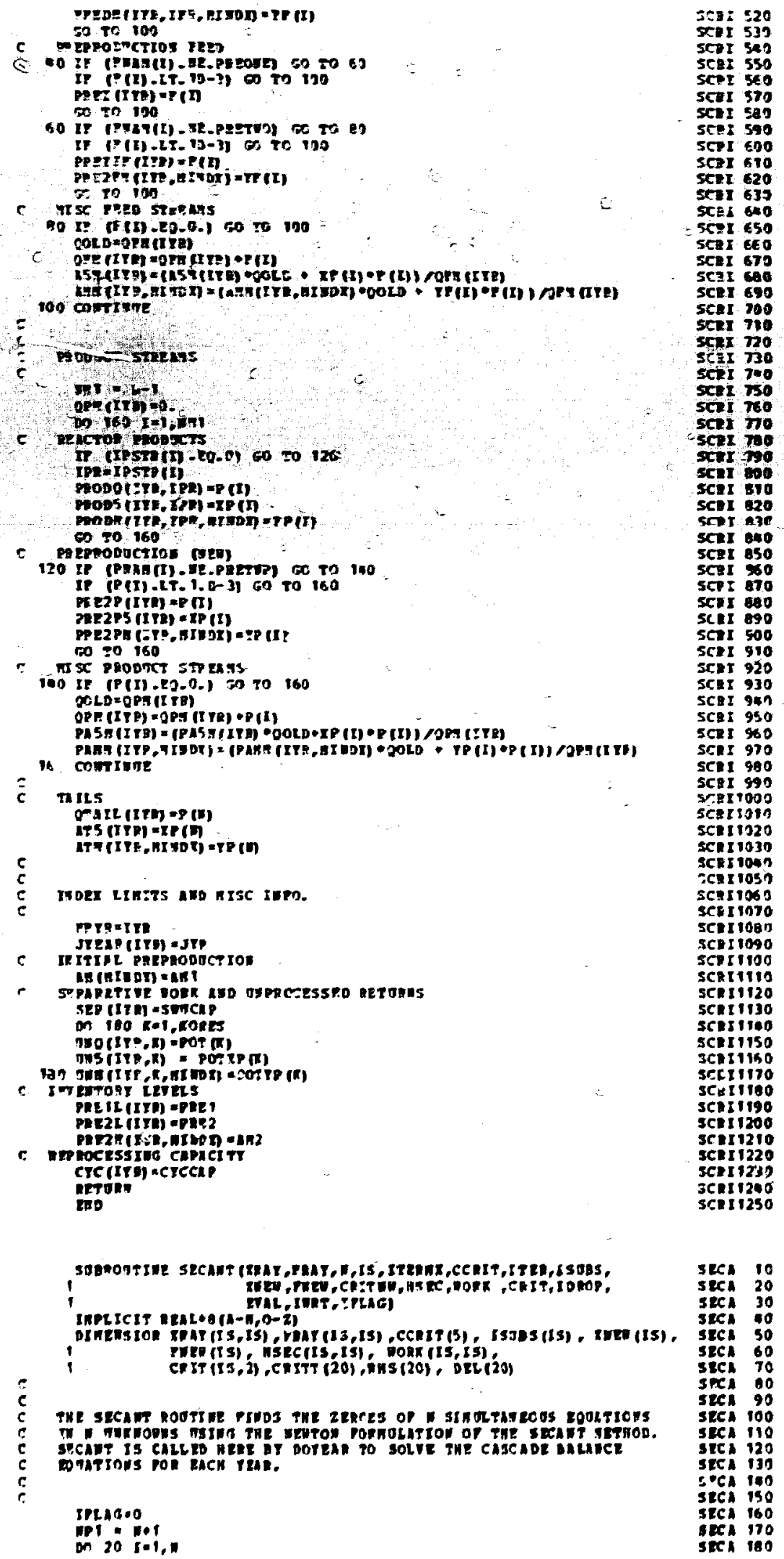




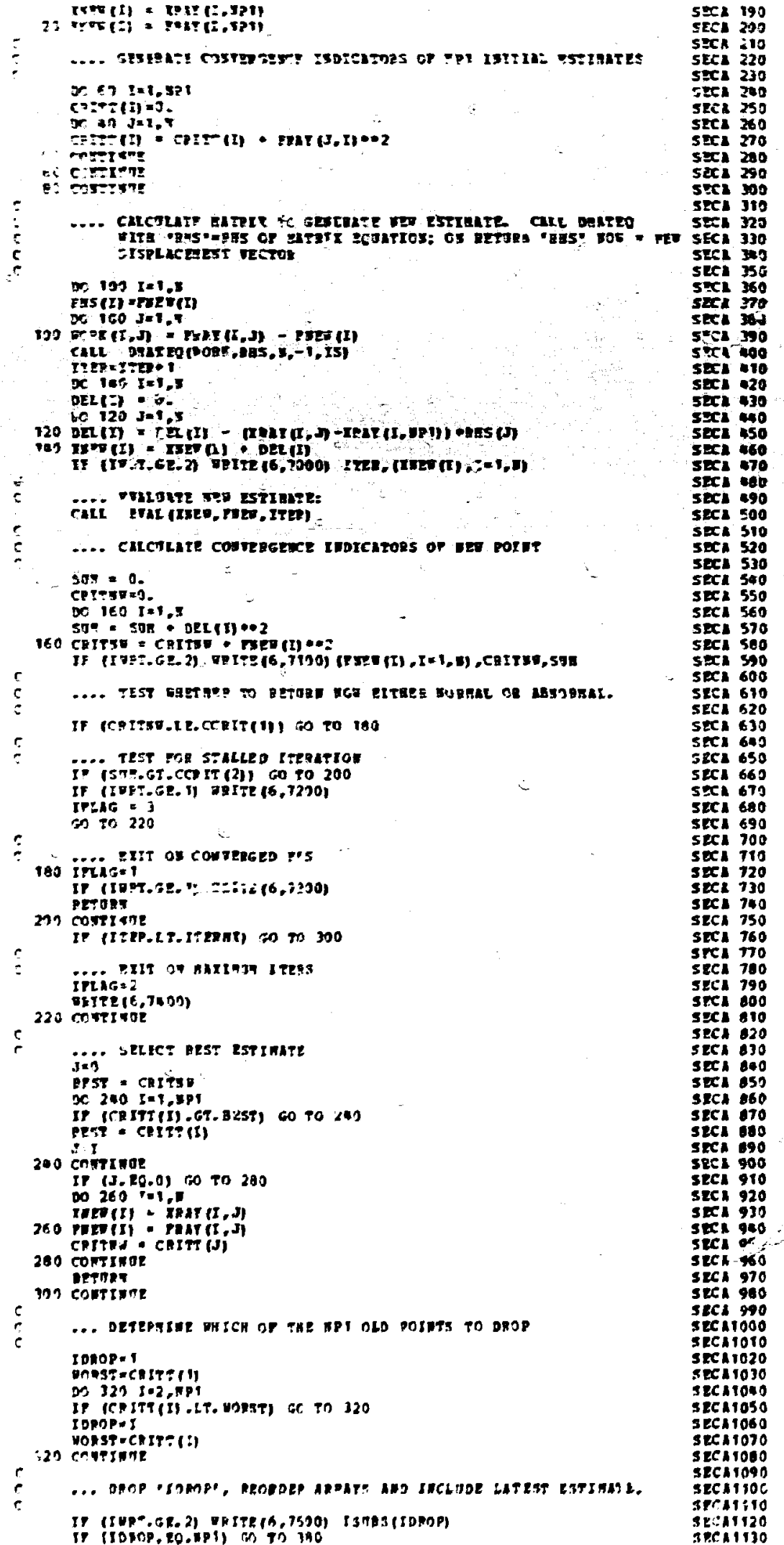




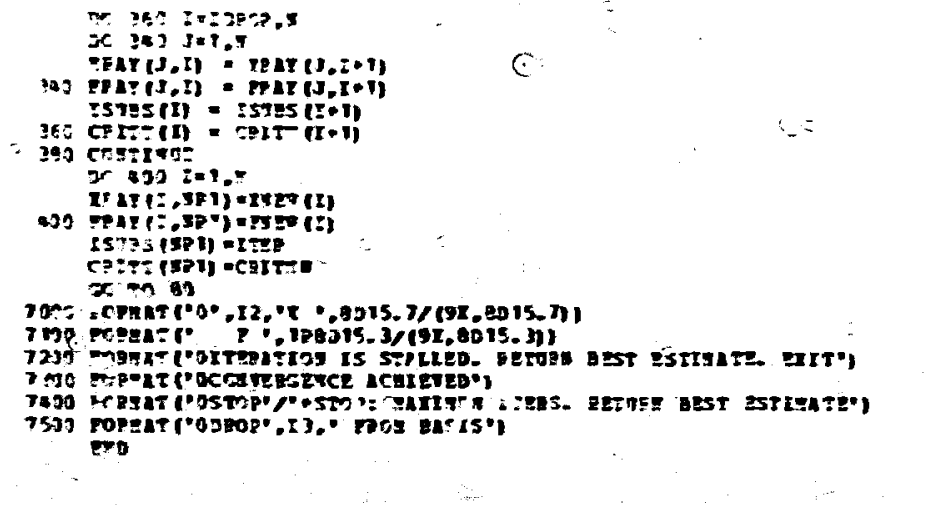

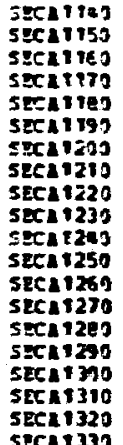

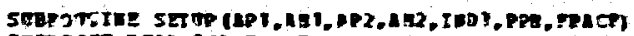
TRPLICT: EELOA (A-B,O-Z)

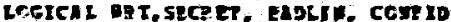

YPTEGS OTF, PRE

- 6 sero 50

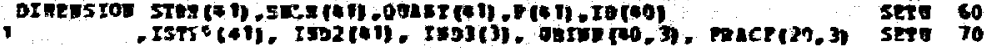

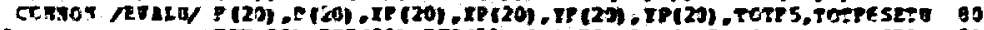

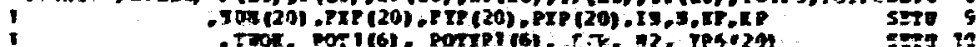

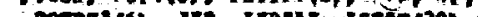

congor recrel aq (6.

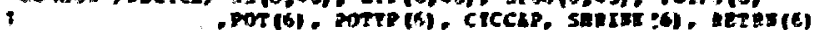
seto 120 Sero 130 SErT 190 SET⿱ 250

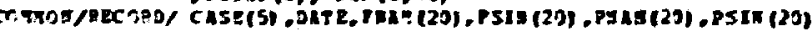

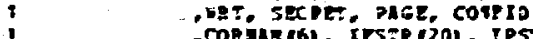

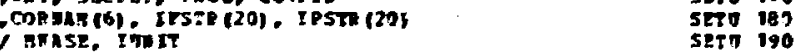

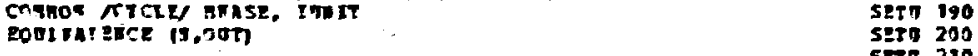

$\operatorname{set} 220$

SET0 230

5ह71 250 SETO 290 EFo 260 S2T 270 5Eo 200 set0 290 IT) 300 SE:3 370 SET $32 \mathrm{C}$ serd 330 5 380 350 SErJ 350 setio 370 sent 5 to 390 gert 190 serv 10 10 2ro 450 SETO 460 S2TU 670 SETO stro $\$ 90$ SET0 500 SETO $\$ 10$ 3 TTO 320 5xo 530 3270 540 SETO S50

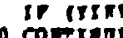

(2)

270

5e.0 610

serv 6 in

$\operatorname{sen} 600$

gerg 650

$\operatorname{sep} 660$

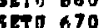

$3 \operatorname{sen} 600$

$\operatorname{sect} 630$

710

SRTT 720 


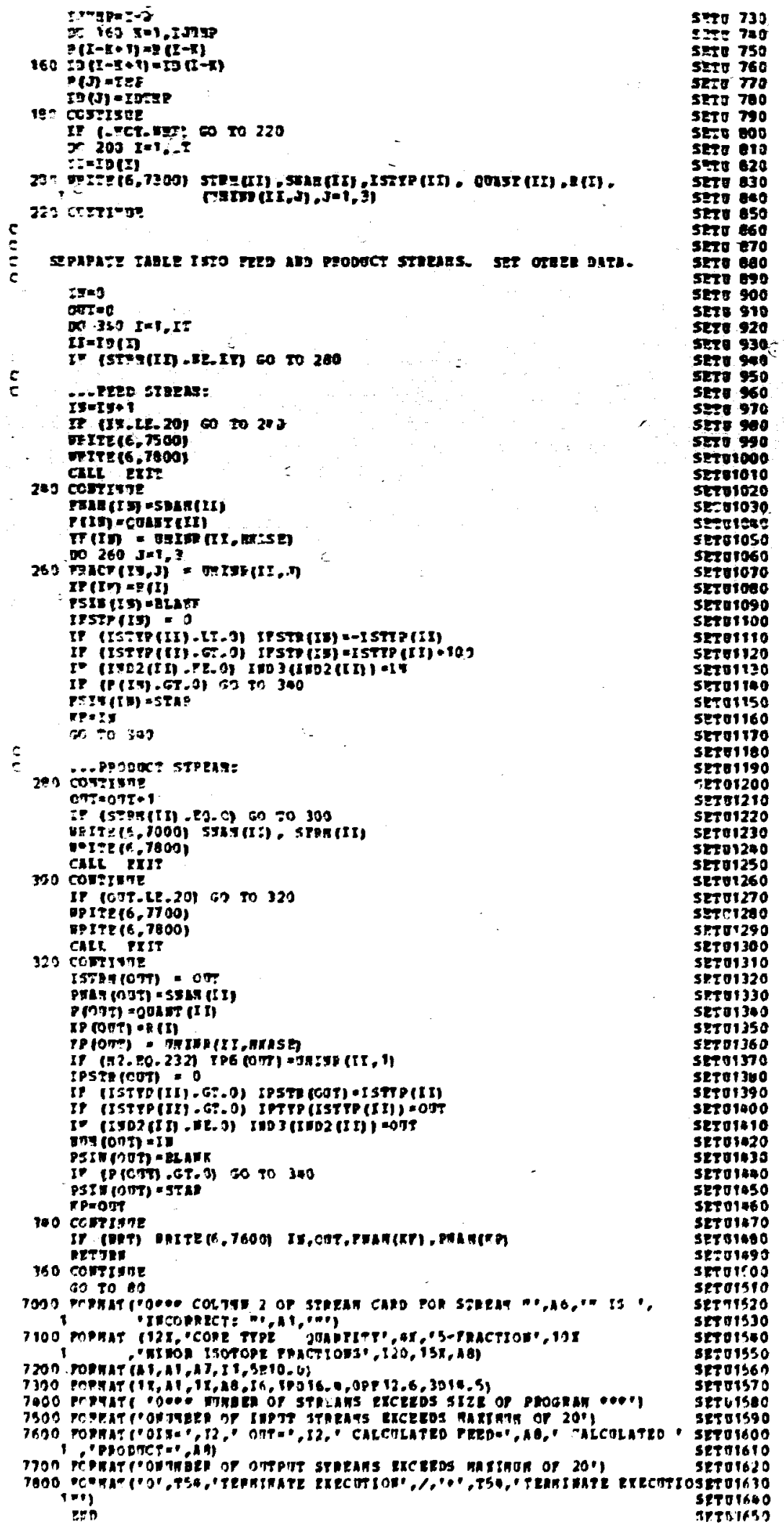




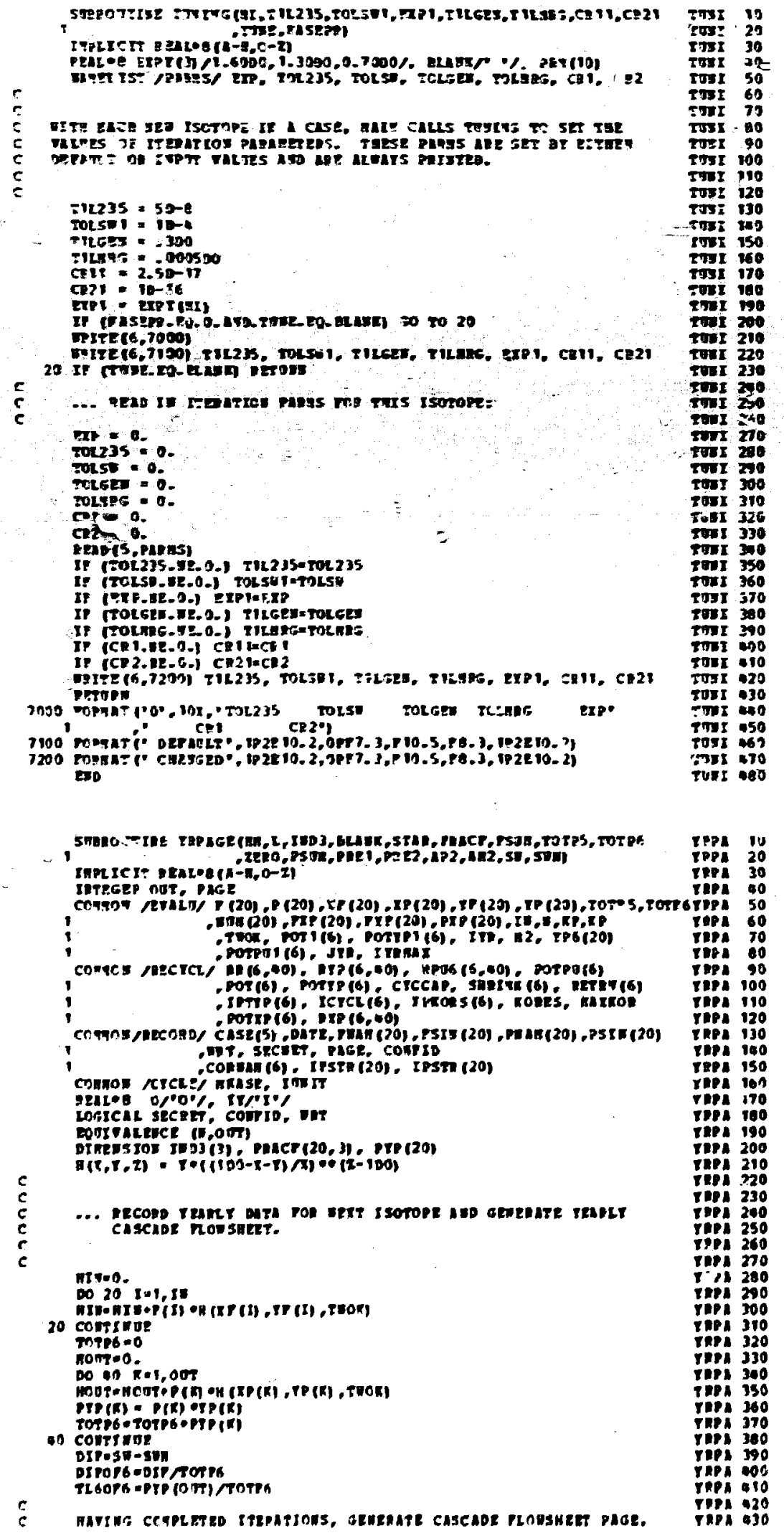




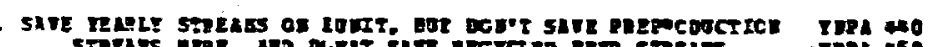

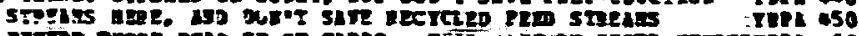

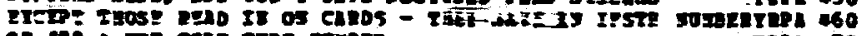

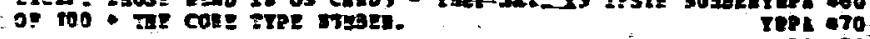

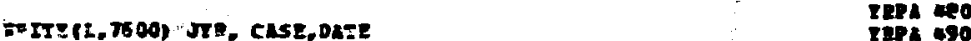

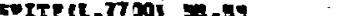
$269-1015$

Tongs (E) $-L=10-3) 60$ to 60

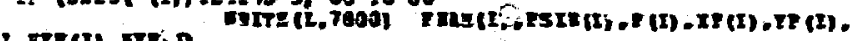

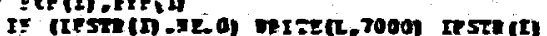

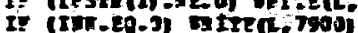

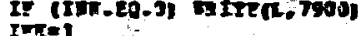

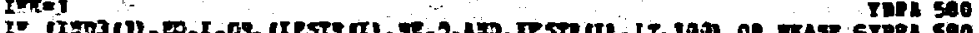

II.1) 60 T0 60 .

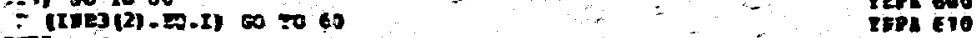
art. * D

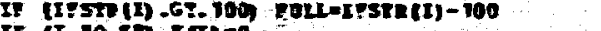

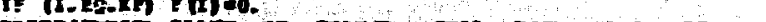

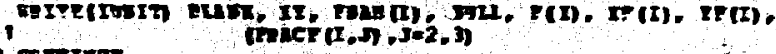

0 corrryos

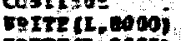

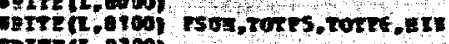
pirzo,es00)

rears

Do $80 \mathrm{IN}=1, \mathrm{~B}$

1. Cones (P(m) -ct-10-3) 00 20 00

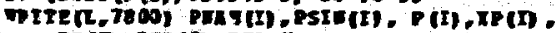

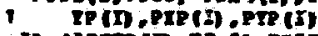

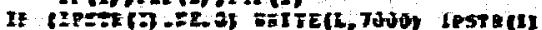
IP (IFI-E0-0) ORTYE $(L, B 200)$

III $=1$

TEP

If (1. 2G.3) TE BTESTAF

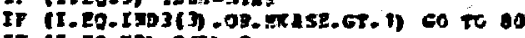

IF (I. EQ.EP) $P(\mathrm{~B})=0$

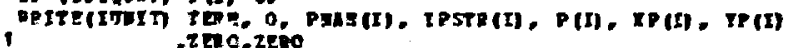

eo cCrTs50e .zEc.zeno

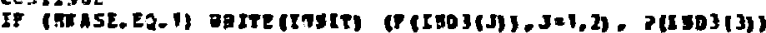
Eptre(t,enoo)

DEITP(L,8100) PSHS,TO:PS,TOTP6, HOT

DITE CI, T100:

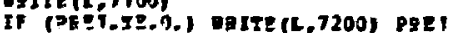

IF (PQ12.3E.j.) DRTE(L,7300) PRE2, AP2, AT2

IP IPEETGPEE2-E2-0.1 DOtTE(R, e70O)

DPIT: (t., 2000)

Irt $=0$

os $100 \mathrm{mel}, \mathrm{KDF}=\mathrm{s}$

IP IPOT (K) - ED-0.) 50 Y0 100

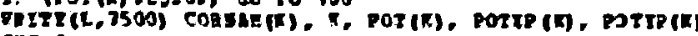
$\sum \pi \pi=1$

100 cotersos

$C$ If (ITR.80.0) verte(L, 0700)

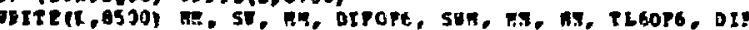

DIre(k,8600)

It (SECALT) in t?E (L,8B00)

IP (COAPIO) DEITE(L,9900)

pequen

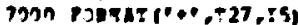

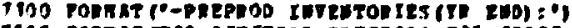

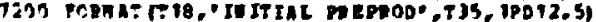

1300 PCPA

1000 mp

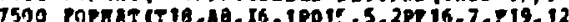

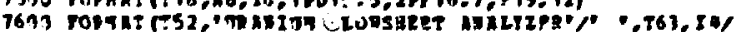

Teis 650

The 668

T210 670

Tapt 69

$\operatorname{res} 69$

Tein 78

Ther 720

reP 75

Tare 708

repe 760

row 770

7eq 790

Tom 700

repa 400

TEFA 200

TEPA 810

T2p 030

rapa

repa aso

ropa 860

TBPI GTO

ropa 800
TDPa

ropa 890

Trpe 900

reph 910

reph 920

TEPL 530

TSP 900

TSPA 950

TRPA 960

TAP 970

TRP 900

IIPA 990

TEP\$1000

T9P21010

TPE\$1020

TEP N1039

TEPa10as

IEP 1050

TPPa1060

IIP 1070

ImP 1000

rap A1090

IRP iliog

TPPilito

TRPBI120

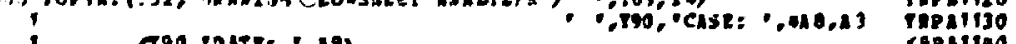

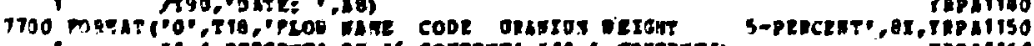

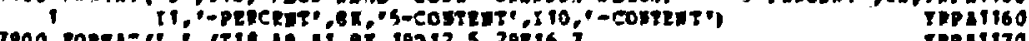

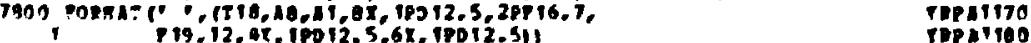

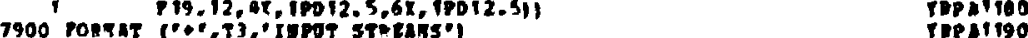

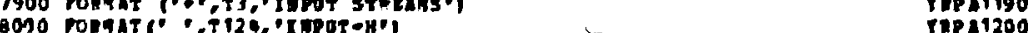

Poso ropat?

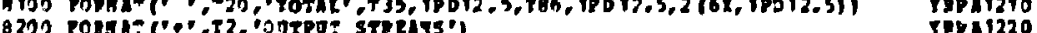

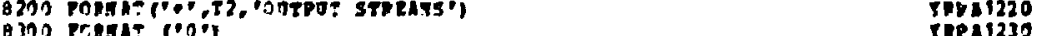

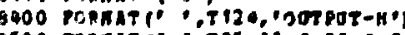

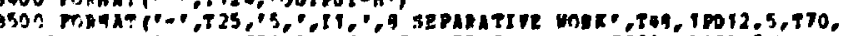

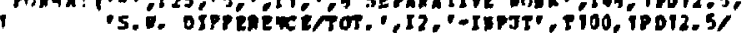

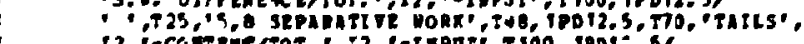

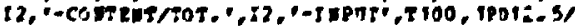

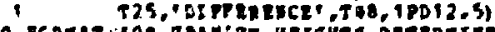

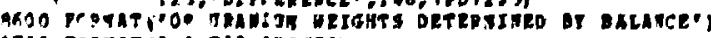

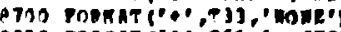

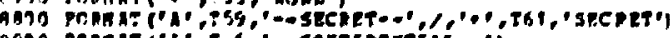

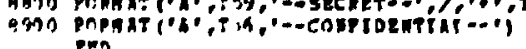

top 1230

ThPis250

$\because 260$

ripar270

rRD 1280

TPPAi290

TAPATJOO

ropat310

ropa1320

TEPAIBOO 


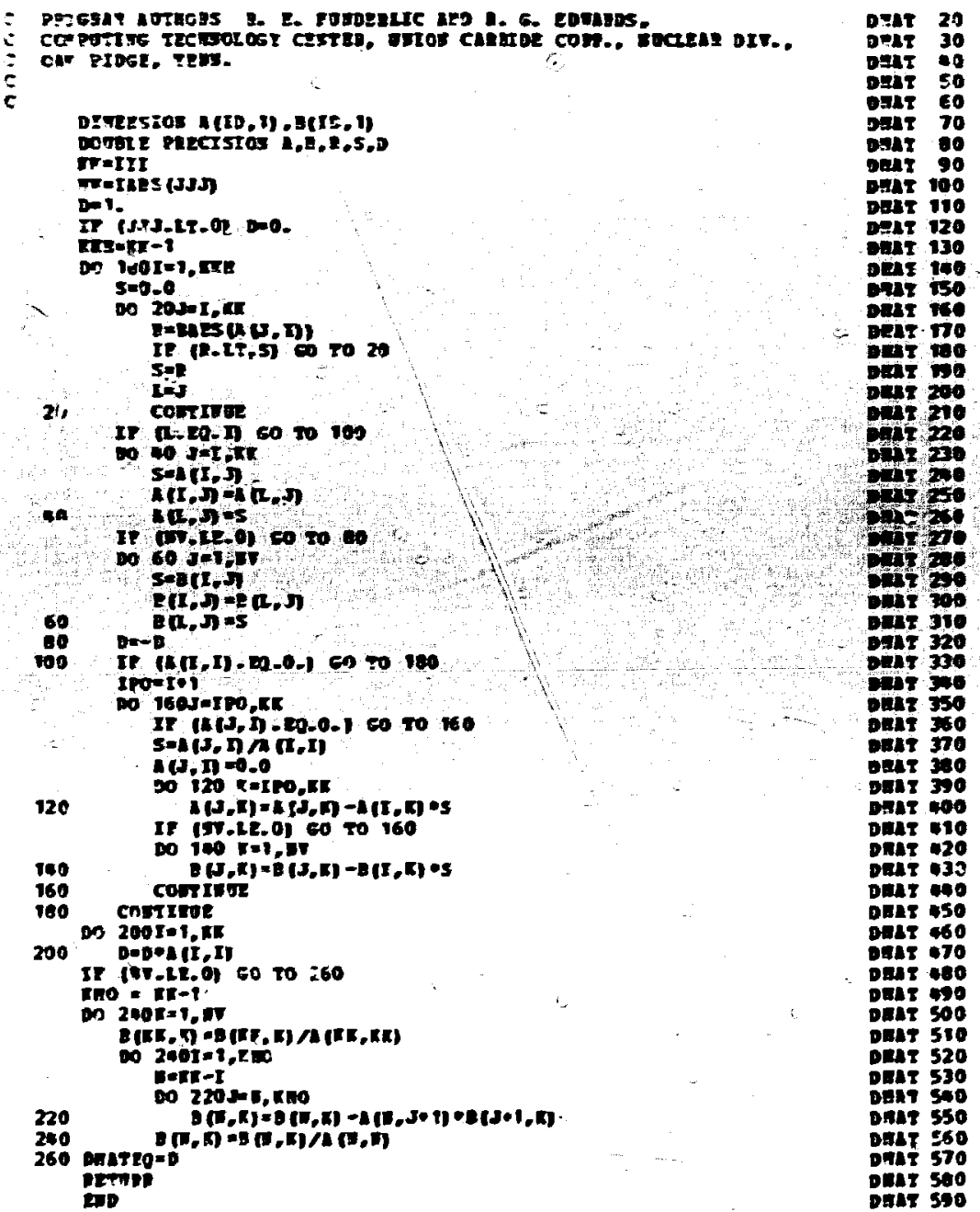


103

APPENDIX D

MUIFAP PROGRAM LISTING 


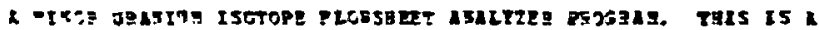

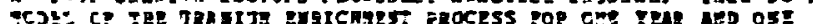
C.

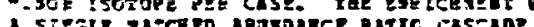

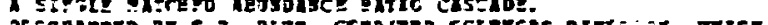
PF

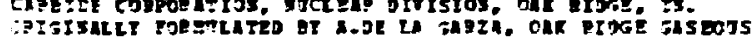

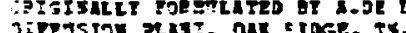

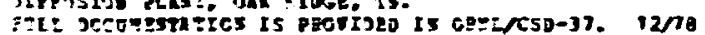

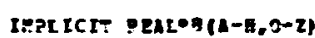

iTEFEF CMT.TOTEAT.PAEE

lesickl Det, st EQ ET, EADID, COMPID

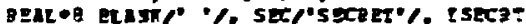

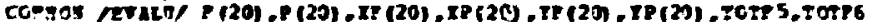

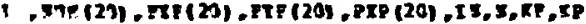

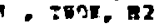

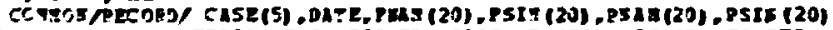

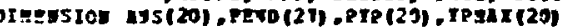

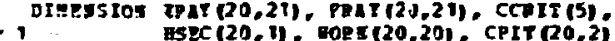

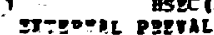

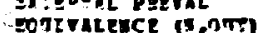

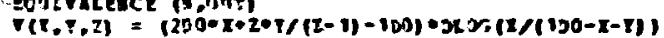

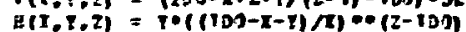

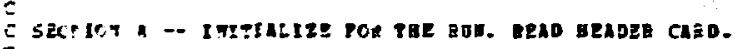

CALL EASET $(263,1000,-1)$

CatL TonT (DRTE)

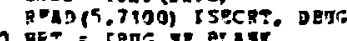

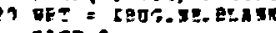

PAriexo

SECPO = ISECP . . 20.5EC

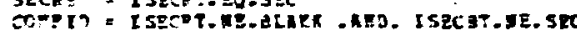

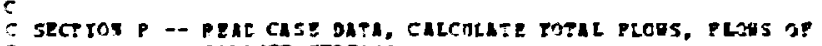
BaLANr. STPEATS.

Q) Cartene

QPT? 16,7220$)$

Cati

$\cot 5 \times 1$

mipe:

Tress $=0$.

60 ini, Is

(P (I) $2=0.0000$

$\operatorname{mr}(\mathrm{T})=\mathrm{F}(\mathrm{I}) \cdot \mathrm{ir}(\mathrm{I})$

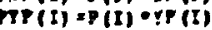

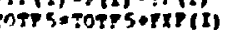

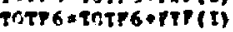

P5T-P soner(t)

en contrine

TrFs=0.

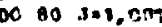

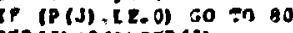

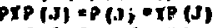

TOTP5=TOEPSeVtP $(J)$

P57R-PSOR० P(N)

no contrine

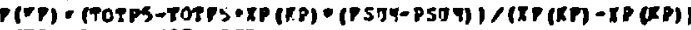

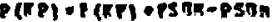

TIP(RT) -P(Kn) IP (KT)

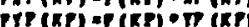

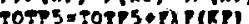

TCT76-70tesertp(eP)

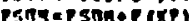

PIP $(R P)=P(K P) \cap X P(K P)$

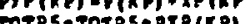

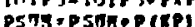

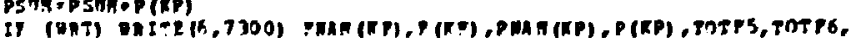

it

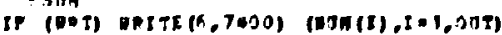

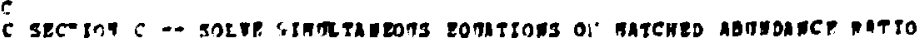
CASCED in Geverte solotrol or case.

Calt. STAPT

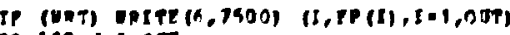

on ino $J=1,0$ TाT

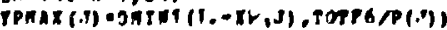

ish entrinue

on in? ri: $1, \pi$.

0 izn

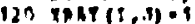





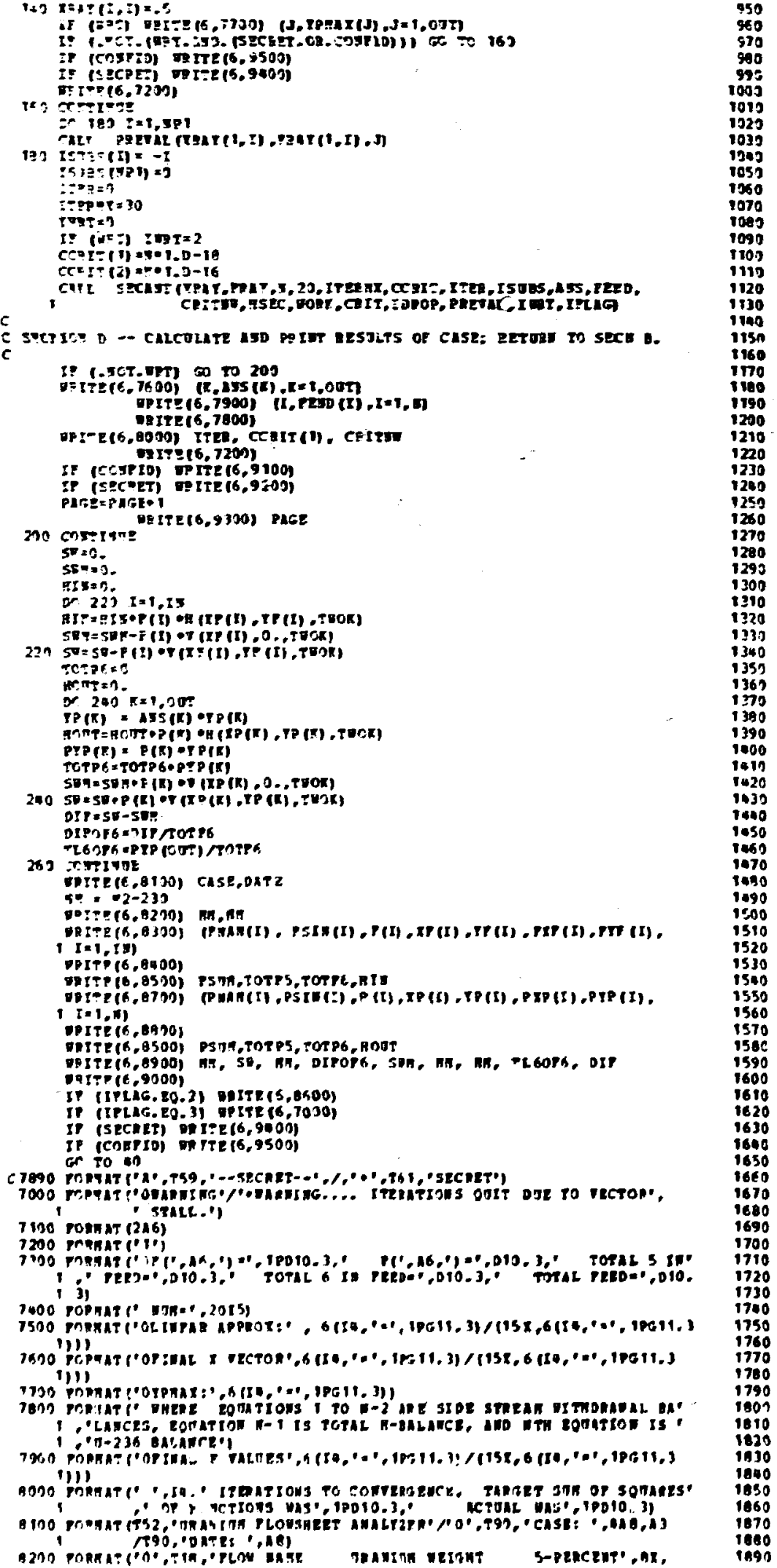




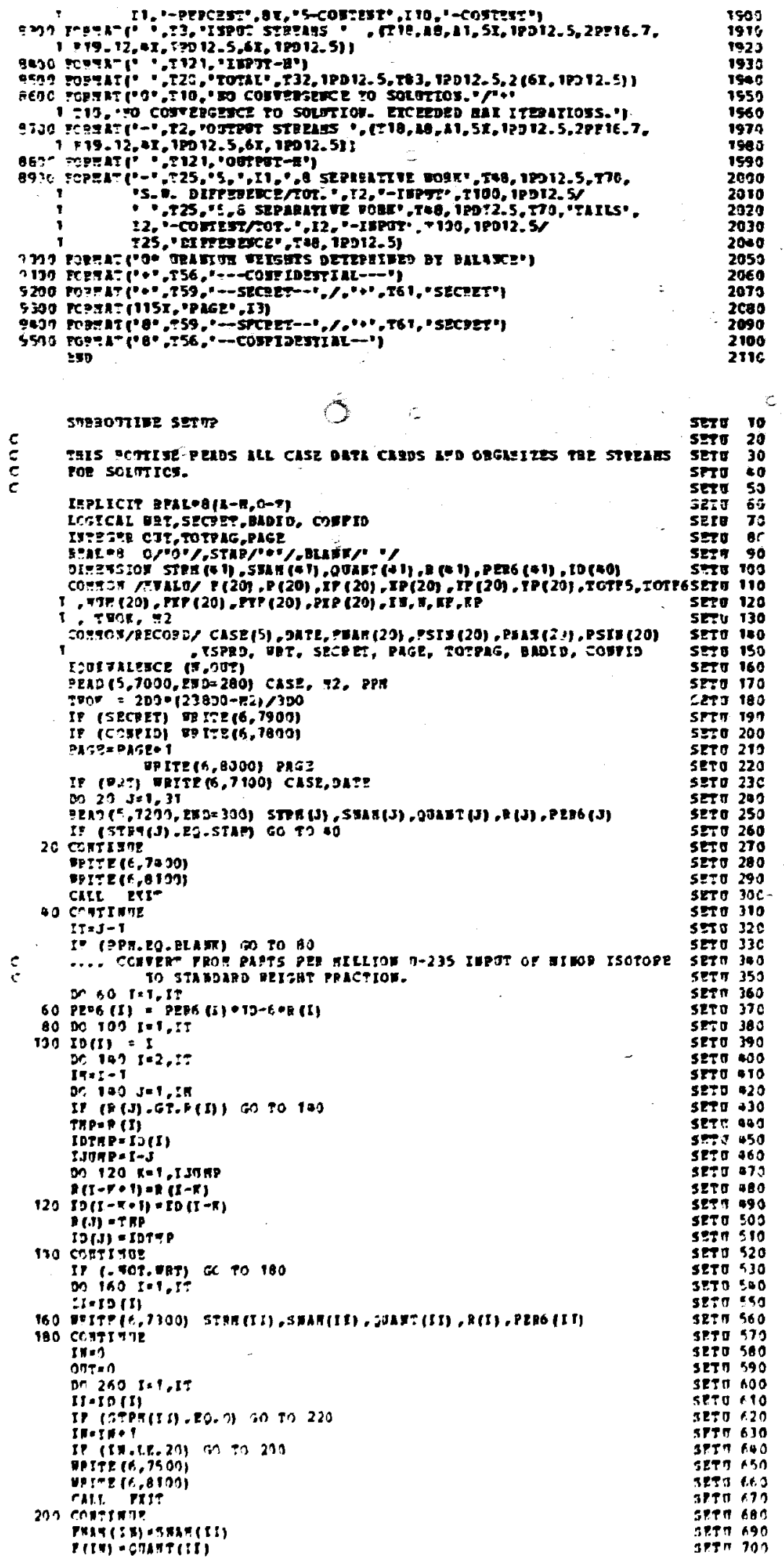





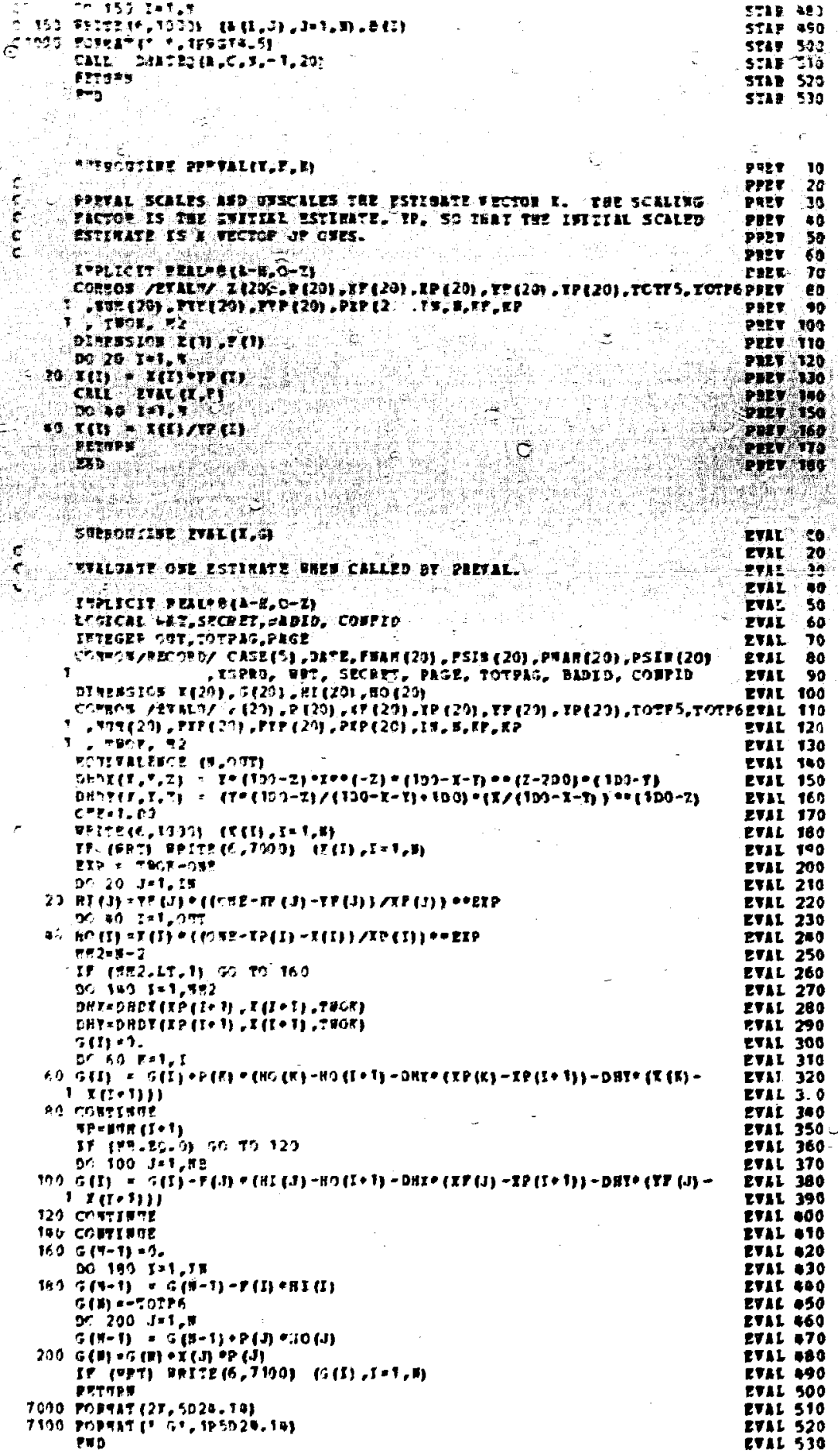



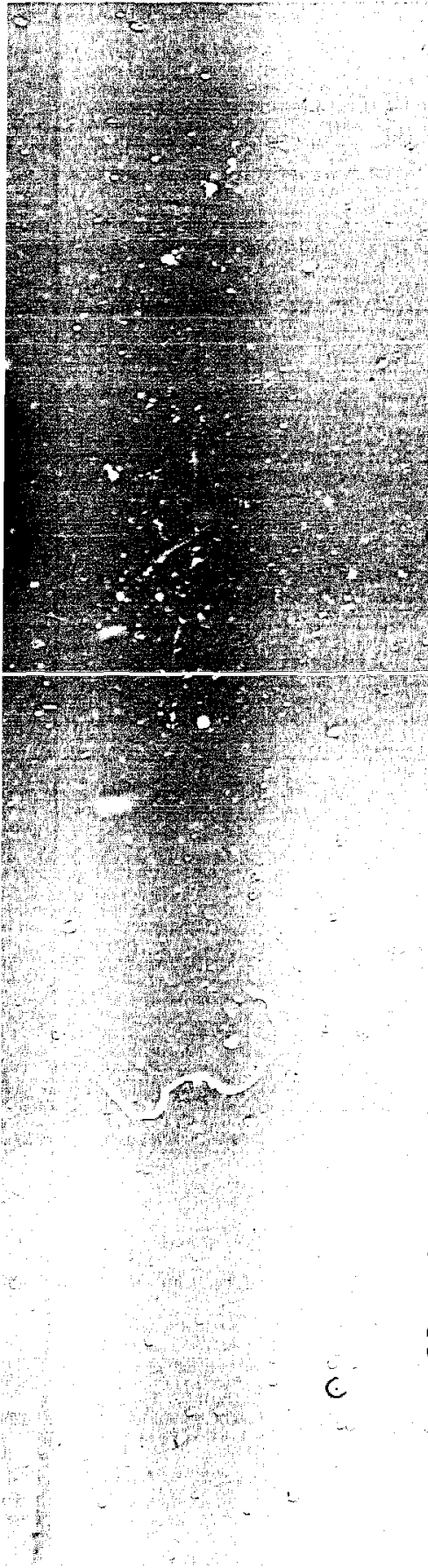

c

c

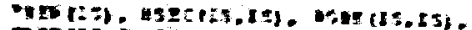

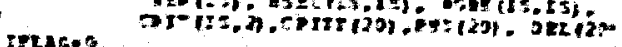

$\rightarrow-1.1$

0 ro te.

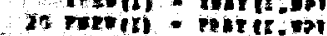

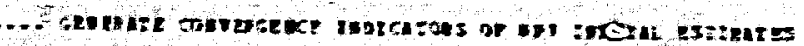

$+4 x-1, w$

4) $\rightarrow 10$

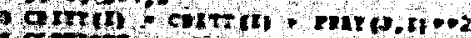

$+\rightarrow+1$

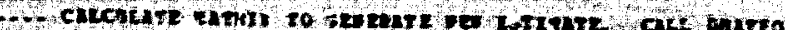

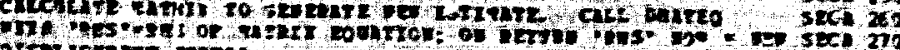

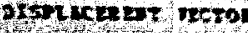

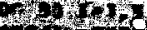

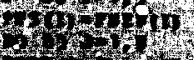

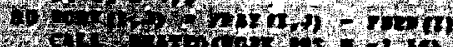

Qf

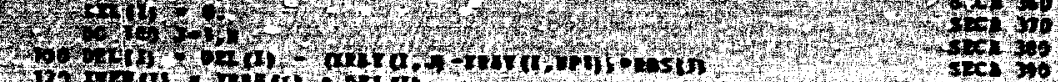

(2)

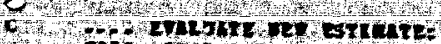

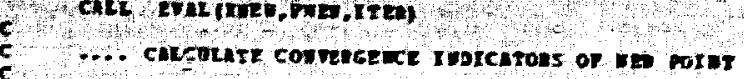

sys $=0$

CrTive-

Da 190 ret,

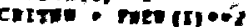

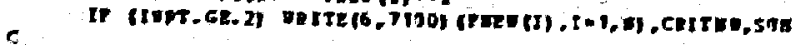

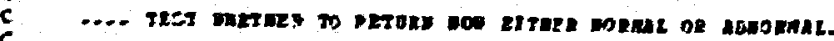

- If cestue.re.cretrili) co to 160

c

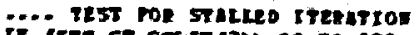

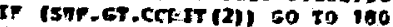

IF (rets.ck. V derte $(6,7200)$

कo 20200

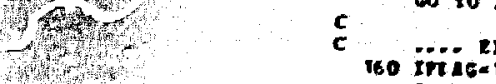

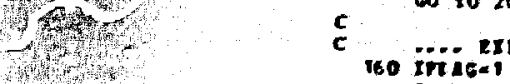

on cosveraes pis

If (INkT-RE. I) GeTre(6,7100)

190 cothipge

IP (ITTF, LT.ITEAI) on to 280

.... exrt on sirreas treas

iriege

Dite $(6,7000)$

.... SELET aEst ESTIMLTE

Jis

Dest a certun

DO 220 I-I, 1101.

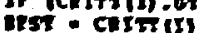

insh

no cominos

IF (J.te.0) 60 to 260

$202405=1$,

Iinte (T) - Tht

200 met (I) - marg

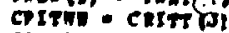

200 conrivos.

crove

200 constone

1090p+1

0.0.

Do 300 Iez in

IF (CRsts (t) , L2, v0nst) 50 to 300

IDRop-8

mostecespret

c

conirivos

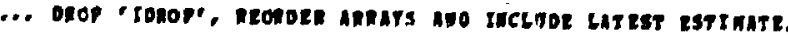

iscs 190

sect 170

ste: ist

ezca 1to

sec 190

sex in

sese te?

seca ns

set 27

ser 79

set 239

20127 $1+20$ $\rightarrow \times 10$ $\rightarrow \infty$ 1- $N$ ra stet 10 ster 10 $=-1+$ sta on sect 10 sect 450 seck 40 sece 70 sece 100 SEC 490 FEC 500 ste 516 sec 520 SEC 530 sect sed SReA 550 secr 540 ser 570 ster sno sec 590 sec 500 5ec. 500 5ee 619 sex sec 690 sec: 690 seca 650
ster 660 ser. 670 secs 600 seck $690^{\circ}$ sec: 7no SEC 710 sect $72 n$ SECA 730 sech 700 seca 750

SECA 76

IEC 70

SECA 700

SEch 790

SEC 000 tes 820 seci oso sec szen esa sect 06 sten 670 sten sec

sec

sech 910

seca 920

sech 910

sten 900

sसCA 450

sech 970 seca 900 secs 990 SECA 1000 SECATO20 SECA 1030 sechioso 


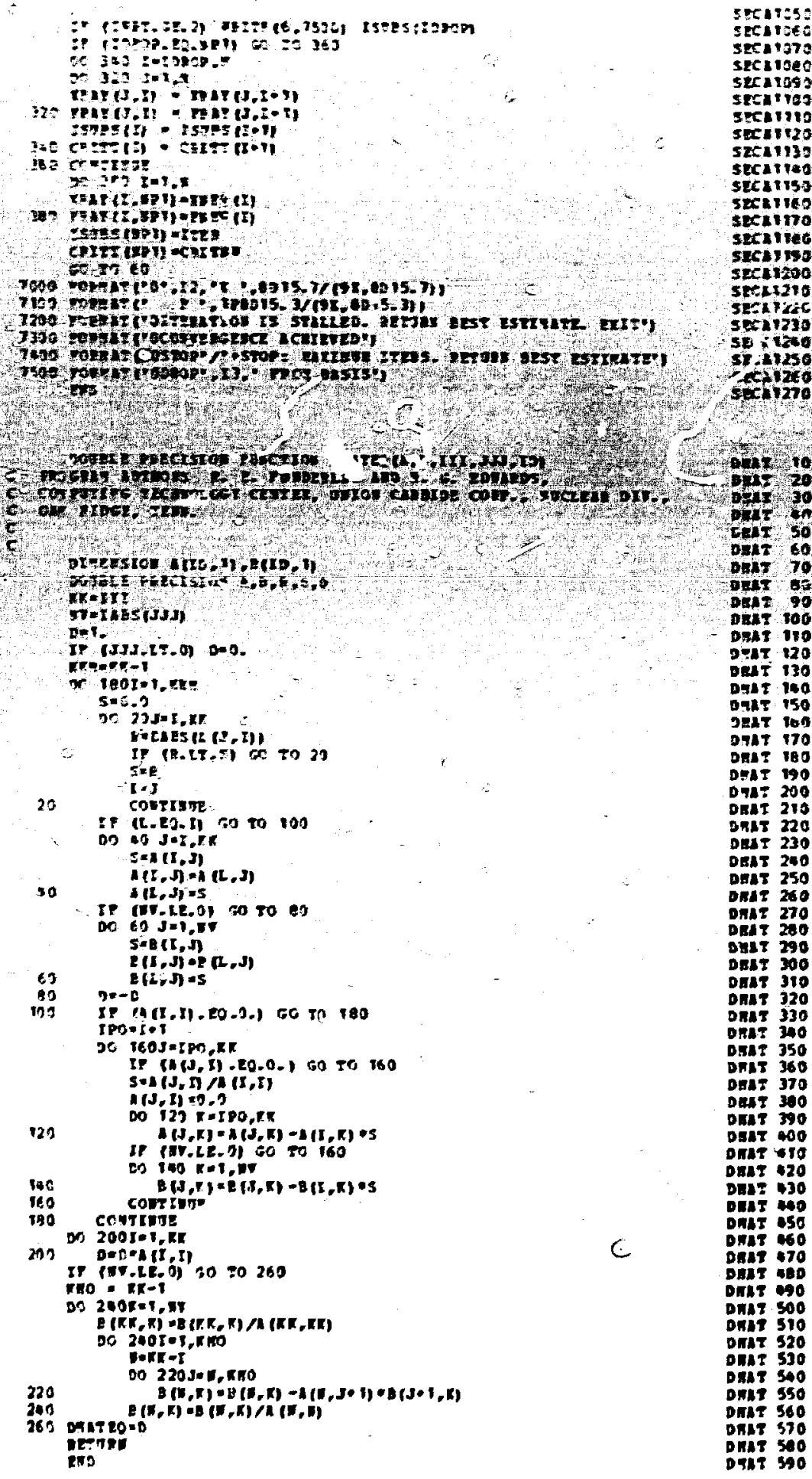

IRCON2 I STOP 